\title{
Looking beyond the fracture : prevention in fracture care
}

Citation for published version (APA):

van Helden, S. (2008). Looking beyond the fracture : prevention in fracture care. [Doctoral Thesis, Maastricht University]. Maastricht University. https://doi.org/10.26481/dis.20080905sh

Document status and date:

Published: 01/01/2008

DOI:

10.26481/dis.20080905sh

Document Version:

Publisher's PDF, also known as Version of record

\section{Please check the document version of this publication:}

- A submitted manuscript is the version of the article upon submission and before peer-review. There can be important differences between the submitted version and the official published version of record.

People interested in the research are advised to contact the author for the final version of the publication, or visit the DOI to the publisher's website.

- The final author version and the galley proof are versions of the publication after peer review.

- The final published version features the final layout of the paper including the volume, issue and page numbers.

Link to publication

\footnotetext{
General rights rights.

- You may freely distribute the URL identifying the publication in the public portal. please follow below link for the End User Agreement:

www.umlib.nl/taverne-license

Take down policy

If you believe that this document breaches copyright please contact us at:

repository@maastrichtuniversity.nl

providing details and we will investigate your claim.
}

Copyright and moral rights for the publications made accessible in the public portal are retained by the authors and/or other copyright owners and it is a condition of accessing publications that users recognise and abide by the legal requirements associated with these

- Users may download and print one copy of any publication from the public portal for the purpose of private study or research.

- You may not further distribute the material or use it for any profit-making activity or commercial gain

If the publication is distributed under the terms of Article $25 \mathrm{fa}$ of the Dutch Copyright Act, indicated by the "Taverne" license above, 


\title{
Looking beyond the fracture
}

\author{
Prevention in fracture care
}


Low power scanning electron microscope image, showing osteoporotic architecture in the fourth lumbar vertebra of an 89 year old woman (20 times magnified). The bone is heavily eroded in places by the action of osteoclasts and consists mainly of thin, fragile struts.

By kind permission of Alan Boyde (a.boyde@qmul.ac.uk)

http://www.brsoc.org.uk/gallery/default.htm 


\title{
Looking beyond the fracture
}

\author{
Prevention in fracture care
}

\section{PROEFSCHRIFT}

ter verkrijging van de graad van doctor

aan de Universiteit Maastricht, op gezag van de Rector Magnificus,

Prof. mr. G.P.M.F. Mols

volgens het besluit van het College van Decanen,

in het openbaar te verdedigen

op vrijdag 5 september 2008 om 14.00 uur

door

Svenhjalmar van Helden

Geboren op 5 december 1968 te Eindhoven 


\section{Promotores:}

Prof.dr. P.R.G. Brink

Prof.dr. P. Geusens

Beoordelingscommissie:

Prof. dr. R.G.T. Geesink (voorzitter)

Prof. dr. P.L.O. Broos (Katholieke Universiteit Leuven)

Prof. dr. W.A. Buurman

Prof.dr. H.J. ten Duis (Universitair Medisch Centrum Groningen)

Dr. A. McLellan (Western Infirmary Glasgow)

Dr. P. Stalenhoef

ISBN: 978-90-808755-6-2

NUR: 883

Layout: B-Point, 's-Hertogenbosch

Druk: Gildeprint, Enschede

Dit proefschrift is mede mogelijk gemaakt door De Nederlandse vereniging voor traumatologie, Stichting Interdisciplinaire Werkgroep Osteoporose (Iwo), Synthes, Mathys orthopaedics, Stryker, Biomet, Smith\&Nephew, Bauerfeind, Merck Sharp \& Dohme, Servier Nederland Farma, Nycomed, Proctor \& Gamble, Lilly, GlaxoSmithKline, het Anna Fonds en Orthopaedie 2000. 


\section{CONTENTS}

$\begin{array}{lll}\text { CHAPTER } 1 \text { General Introduction } & 7\end{array}$

ChAPTER 2 Risk of new clinical fractures within two years

following a fracture

CHAPTER 3 The fracture and osteoporosis outpatient clinic: an effective strategy for improving implementation of an osteoporosis guideline

CHAPTER 4 Bone and fall related fracture risks in women and men with a recent clinical fracture

CHAPTER 5 Evaluation of patients with a recent clinical fracture and osteoporosis. A multidisciplinary approach

CHAPTER 6 Prevalence of morphometric vertebral deformities determined by absorptiometry in patients presenting with a non-vertebral fracture

CHAPTER 7 Risk of falling in patients with a recent fracture

CHAPTER 8 Implementation of guidelines for osteoporosis and fall prevention in patients with a recent clinical fracture reduces the risk of new fractures

CHAPTER 9 Summary and conclusions

CHAPTER 10 Samenvatting en conclusies

DANKWOORD 
Chapter 1

General Introduction 


\section{FRACTURES AND RISK FACTORS FOR FRACTURES}

Fractures are the expression of bone's fragility and failure to resist applied mechanical load. Also, in most cases of clinical fractures, they are the expression of the body's failure to resist falls. After the age of 50 years, any fracture is a sentinel event in a person's life. Therefore, measures to effectively prevent fractures are advocated in national and international guidelines ${ }^{1-4}$. These fracture prevention guidelines advocate case finding to identify patients at highest risk based on two categories of risk factors for fractures: those that are bonerelated and those that are fall-related.

In this thesis, we concentrate on the prevalence and the impact of counselling on these two categories of risk factors in patients treated in hospital because of a recent clinical fracture.

\section{Fractures AND BONE-RELATED RISK-FACTORS: MORE THAN 'OSTEOPOROSIS' ALONE}

The term osteoporosis literally refers to porosity of bone. Sir Astley Paston Cooper (1768 - 1841) already reported observations regarding old age and fractures in his book "a treatise on dislocations and fractures of the joints" 5 :

"That regular decay of nature which is called old age, is attended with changes which are easily detected in the dead body; and one of the principal of these is found in the bones, which become thin in their shell, and spongy in their texture; hence the light soft bones of old persons may be cut with a pen-knife, with which we are not capable of making any impression on those of adults".

In 1994, osteoporosis was defined by the World Health Organisation (WHO) as a diffuse skeletal condition in which bone mass is reduced and micro architectural changes occur, resulting in an increased risk of fractures, even following minimal trauma ${ }^{6}$.

In clinical practice, the current golden standard to measure bone mineral density (BMD) is dual energy X-ray absorptiometry (DXA). DXA has contributed considerably to epidemiological research on fracture risk, case finding, and clinical decision-making regarding treatments for reducing fracture risk ${ }^{2,7-10}$.

DXA measures the two dimensional projection of BMD and therefore allows the structural components of bone (such as bone size, cortical bone dimensions, and femoral neck length and angle) to be evaluated.

However, DXA does not directly measure micro architectural aspects of bone, and thus does not evaluate the second part of the WHO definition. In essence, DXA reflects only one of the many components that contribute to bone's resist- 
ance to fracture and thereby accounts for only part of the biomechanical characteristics of bone.

Additionally, despite the fact that the WHO has operationally defined osteoporosis as having a BMD of more than 2.5 standard deviations below the mean BMD for a young white woman, most patients with a clinical fracture do not meet this criteria $^{6,11-13}$.

This suggests that there are other bone-related fracture risks in addition to $\mathrm{BMD}$. The definition of osteoporosis has therefore been extended and broadened by the National Institutes of Health $(\mathrm{NIH})$ to entail a bone disease with compromised bone strength that in turn predisposes one to an increased risk of fracture, taking into account failure of any factors that contribute to bone's resistance to fracture ${ }^{14,15}$.

However, there is currently no accurate measurement that captures overall bone strength and that can be used in clinical practice.

In an effort to fine tune case finding, the concept of absolute risk (AR) has emerged. This refers to the individual risk for fracture over a period of time (e.g. over the next 5 to 10 years or over a lifetime $)^{16,17}$. The AR calculation is based on the finding that certain clinical risk factors predict fractures independently of BMD and partially independent of each other. These include gender, age, personal and parental fracture history, low body weight, severe immobility, smoking cigarettes, alcohol abuse, rheumatoid arthritis, and current use of glucocorticoids ${ }^{18}$.

Fracture treatment is a major part of surgical practice. Acute treatment of a fracture is aimed to consolidate the fractured bone or replace it with a prosthesis. However, the underlying cause of fracture is not approached this way. It does not consider the risk factors associated with the occurrence of the fracture, nor does it consider the future fracture risk. Therefore, in terms of future fracture risk, the patient's perspective worsens. It has been shown that men and women with a history of clinical fracture are at increased risk for developing a new fracture, independent of BMD and other clinical risk factors ${ }^{18-21}$. The risk for subsequent fracture is even higher in the short term, as has been shown for recurrent morphometric vertrebral fractures. Several studies report a recent fragility fracture to be more predictive of a subsequent fracture than low bone density ${ }^{22-24}$.

If indeed subsequent fracture risk is independent of BMD, we must then question why BMD is measured immediately after a fracture? Vertebral fractures are an example in which BMD measurement is not necessary to determine treatment. Their presence increases the risk for subsequent vertebral and non-vertebral fractures and RCT's on fracture prevention are available in patients solely selected on the presence of a vertebral fracture, independent of $\mathrm{BMD}^{8}$. 
However, the most frequent fractures that require a surgeon's attention are clinical, non-vertebral fractures. For these patients, guidelines advocate evaluating for fracture risk. This evaluation includes a BMD measurement to aid in the decision about fracture prevention.

As subsequent fracture risk is increased in such patients, several guidelines propose treatment in patients with a higher $\mathrm{T}$ score than -2.5 (e.g. -2, -1). Recent research has shown that prevention of a subsequent fracture is even possible when patients are selected solely on the basis of having had a nonvertebral fracture in the past without even referring to BMD. Patients who had had a hip fracture were randomised for treatment with intravenous zoledronate or placebo regardless of their measured $\mathrm{BMD}^{25}$, in analogy with studies in patients selected with a pre-existing vertebral fracture regardless of BMD. The results showed a $35 \%$ risk reduction in the intervention group.

Thus, there is some controversy about the way patients with a recent fracture should be evaluated for bone-related risks and whether DXA should be used for subsequent fracture prevention.

\section{FRACTURES AND FALL-RELATED RISK FACTORS: AN OVERLOOKED ASSOCIATION}

Fall risks are the primary extra-skeletal factors contributing to clinical, non-vertebral fractures ${ }^{26}$. Except for age and immobility, which are also related to fall risk, none of the above-mentioned bone-related risk factors explicitly take the risk of falls into account.

Fall-related risks that are a part of fall prevention guidelines include impaired mobility, a history of falls, the use of psychoactive drugs, low activity in daily living (ADL), physical activity, joint disease, impaired vision, urinary incontinence, Parkinson's disease, vertigo, the use of multiple medications, age, female gender, and cognitive impairment ${ }^{4}$.

Guidelines on fall prevention advocate that a fall risk evaluation should be performed for patients with a recent clinical fracture. The fall risk profile is then used to make decisions about targeted or multidimensional fall prevention, both of which have been shown to reduce the number of patients with falls. However, no fall prevention study has been able to prove actual fracture prevention ${ }^{27-29}$.

With the knowledge that $1 \%$ to $5 \%$ of falls result in a fracture, and with the assumption that a fall prevention program is capable of reducing falls by $20 \%$, it would take several thousands of patients per treatment arm to prove that fall prevention indeed results in fracture prevention ${ }^{28}$.

Another fall related approach to reduce fracture risk is "impact protection". This strategy has been investigated for the prevention of hip fractures. To reduce the impact on the trochanter of the hip in a sideways fall, underwear with 
special pads over the hip region has been developed. Although promising according to the first published papers, it is now evident that, because of low acceptance and low compliance, these devices do not prevent hip fractures ${ }^{30-32}$. Furthermore, hip protectors can only have an effect on possible hip fractures, which comprise only a small portion of all clinical fractures.

Thus, there is some controversy regarding if and how patients with a recent fracture should be evaluated for fall related risks by the surgeon treating the fracture.

\section{Putting it together: Fracture PREVEntion in fRActure PatientS}

The interaction of bone fragility and the occurrence of a fall can ultimately result in a fracture. Osteoporosis prevention guidelines have mainly focused on bonerelated fracture risk, and fall prevention programs have mainly focused on fallrelated risk factors. Nonetheless, both aspects deserve attention in fracture patients. As has been shown for hip fractures, combining measures aimed to evaluate bone fragility and fall prevention might result in a better total risk profile for fractures ${ }^{33}$. Therefore, the first aim of this thesis was to analyse the overall risk profile in fracture patients.

Ideally, one should attempt to prevent the first fracture. This is called primary prevention. In as far as case finding is appropriately performed, patients at high risk for a fracture can be identified and treated to prevent that first fracture. Unfortunately, implementation of case finding is limited.

Nonetheless, the occurrence of a new fracture gives the surgeon the unique opportunity to take responsibility for prevention of a subsequent fracture. This is termed secondary prevention. Trauma and orthopaedic surgeons treating fractures are in the ideal position to inform their patients and to initiate a program that looks beyond the fracture. Consequently, the second aim of this thesis was to evaluate the impact of a systematic implementation of a bone and fall-related risk assessment and intervention program that targeted the bone and fall-related risks found upon assessment. The project called "the fracture and osteoporosis outpatient clinic" was initiated in September, 2004 for fracture patients treated at Maastricht University Hospital.

\section{THESIS OUTLINE AND OBJECTIVES}

Chapter 1 provides a general introduction with the thesis outline and objectives. In Chapter 2, we investigate the incidence of subsequent fractures (i.e. the 1 
and 2 year absolute fracture risk) in a cohort of men and women 50 years of age and older with a recent clinical fracture. All of these patients were treated at Maastricht University Hospital in 1999, 2000, and 2001, in the absence of osteoporosis and fall prevention guidelines. The patients in this retrospective study served as a control group for subsequent fracture incidence before osteoporosis and fall prevention guidelines were available.

Chapter 3 evaluates the impact of a fracture nurse on referral for a DXA measurement compared to referral in surrounding hospitals without a fracture nurse. In Chapter 4, we look beyond the fracture and discuss how we systematically implemented, over a one year period, an integrated bone and fall-related risk evaluation among subjects with a recent clinical fracture. This evaluation was carried out in accordance with the guidelines that had become available. In Chapter 5, we evaluate the prevalence of contributors to secondary osteoporosis in patients with a recent clinical fracture.

As mentioned in the introduction, vertebral fractures contribute to fracture risk and are an indication for treatment at any level of bone mineral density (BMD), but most vertebral fractures are not clinically diagnosed. We therefore report in Chapter 6 findings from a systematic evaluation of the prevalence of vertebral deformities in patients with a recent non-vertebral fracture. This was measured by quantitative vertebral fracture assessment (VFA) using lateral DXA.

In Chapter 7, we assess the number of patients with falls and fractures during the first three months after a clinical fracture, and the degree to which bone and fall-related risks could be helpful in identifying such patients.

Finally, in Chapter 8 we report the effect of systematic implementation of guidelines for osteoporosis and fall prevention in patients with a recent clinical fracture on fracture risk. The one year absolute risk for subsequent fractures was compared with the above mentioned control group from the years before preventive measures were advised.

Chapter 9 summarises the results and provides recommendations for future research in the field of secondary prevention in fracture care. Chapter 10 is the Dutch translation of the summary.

\section{REFERENCES}

1. Gass M, Dawson-Hughes B. Preventing osteoporosis-related fractures: an overview. Am J Med. 2006 Apr;119(4 Suppl 1):S3-S11.

2. Geusens PP. Review of guidelines for testing and treatment of osteoporosis. Curr Osteoporos Rep. 2003 Sep;1(2):59-65. 
3. CBO kvdg. Osteoporose. Tweede herziene richtlijn 2002. available at : http://wwwcbonl/ product/richtlijnen/folder20021023121843/osteoporosepdf/view.accessed august 17, 2005.

4. CBO kvdg. Preventie van valincidenten bij ouderen 2004. available at: http://wwwcbonl/ product/richtlijnen/folder20021023121843/val-richtlijn2004pdf/view.accessed june 5, 2006.

5. Cooper A. A treatise on dislocations and fractures of the joints. a new american edition ed. Philadelphia: Blanchard and Lea 1851; internetlink: http://books.google.com/books? $i d=E K 99 d o H V Y \_A C \&$ printsec $=$ frontcover\&dq=a+treatise $+a n+$ dislocations $+a n d+$ frac tures+of+the+joints\&hl=nl\#PPP2,M1

6. Consensus development conference: prophylaxis and treatment of osteoporosis. Osteoporos Int. $1991 \mathrm{Feb} ; 1(2): 114-7$.

7. Geusens PP, Lems WF, Verhaar HJ, Leusink G, Goemaere S, Zmierczack H, et al. Review and evaluation of the Dutch guidelines for osteoporosis. J Eval Clin Pract. 2006 Oct;12(5):539-48.

8. Sambrook P, Cooper C. Osteoporosis. Lancet. 2006 Jun 17;367(9527):2010-8.

9. Black DM, Cummings SR, Karpf DB, Cauley JA, Thompson DE, Nevitt MC, et al. Randomised trial of effect of alendronate on risk of fracture in women with existing vertebral fractures. Fracture Intervention Trial Research Group. Lancet. 1996 Dec 7;348(9041):1535-41.

10. Cummings SR, Black DM, Thompson DE, Applegate WB, Barrett-Connor E, Musliner $\mathrm{TA}$, et al. Effect of alendronate on risk of fracture in women with low bone density but without vertebral fractures: results from the Fracture Intervention Trial. Jama. 1998 Dec 23-30;280(24):2077-82.

11. Hegeman JH, Willemsen G, van Nieuwpoort J, Kreeftenberg HG, van der Veer E, Slaets JP, et al. Effective tracing of osteoporosis at a fracture and osteoporosis clinic in Groningen; an analysis of the first 100 patients. Ned Tijdschr Geneeskd. 2004 Oct 30;148(44):2180-5.

12. McLellan AR, Gallacher SJ, Fraser M, McQuillian C. The fracture liaison service: success of a program for the evaluation and management of patients with osteoporotic fracture. Osteoporos Int. 2003 Dec;14(12):1028-34.

13. Miller PD, Barlas S, Brenneman SK, Abbott TA, Chen YT, Barrett-Connor E, et al. An approach to identifying osteopenic women at increased short-term risk of fracture. Arch Intern Med. 2004 May 24;164(10):1113-20.

14. Osteoporosis prevention, diagnosis, and therapy. NIH Consens Statement. 2000 Mar 27-29;17(1):1-45.

15. National Institutes of Health. Consensus Development Conference Statement, March 27-29, 2000. website accessed at 13-12-2007 http://consensusnihgov/2000/2000 Osteoporosis111htmlhtm. 2000.

16. Kanis JA, Oden A, Johnell O, Johansson H, De Laet C, Brown J, et al. The use of clinical risk factors enhances the performance of BMD in the prediction of hip and osteoporotic fractures in men and women. Osteoporos Int. 2007 Aug;18(8):1033-46.

17. Nguyen ND, Ahlborg HG, Center JR, Eisman JA, Nguyen TV. Residual lifetime risk of fractures in women and men. J Bone Miner Res. 2007 Jun;22(6):781-8.

18. Kanis JA, Borgstrom F, De Laet C, Johansson H, Johnell O, Jonsson B, et al. Assessment of fracture risk. Osteoporos Int. 2005 Jun;16(6):581-9. 
19. Lindsay R, Silverman SL, Cooper C, Hanley DA, Barton I, Broy SB, et al.: Risk of new vertebral fracture in the year following a fracture. : Jama. 2001;285(3):320-3.

20. Kanis JA. : Diagnosis of osteoporosis and assessment of fracture risk. : Lancet. 2002;359(9321):1929-36.

21. Center JR, Bliuc D, Nguyen TV, Eisman JA. Risk of subsequent fracture after low-trauma fracture in men and women. Jama. 2007 Jan 24;297(4):387-94.

22. Albrand G, Munoz F, Sornay-Rendu E, DuBoeuf F, Delmas PD. Independent predictors of all osteoporosis-related fractures in healthy postmenopausal women: the OFELY study. Bone. 2003 Jan;32(1):78-85.

23. van Geel AC, Geusens PP, Nagtzaam IF, Schreurs CM, van der Voort DJ, Rinkens PE, et al. Timing and risk factors for clinical fractures among postmenopausal women: a 5year prospective study. BMC Med. 2006;4:24.

24. van Geel TA, Geusens PP, Nagtzaam IF, van der Voort DJ, Schreurs CM, Rinkens PE, et al. Risk factors for clinical fractures among postmenopausal women: a 10-year prospective study. Menopause Int. 2007 Sep;13(3):110-5.

25. Lyles KW, Colon-Emeric CS, Magaziner JS, Adachi JD, Pieper CF, Mautalen C, et al. Zoledronic Acid and Clinical Fractures and Mortality after Hip Fracture. N Engl J Med. 2007 Sep 26.

26. Cummings SR, Nevitt MC. Non-skeletal determinants of fractures: the potential importance of the mechanics of falls. Study of Osteoporotic Fractures Research Group. Osteoporos Int. 1994;4 Suppl 1:67-70.

27. Oliver D, Britton M, Seed P, Martin FC, Hopper AH. Development and evaluation of evidence based risk assessment tool (STRATIFY) to predict which elderly inpatients will fall: case-control and cohort studies. Bmj. 1997 Oct 25;315(7115):1049-53.

28. Chang JT, Morton SC, Rubenstein LZ, Mojica WA, Maglione M, Suttorp MJ, et al. Interventions for the prevention of falls in older adults: systematic review and metaanalysis of randomised clinical trials. Bmj. 2004 Mar 20;328(7441):680.

29. Stenvall M, Olofsson B, Lundstrom M, Englund U, Borssen B, Svensson O, et al. A multidisciplinary, multifactorial intervention program reduces postoperative falls and injuries after femoral neck fracture. Osteoporos Int. 2007 Feb;18(2):167-75.

30. Kiel DP, Magaziner J, Zimmerman S, Ball L, Barton BA, Brown KM, et al. Efficacy of a hip protector to prevent hip fracture in nursing home residents: the HIP PRO randomized controlled trial. Jama. 2007 Jul 25;298(4):413-22.

31. Kannus P, Parkkari J, Niemi S, Pasanen M, Palvanen M, Jarvinen M, et al. Prevention of hip fracture in elderly people with use of a hip protector. N Engl J Med. 2000 Nov 23;343(21):1506-13.

32. Parker MJ, Gillespie WJ, Gillespie LD. Hip protectors for preventing hip fractures in older people. Cochrane Database Syst Rev. 2005(3):CD001255.

33. Cummings SR, Nevitt MC, Browner WS, Stone K, Fox KM, Ensrud KE, et al. Risk factors for hip fracture in white women. Study of Osteoporotic Fractures Research Group. N Engl J Med. 1995 Mar 23;332(12):767-73. 


\section{CHAPTER 2}

Risk of new clinical fractures within two years following a fracture

Svenhjalmar van Helden, Jochen Cals, Fons Kessels,

Peter Brink, Geert Jan Dinant, Piet Geusens

Osteoporosis International, 2006; 17(3): 348-354 


\section{ABSTRACT}

Context: Clinical fractures are associated with an increased relative risk of future fractures, but the absolute risk and timing of new clinical fractures immediately after a clinical fracture have not been reported extensively.

Objective: To determine the absolute risk of subsequent clinical fractures within 2 years after a clinical fracture.

Design and setting: Analysis of clinical fracture data from a university hospital recruiting all fractures in the area between January 1999 and December 2001. Subjects 2419 male and female patients aged 50 years and older with a total of 2575 fractures. There were 139 patients with more than one simultaneous fracture occurring at the same time.

Main outcome measure: Absolute fracture incidence within two years following a clinical fracture.

Results: Mean age was 66 years for males and 72 for females. The cumulative incidence of patients with new clinical fractures over 2 years was $10.8 \%$ (262/2419).

In the 262 patients with subsequent fractures we observed a higher mean age, more females and more often multiple baseline fractures compared to the 2157 patients without subsequent fractures. Kaplan Meier analysis indicated that age, gender and having multiple baseline fractures contributed significantly to cumulative new fracture incidence.

Cox regression showed that these variables independently contributed to a higher subsequent fracture incidence. New fracture incidence was higher with increasing age $(p<0.001 ;$ HR 1.2 per decade $\{\mathrm{Cl} 1.1-1.3\})$. Females had a new fracture incidence of $12,2 \%$ compared to $7.4 \%$ in males $(p=0.015 ; \mathrm{HR} 1.5\{\mathrm{Cl}$ 1.1-2.0\}). Patients with multiple baseline fractures had a new fracture incidence of $17,3 \%$ compared to $10.4 \%$ for subjects with one baseline fracture $(p=0.006$; $\mathrm{HR} 1.8\{\mathrm{Cl} 1.2-2.7\})$. Of all clinical fractures occurring within 2 years after a clinical fracture, $60 \%$ occurred during the first year and $40 \%$ during the second year $(p=0.005)$.

Conclusion: The absolute risk to develop an incident clinical fracture within two years after any clinical fracture was $10.8 \%$. Increased age, female gender and the presence of multiple simultaneous fractures at baseline each independently increased the risk of incident fracture. Significantly more fractures occurred in the first year following the index fracture than in the second year. Altogether these data support the need for early prevention of future fracture among individuals with a fracture after age 50 , using interventions which have been shown to have a rapid antifracture benefit. 


\section{INTRODUCTION}

Several studies indicate that having a fracture during adulthood is associated with an increased relative risk of developing a subsequent fracture, both in men and in women ${ }^{1-4}$. Klotzbuecher showed in an extensive meta-analysis a significant increased relative risk of 1.7-2.6 for any subsequent fractures among people with a history of any fracture. No absolute fracture risk calculation was given, nor information about the timing of the next fracture. Johnell et al. found the relative risk in their population to be the highest during the first years after the event ${ }^{5}$.

Studies on the short-term absolute fracture risk and timing of the subsequent fractures during the first years after a fracture are scarce. Prior morphometric vertebral fractures have a striking effect on future risk of new morphometric vertebral fractures within one year with an absolute risk of $20 \%$ for new vertebral fractures $(25 \%$ in the presence of $>2$ vertebral fractures at baseline and $25 \%$ for any fracture within one year 6 . In Johnell's study, the absolute risk estimate was given for patients who developed a fracture of the hip, forearm, spine or shoulder as first and second fracture and the incidence was $12.0 \%(n=230 / 1918)$ during 2-year follow-up.

There is a tendency to progress from relative risk calculation to the 5- or 10years absolute risk evaluation in the individual patient, in order to recognise patients at highest risk for fractures within short time ${ }^{7}$. We therefore investigated the incidence and timing of subsequent clinical fractures within two years after a clinical fracture in men and women aged over 50 years.

\section{MATERIALS AND METHODS}

All patients aged over 50 years with a clinical fracture, who were treated in an European level-one trauma centre between January 1999 and December 2001, were included. Fractures were confirmed on X-ray. Patients with pathological fractures were excluded as well as patients not currently living in the Netherlands or living in the Belgian boarder area in close proximity of Maastricht.

A fracture questionnaire was sent to all survivors. Self-reported fractures were confirmed by review of the radiography reports in the hospital database. Self reported fractures treated in other hospitals could not be verified with radiography reports. Additionally the non responders and deceased patients were individually entered into the hospital database and subsequent fractures were investigated by studying the radiography reports in the 2 years after the baseline fracture until April 2004. 
Clinical fractures were classified in 15 categories, according to the International Classification of Disease (ICD-9): (skull (800-804), vertebra (805-806), clavicle (810), thorax $(807,811)$, pelvis (808), humerus (812), forearm (813), wrist (813), hand (814-817), hip (820), femur (821), patella (822), tibia/fibula (823), ankle (824), foot (825-826)). The 15 categories were subsequently divided over 5 large groups for further analysis: humerus, radius/ulna, hip, other fractures and multiple fractures. Fractures at the classic osteoporotic sites (humerus, wrist, hip and vertebra) were also grouped for subsequent fracture analysis.

All study subjects were followed forward in time until death or the most recent clinical contact, with a maximum follow-up of two years.

Demographic and baseline characteristics were summarized using descriptive statistics. The cumulative number of patients with new fractures, based on time between the first and second fracture, was analysed using Kaplan-Meier methods with stratification for age, gender, number of baseline fractures and location of fractures. Cox regression was used to analyse independent contribution of those risk factors significant in Kaplan-Meier analysis to new fracture incidence and calculation of hazard ratios and their confidence intervals. Interactions were also investigated in the cox regression.

\section{RESULTS}

2419 Patients with 2575 fractures were included in the study. There were 139 patients with more than one simultaneous fracture.

Table 1: mean age and $\%$ in female and male group by fracture site

\begin{tabular}{|c|c|c|c|c|}
\hline fracture site & patient number & female group $(n=1745)$ & male group $(n=674)$ & mean age (sd) \\
\hline humerus & 256 & 11.8 & 7.4 & $73(11)$ \\
\hline radius/ulna & 611 & 29.5 & 14.2 & $69(11)$ \\
\hline hip & 525 & 22.2 & 20.3 & $80(9)$ \\
\hline multiple & 139 & 5.3 & 7 & $71(12)$ \\
\hline other fractures & 888 & & & $66(12)$ \\
\hline skull & 9 & 0.2 & 0.7 & \\
\hline spine & 54 & 1.7 & 3.7 & \\
\hline clavicule & 42 & 1.3 & 3 & \\
\hline thorax & 81 & 2.1 & 6.7 & \\
\hline hand & 246 & 7.7 & 16.5 & \\
\hline femur & 42 & 1.9 & 1.3 & \\
\hline patella & 19 & 0.7 & 0.9 & \\
\hline tibia/fibula & 68 & 2.5 & 3.6 & \\
\hline ankle & 192 & 8.1 & 7.4 & \\
\hline foot & 135 & 4.9 & 7.3 & \\
\hline Total & 2419 & $100 \%$ & $100 \%$ & \\
\hline
\end{tabular}


The group consisted of 1745 females and 674 males with a mean age and range of respectively 72 years (50-103) and 66 years (50-94). Fracture location and distribution of these subjects are shown in table 1.15 Patients from abroad and 10 patients with pathologic fractures were excluded. Single humerus, radius/ulna and hip fractures formed the majority of fractures with a total of 1392 fractures.

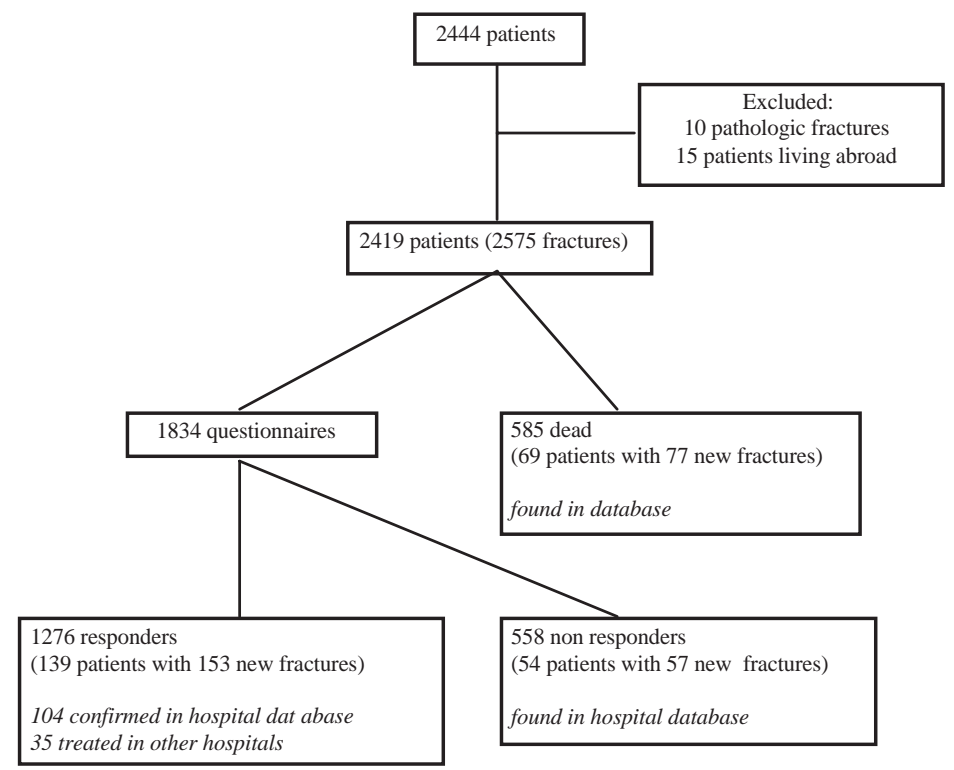

Figure 1: Flowchart of patients included in the study

585 Patients had died at the time of the study; the remaining 1834 subjects received the questionnaire. The response rate was $70 \%$ (1276 patients). X-ray reports of all 2419 subjects were studied for subsequent fractures in our own hospital database (Figure 1). In the responder group a total of 139 patients reported new fractures in the questionnaire. In 104 patients this could be confirmed in the database of our hospital. The other 35 patients were treated in other hospitals. All the patients in the responder group where hospital database reported a fracture reported this on the questionnaire.

Questionnaire and database research together showed during the 2 year follow up 262 patients with 286 subsequent fractures. The absolute risk for new fractures within two years was $10.8 \%$ (262/2419). Mean overall interval between first fracture and subsequent fracture was 10.8 months. Of all clinical 
Table 2: new fracture sites according to site of prior fracture by time and absolute fracture risk

\begin{tabular}{|c|c|c|c|c|}
\hline \multirow{3}{*}{$\begin{array}{l}\text { site of new fracture } \\
\text { prior humerus fracture }(n=256)\end{array}$} & \multicolumn{3}{|c|}{ year of study } & \multirow[t]{2}{*}{$\begin{array}{c}\text { absolute new fracture risk } \\
\text { (2year) }\end{array}$} \\
\hline & & $0-1$ & $1-2$ & \\
\hline & & & & $12,1 \%$ \\
\hline & humerus & 0 & 3 & \\
\hline & ulna/radius & 1 & 3 & \\
\hline & hip & 3 & 2 & \\
\hline & other & 12 & 5 & \\
\hline & multiple & 2 & 0 & \\
\hline prior ulna/radius fracture $(n=611)$ & & & & $9,2 \%$ \\
\hline & humerus & 4 & 0 & \\
\hline & ulna/radius & 8 & 6 & \\
\hline & hip & 7 & 7 & \\
\hline & other & 12 & 8 & \\
\hline & multiple & 1 & 3 & \\
\hline prior hip fracture $(n=525)$ & & & & $11,4 \%$ \\
\hline & humerus & 2 & 5 & \\
\hline & ulna/radius & 2 & 3 & \\
\hline & hip & 10 & 7 & \\
\hline & other & 19 & 9 & \\
\hline & multiple & 2 & 1 & \\
\hline prior other fracture $(n=888)$ & & & & $10,2 \%$ \\
\hline & humerus & 3 & 1 & \\
\hline & ulna/radius & 11 & 2 & \\
\hline & hip & 11 & 6 & \\
\hline & other & 26 & 25 & \\
\hline & multiple & 3 & 3 & \\
\hline prior multiple fractures $(n=139)$ & & & & $17,3 \%$ \\
\hline & humerus & 3 & 0 & \\
\hline & ulna/radius & 2 & 2 & \\
\hline & hip & 4 & 1 & \\
\hline & other & 7 & 0 & \\
\hline & multiple & 3 & 2 & \\
\hline Total & & 158 & 104 & $10,80 \%$ \\
\hline
\end{tabular}

fractures occurring within 2 years after a clinical fracture, $60 \%$ occurred during the first year and $40 \%$ during the second year $(p=0.005)$. Men tend to develop a new clinical fracture earlier in the 2-year follow up (mean time to fracture: 9,5 months) than women do (11,1 months). $70 \%$ of all men who developed a new clinical fracture did so in the first year after their first fracture, in women this was $58 \%$. In the 262 patients with subsequent fractures we observed a higher mean age, more females and more often multiple baseline fractures compared to the 2157 patients without subsequent fractures . Kaplan Meier analysis indicated that age, gender and having multiple baseline fractures significantly contribute to new fracture incidence. Absolute fracture risk according to prior fracture type showed the highest risk in subjects with multiple baseline fractures (Table 2). The most frequent new fractures were hip fractures $(22,1 \%)$ followed 


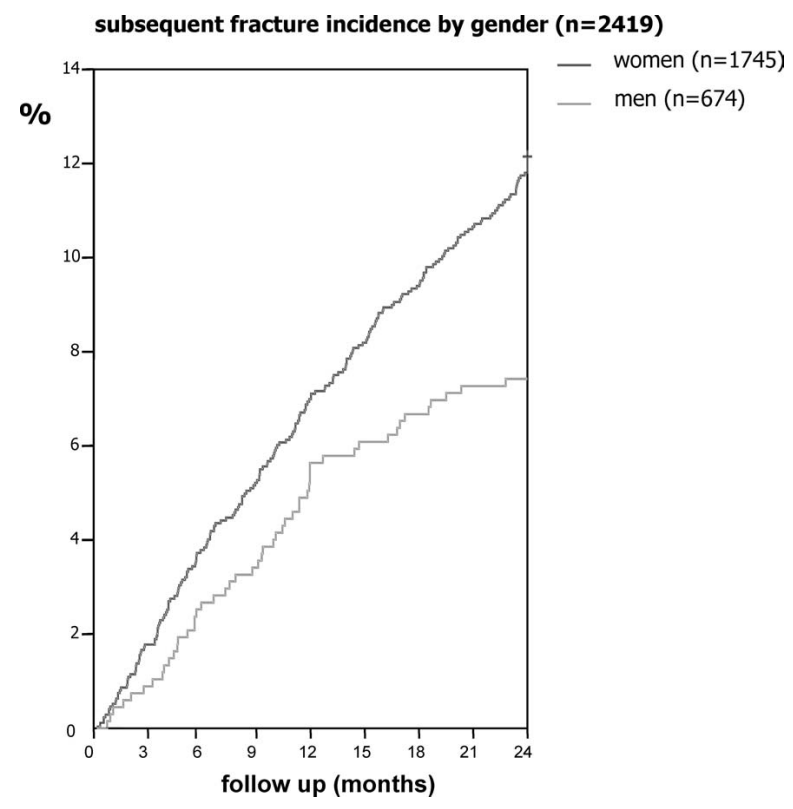

Figure 2:Subsequent fracture incidence by gender ( $n=2419$ ). $p=0.001$

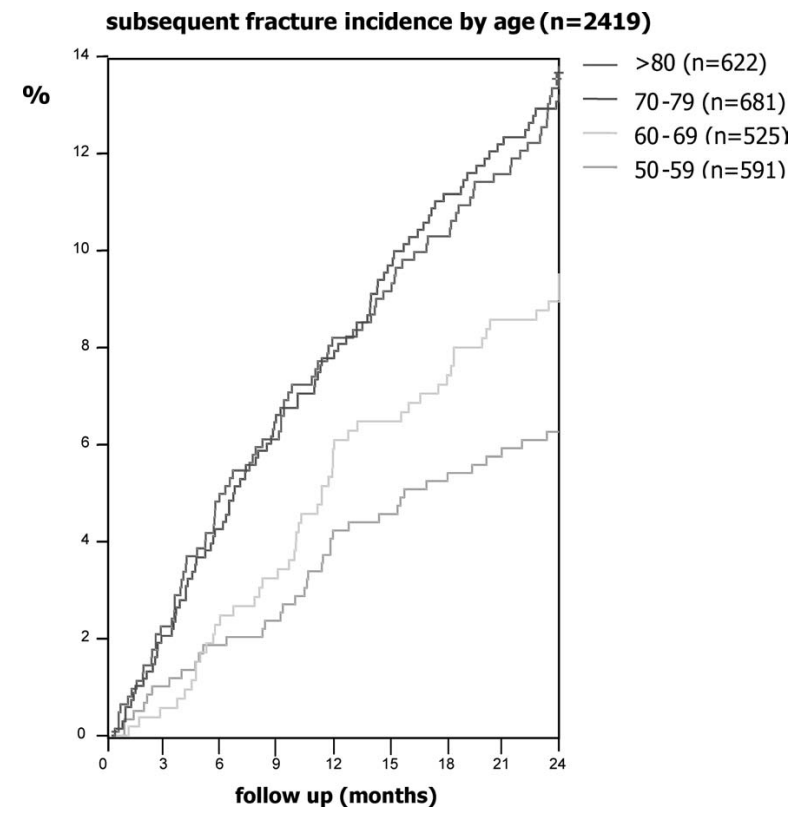

Figure 3: Subsequent fracture incidence by age $(n=2419)$. $p<0.001$ 


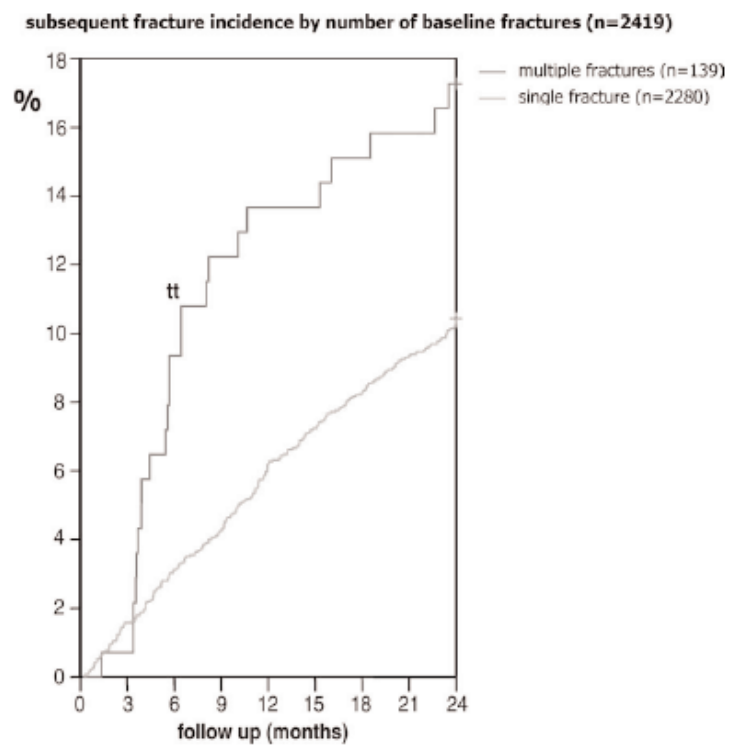

Figure 4: Subsequent fracture incidence by number of baseline fractures ( $n=2419)$. $p=0.007$

Table 3: Cox regression with age, gender and number of baseline fractures

\begin{tabular}{llll}
\hline & hazard ratio & confidence interval & p-value \\
\hline Age (per decade) & 1,2 & $1.1-1.3$ & $<0,001$ \\
gender & 1,5 & $1.1-2.0$ & 0,015 \\
number of baseline fractures & 1,8 & $1.2-2.7$ & 0,006 \\
\hline
\end{tabular}

by spine- $(16 \%)$, wrist- $(15,3 \%)$, humerus- $(8 \%)$, foot - $(6,5 \%)$. and hand -fractures $(6,1 \%) .7,6 \%$ Of the patients with new fractures had multiple fractures. Females had a new fracture incidence of $12,2 \%$ compared to males with $7.4 \%$ (Figure 2; $p=0.001$ ). New fracture incidence was higher with increasing age (Figure 3; $p<0.001$ ). Patients with multiple baseline fractures showed a new fracture incidence of $17,3 \%$ compared to $10.4 \%$ for subjects with one baseline fracture (Figure $4 ; p=0.007$ ).

Cox regression showed age, gender and having multiple baseline fractures as variables independently contributing to a higher subsequent fracture incidence (Table 3). Interactions were considered in the cox regression but were not significant. 


\section{DISCUSSION}

To our knowledge this is the first study to identify the number of concomitant baseline fractures as an independent risk factor for new fractures. In the metaanalysis of Klotzbuecher, it was suggested that the number of fractures in patient history could be more significant then the location of the fracture ${ }^{8,9}$. This differs from our result in the fact that we did not look at the number of fractures in patient history but at the number of concomitant fractures present at the same time.

The absolute new fracture risk of $10.8 \%$ for any clinical fracture and the observation that $60 \%$ of these new fractures occurred within one year, were quite similar to the study of Johnell et al who reported on fractures of hip, forearm, shoulder and vertebrae ${ }^{10}$. They found an incidence of $12.0 \%$ for the same subsequent fractures over 2 years and the highest incidence immediately after the first fracture. Our study indicates that the same incidence is found for all clinical fractures. This underscores the importance of a prevention strategy starting soon after the first fracture for all fracture types.

One may wonder why patients with a fracture are at an increased risk for developing a new fracture immediately following a prior fracture. Silman et al. proposed several possible mechanisms in this prospect ${ }^{2}$. Firstly, bone loss occurs after a fracture, independent of bone mineral density at the time of the fracture. Secondly, risk factors for the development of the first fracture most often remain untreated and increase the susceptibility to subsequent fractures ${ }^{3}$, 9 . Thirdly, any mechanically induced deformity alters weight distribution in that particular bone, such as in vertebrae, and therefore is associated to an increased risk of fracture at another site ${ }^{2,6}$. Furthermore, as most fractures occurred after a trauma such as a fall, all such patients are also at increased risk for further falls.

This study has several limitations. Firstly, some subsequent fractures may have been missed in the patient group of non-responders to the questionnaire and the patients that already deceased at the time of the study. Systematic research in our own hospital database showed subsequent fractures in these two groups, but certainly some patients were treated in other hospitals as was the case in the responder group. This results in an underestimation of the new fracture incidence.

Secondly, it is possible that some people did not correctly answer the questionnaire. However, a study performed by Ismail assessed the validity of selfreported incident non-spine fractures using a postal questionnaire and concluded that this method was accurate for obtaining information about the occurrence of most fractures, especially hip and distal forearm fractures, including their timing ${ }^{10}$. 
It was also stated that, if possible, self-reported fractures ideally should be verified from other sources, which we did in our own database research in the responder group.

We conclude that increasing age, female gender and having multiple concomitant fractures independently influence the short-term risk to develop a new clinical fracture after any clinical fracture. This risk is highest in the first year following the fracture.

\section{REFERENCES}

1. Klotzbuecher CM, Ross, PD, Landsman, PB, Abbott, TA, 3rd, Berger, M (2000) Patients with prior fractures have an increased risk of future fractures: a summary of the literature and statistical synthesis. J Bone Miner Res 15:721-739.

2. Silman AJ (1995) The patient with fracture: the risk of subsequent fractures. Am J Med 98:12S-16S.

3. Karlsson MK, Hasserius, R, Obrant, KJ (1993) Individuals who sustain nonosteoporotic fractures continue to also sustain fragility fractures. Calcif Tissue Int 53:229-231.

4. van der Klift M, de Laet, CE, McCloskey, EV, Johnell, O, Kanis, JA, Hofman, A, Pols, HA (2004) Risk factors for incident vertebral fractures in men and women: the Rotterdam Study. J Bone Miner Res 19:1172-1180.

5. Johnell O, Kanis, JA, Oden, A, Sernbo, I, Redlund-Johnell, I, Petterson, C, De Laet, C, Jonsson, B (2004) Fracture risk following an osteoporotic fracture. Osteoporos Int 15:175-179.

6. Lindsay R, Silverman, SL, Cooper, C, Hanley, DA, Barton, I, Broy, SB, Licata, A, Benhamou, L, Geusens, P, Flowers, K, Stracke, H, Seeman, E (2001) Risk of new vertebral fracture in the year following a fracture. Jama 285:320-323.

7. Kanis JA (2002) Diagnosis of osteoporosis and assessment of fracture risk. Lancet 359:1929-1936.

8. Torgerson DJ, Campbell, MK, Thomas, RE, Reid, DM (1996) Prediction of perimenopausal fractures by bone mineral density and other risk factors. J Bone Miner Res 11:293-297.

9. Port L, Center, J, Briffa, NK, Nguyen, T, Cumming, R, Eisman, J (2003) Osteoporotic fracture: missed opportunity for intervention. Osteoporos Int 14:780-784.

10. Ismail AA, O'Neill, TW, Cockerill, W, Finn, JD, Cannata, JB, Hoszowski, K, Johnell, O, Matthis, C, Raspe, H, Raspe, A, Reeve, J, Silman, AJ (2000) Validity of self-report of fractures: results from a prospective study in men and women across Europe. EPOS Study Group. European Prospective Osteoporosis Study Group. Osteoporos Int 11:248254. 


\section{CHAPTER 3}

The fracture and osteoporosis outpatient clinic: an effective strategy for improving implementation of an osteoporosis guideline

Svenhjalmar van Helden; Evelyne Cauberg, Piet Geusens; Bjorn Winkes; Trudy van der Weijden; Peter Brink

Journal of Evaluation in Clinical Practice 2007; 13(5):801-5 


\section{ABSTRACT}

Background: Clinical screening for osteoporosis in women over 50 following a fracture is advocated by all guidelines on osteoporosis, but such attitude is widely reported to be inadequate. The aim of this study was to evaluate the effect of a strategy comparing referral to a DXA measurement as part of the osteoporosis guideline by a dedicated osteoporosis nurse versus referral in hospitals without the presence of an osteoporosis nurse.

Methods: We retrospectively compared one reference hospital with 5 surrounding hospitals in the Netherlands. During a two-week period all female patients over 50 years who presented with a fracture at the emergency department of the 6 hospitals were included. Follow up was minimal 11 weeks. The primary outcome was the referral for DXA measurement.

Results: In total 135 patients were included, of whom 33 were seen in the reference hospital and 102 in the surrounding hospitals. In both groups mean age and fracture location were similar. In the reference hospital 14 patients qualified for DXA measurement, of whom 10 patients effectively underwent a DXA scan $(71 \%)$. In the surrounding hospitals 78 patients qualified for a DXA of whom only 3 effectively underwent a DXA scan (4\%). Taking into account a refusal percentage for DXA of $33 \%$ as was found in the reference centre, 47 patients in the surrounding hospitals should have been qualified for DXA measurement. Thus successful referral in the surrounding hospitals was 3 on $47(6 \%)$ patients. The presence of an osteoporosis nurse did have a significant influence on the amount of DXA scan's after fractures (RR 11 (95\% Cl: 3.6 - 35.1).

Conclusions: This study indicates that referral for DXA is low in surrounding hospitals and suggests that the presence of an osteoporosis nurse in the reference hospital significantly increased the amount of patients receiving adequate osteoporosis screening with DXA measurement after a recent fracture. With this strategy patients at risk for osteoporosis are identified effectively, after which treatment can be started, in order to reduce the risk of future fractures. 


\section{INTRODUCTION}

Low bone mineral density is associated with an increased risk of fractures. An other independent fracture risk is the history of a fracture. ${ }^{1-5}$ Therefore, the treatment of patients with fragility fractures should not be confined to the treatment of the fracture itself. Attention has to be paid to osteoporosis as a possible underlying cause of the fracture. This is clinically important, as pharmacological treatment of osteoporosis significantly reduces the risk of a new clinical fracture..$^{6.8}$

Several guidelines concerning osteoporosis have been published the previous decades. The latest update of the evidence based guideline on osteoporosis of the Dutch Institute for Healthcare Improvement (CBO) was published in 2002. Screening for osteoporosis using DXA is not recommended in the general population, but clinical case-finding is. For this high-risk approach, the fracture risk-estimation is based on several risk factors (Table 1). In case of an elevated fracture risk, a bone-density scan (by dual-energy X-ray absorptiometry (DXA)) is indicated. A crucial recommendation in the guideline is that all women over the age of 50 who experience a non-vertebral fracture should undergo a bonedensity scan. ${ }^{9}$

In a recent survey in North West England 140 GPs and 140 orthopaedic surgeons were questioned on their routine clinical practice concerning investigation for osteoporosis in general and in the following clinical scenarios: a 55 year old woman with a low trauma fracture of the distal radius, a 60 year old woman with a vertebral wedge fracture, a 70 year old woman with a low trauma neck of femur fracture. Both the GPs and orthopaedic surgeons stated that further investigation for osteoporosis in general is necessary in patients over 50 years old with a low trauma fracture. However, being confronted with the cases only $7 \%$ of the orthopaedic surgeons would actually assess the patient with the colles fracture for osteoporosis. For the scenario with the vertebral wedge fracture and the neck of femur fracture, the numbers were $14 \%$ and $11 \%$ respectively. ${ }^{10}$ In several international studies similarly results were demonstrated. ${ }^{11-14}$

The aim of this study was to evaluate the effect of a strategy for implementation of the Dutch osteoporosis guideline. The strategy consisted of organising a fracture and osteoporosis out-patient clinic with active case-finding after a clinical fracture by a trained nurse specialist. The focus is on the recommendation to do further investigation for osteoporosis on all female patients with a fracture after the age of 50 . 


\section{MATERIALS AND METHODS}

Design. Prospective observational study comparing a reference hospital where a specialist osteoporosis nurse is employed, with the 5 surrounding hospitals, without such a nurse.

Patients. All female patients over 50 years old, who presented with a fracture at the emergency department of the 6 hospitals in Limburg in week 49 and 50 of 2005 (5th December-18th December), were included. We have chosen to include women only, since the earlier mentioned osteoporosis guideline of the $\mathrm{CBO}$ is more explicit about women than about men. ${ }^{9}$. If in the radiology report the presence of a fracture could not be proven or if a pathological fracture was present, the patient was excluded. Other exclusion criteria were living outside the district of the hospital, being already evaluated for osteoporosis elsewhere or death within 30 days after the fracture event.

Strategy. The strategy consisted of organising a fracture and osteoporosis outpatient clinic operated by a trained specialist nurse. All women 50 years of age or older presenting with a fracture at the emergency department are actively invited to visit the clinic. The nurse specialist identifies these patients every morning from the files in the emergency department. Outpatients are seen directly after their first visit to the fracture clinic at general surgery or orthopaedic surgery. Inpatients are enrolled during their hospital stay. At the first visit to the outpatient clinic patients are educated about the clinic itself and about osteoporosis. Also an appointment for DXA scan is made. At the second visit patients are interviewed and an osteoporosis risk factor assessment is done. The results of the DXA scan are explained to the patient and if indicated treatment is started. If secondary osteoporosis is suspected, patients are referred to internal medicine for further evaluation. Besides the assessment for bone density, a fall-risk assessment is done at the same time. This strategy was implemented in September 2004 in the academic hospital in Maastricht.

Outcome variables. The primary outcome was the appropriate referral of bone mass density with DXA scan, which we expressed as the following performance indicator: the population for which investigation is indicated and actually performed divided by the population for which investigation for osteoporosis is indicated. The population for which further investigation is not indicated was defined as: patients with a history of osteoporosis or treatment for osteoporosis, patients who underwent a DXA scan less than 2 years ago, patients who were suffering from dementia, patients who were still rehabilitating or patients who 
refused further investigation. Independent variables were age, fracture location, documented low bone density, osteoporosis treatment, visited hospital and date of bone-density scan. The latter was recorded because repeating a bone-density scan within 2 years is useless according to the CBO guideline and the guideline interpretation bone density measurements of the WHO. ${ }^{9,} 15$ The patient's records were analysed for actually performed bone-density scans, as well as the above mentioned possible explanations for (not) ordering the scan.

Measurements. The cases from each hospital were provided by an independent employee, between 11 and 16 weeks after week 50. The time period of at least 11 weeks was chosen after questioning all hospitals for possible waiting lists for bone-density scan. Since this was two weeks at maximum, we chose for the previous reported period for practical reasons. If a patient is rehabilitating slowly, 11 weeks should still be enough time to be able to undergo a DXA scan. In most hospitals ${ }^{4}$ the case lists were obtained from the emergency department registration, in the other ${ }^{2}$ from the medical archive. The above-mentioned outcome variables were obtained from the electronic patient records, emergency department forms and out-patient clinic records.

Analysis. All analyses were performed with SPSS version 12.0 for Windows. Differences in mean age of the patients of the academic hospital and the district hospitals were tested with the independent T-test with equal variances. If populations were not normally distributed, a non-parametric test was performed (Mann-Whitney). Fracture locations were subdivided into 4 categories for statistical analysis: upper extremities (humerus, radius/ulna, hand), lower extremities (femur, patella, tibia/fibula, foot), trunk (skull, spine, pelvis, clavicle, thorax) and multiple fractures (meaning more than one fracture at the same time). Differences in fracture location between the two hospital groups were tested with the Chi-square test. If predicted values in the cross tables were less than 5 , the Fisher-exact test was performed. The proportion of bone-density scans performed after the fracture was estimated using a multivariate logistic regression with a top-down method based on the likelihood ratio test. In the beginning model the following covariates were used: type of strategy (control condition coded as 0 and fracture and osteoporosis out-patient clinic coded as 1), age, fracture location and interactions between type of strategy and age or fracture location. Observations were considered significant if $p<0.05$. 


\section{RESULTS}

In total 167 women over the age of 50 had presented with a incident fracture at the emergency departments of the 6 hospitals in Limburg in the study period. Of this group 32 patients were excluded for the following reasons: in 23 cases the fracture could not be proven in the radiology report, 7 patients lived outside the hospital district, 1 patient was already evaluated for osteoporosis elsewhere, 1 patient died. Therefore 135 patients were evaluated, of whom 33 were seen in the reference hospital and 102 in the surrounding hospitals.

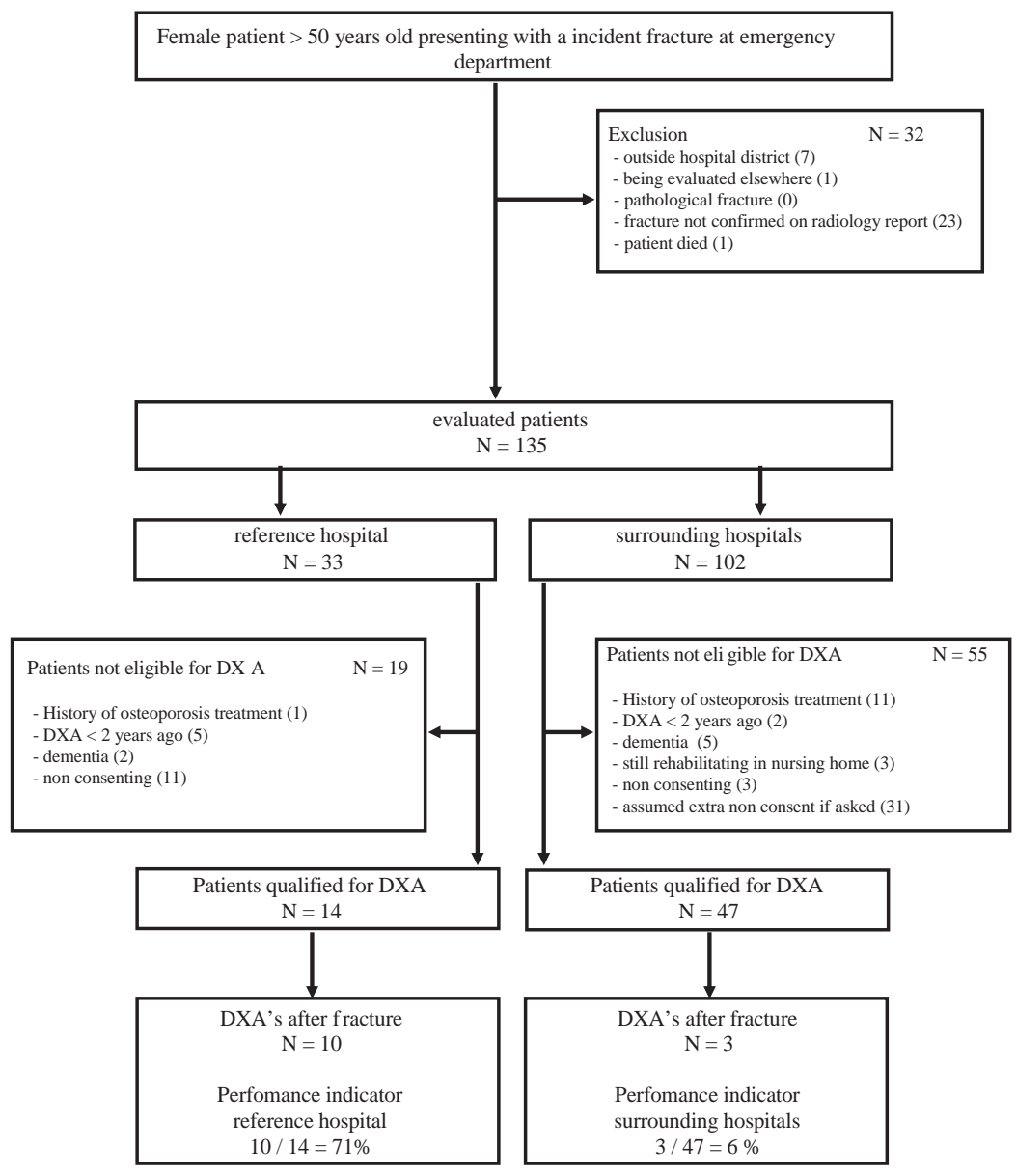

Figure 1: flowchart of patients included in the study 
Table 1. Fracture estimation

\begin{tabular}{lc}
\hline Risk factor & Fracture risk \\
\hline Fracture after age of 50 years & x 2.0 \\
Presence of a vertebral fracture & x 4.0 \\
Positive family history (especially mother with hx of hip fracture) & $\times 1.5$ \\
Low body weight $(<67 \mathrm{~kg})$ & $\times 1.5$ \\
Low body weight $(<60 \mathrm{~kg})$ & $\times 2.0$ \\
Severe immobility & $\times 2.0$ \\
Use of corticosteroids $(>7.5 \mathrm{mg}$ prednisolon (equivalent) per day) & x 2.0
\end{tabular}

Table 2: Comparison of patient groups

\begin{tabular}{lcc}
\hline & \multicolumn{2}{c}{ Included patients } \\
\hline Age in years; mean (SD) & $71.1($ SD: 10.7$)$ & 73.1 (SD: 11.9) \\
\hline Fracture location; number $(\%)$ & & \\
- upper extremity & $12(36.4)$ & $43(42.2)$ \\
- lower extremity & $16(48.5)$ & $47(46.0)$ \\
- trunk & $4(12.1)$ & $6(5.9)$ \\
- multiple & $1(3.0)$ & $6(5.9)$ \\
\hline DEXA scan after fracture; number & $\mathbf{1 0}$ & $\mathbf{3}$
\end{tabular}

Both groups were comparable in mean age and fracture location. The mean age was 71.1 year (SD: 10.7) in the reference hospital group and 73.1 year (SD: $11.9)$ in the surrounding hospital group. There was no significant difference in mean age between these two patient groups ( $T$-test: $p=0.39$; Mann-Whitney: $p=0.33$ ). No significant differences were observed in fracture location distribution between the 2 populations (Chi-square test: $p=0.59$; Fischer exact test: $\mathrm{p}=0.61)$ (Table 1)

The reference hospital scored $71 \%$ on the performance indicator versus $6 \%$ in the surrounding hospitals. All hospitals used DXA as method for bone-density scan and all hospitals were familiar with the CBO guideline on osteoporosis.

Of the 33 patients from the reference hospital 11 refused further investigation and 8 had other reasons for not performing a DXA scan (Figure 1). Of the 14 patients who did qualify for a DXA scan, 10 actually received it within 16 weeks after the fracture date $(10 / 14=71 \%)$. Of the 102 patients from the surrounding hospitals 24 were not eligible for a DXA scan for various reasons (flow chart).

The documentation in the surrounding hospitals for refusal of further investigation was not so accurate. We therefore assumed an equal percentage of refusals as we found in the reference hospital (33\%). Thus 34 patients in the surrounding hospitals were regarded as refusing further investigation. Leaving 
a total of 47 patients qualifying for DXA scan. Only three patients were reffered for a DXA scan within 16 weeks after the fracture date $(3 / 47=6 \%)$.

The presence of an osteoporosis nurse did have a significant influence on the amount of DXA scan's after fractures in univariate analysis (RR 11 (95\% $\mathrm{Cl}: 3.6$ - 35.1).

Multivariate analysis with age, fracture location and presence or absence of an osteoporosis nurse confirmed the univariate results. No other significant variables could be identified. Interactions between age and type of strategy and fracture location and type of strategy were not significant.

\section{DISCUSSION}

We found that $71 \%$ of patients from the reference hospital were adequately investigated for osteoporosis, versus only $6 \%$ of patients from the surrounding hospitals. Several studies have shown that implementation of osteoporosis guidelines without a specific intervention strategy is not successful. The proportions of patients with a fragility fracture adequately being screened for osteoporosis vary between $0 \%$ and $32 \% .{ }^{11,12,14,16}$. In the current study these numbers are confirmed. Several studies have shown that initiating a structured care program for osteoporosis diagnosis and treatment dramatically increases the proportion of patients being adequately investigated for osteoporosis. ${ }^{17-21}$ In the current study these findings are confirmed.

There are a few possible limitations of this study:

First, potential confounding could take place because of the non-randomised design. This is unlikely though, since there are no clear indications for differences in case-mix among patients from the 6 hospitals. The fracture and osteoporosis out-patient clinic strategy was used in only one reference hospital. The huge differences in performance indicator could therefore be related not just to the strategy itself but also to the type of hospital. However the exact same strategy was used since July 2003 in the academic hospital in Groningen (the Netherlands). In a descriptive study of analysis of their first 100 patients similar effective results were shown ${ }^{21}$. Furthermore there are no indications that this strategy is not applicable for the surrounding hospitals. The strength of the current study is that real performance data were used, instead of self-reported performance data. Also the use of a concurrent control group, in comparable hospitals (same region, same case-mix) strengthens the results.

Second, in the surrounding hospitals physicians did not accurately document if they offered the patient a referral for DXA measurement. Several reasons for not 
referring the patient could be found in the medical records (already on treatment for low BMD, DXA within last 2 years, dementia, still rehabiltating in nursing home). It is possible that more patients were offered a DXA, therefore the assumption was made that in the surrouding hospitals an equal number of patients (33\% in the reference hospital) did not give informed consent for referral.

If this percentage is actually higher in the surrounding hospital this would underestimate the performance indicator.

To reduce the risk of future fractures, patients with established osteoporosis can be treated with medication known to have a positive effect on bone mineral density. These interventions have proven to reduce the number of future fractures ${ }^{22}$. Therefore patients at risk for osteoporosis have to be identified and evaluated in order to receive the proper treatment. In this study we showed that with a fracture and osteoporosis out-patient clinic operated by a specialist nurse the amount of patients receiving adequate osteoporosis screening after a recent fracture is significantly increased.

\section{REFERENCES}

1. van Helden S, Cals J, Kessels F, Brink P, Dinant GJ, Geusens P. Risk of new clinical fractures within 2 years following a fracture. Osteoporos Int. 2006;17(3):348-54.

2. Haentjens P, Autier P, Collins J, Velkeniers B, Vanderschueren D, Boonen S. Colles fracture, spine fracture, and subsequent risk of hip fracture in men and women. A metaanalysis. J Bone Joint Surg Am. 2003 Oct;85-A(10):1936-43.

3. Hasserius R, Karlsson MK, Nilsson BE, Redlund-Johnell I, Johnell O. Prevalent vertebral deformities predict increased mortality and increased fracture rate in both men and women: a 10-year population-based study of 598 individuals from the Swedish cohort in the European Vertebral Osteoporosis Study. Osteoporos Int. 2003 Jan;14(1):61-8.

4. Kanis JA, Johnell O, De Laet C, Johansson H, Oden A, Delmas P, et al. A meta-analysis of previous fracture and subsequent fracture risk. Bone. 2004 Aug;35(2):375-82.

5. Klotzbuecher CM, Ross PD, Landsman PB, Abbott TA, 3rd, Berger M. Patients with prior fractures have an increased risk of future fractures: a summary of the literature and statistical synthesis. J Bone Miner Res. 2000 Apr;15(4):721-39.

6. Black DM, Cummings SR, Karpf DB, Cauley JA, Thompson DE, Nevitt MC, et al. Randomised trial of effect of alendronate on risk of fracture in women with existing vertebral fractures. Fracture Intervention Trial Research Group. Lancet. 1996 Dec 7;348(9041):1535-41.

7. Boonen S, Laan RF, Barton IP, Watts NB. Effect of osteoporosis treatments on risk of non-vertebral fractures: review and meta-analysis of intention-to-treat studies. Osteoporos Int. 2005 Oct;16(10):1291-8. 
8. Nguyen ND, Eisman JA, Nguyen TV. Anti-hip fracture efficacy of biophosphonates: a Bayesian analysis of clinical trials. J Bone Miner Res. 2006 Feb;21(2):340-9.

9. CBO. tweede herziene richtlijn osteoporose. 2002.

10. Chami G, Jeys L, Freudmann M, Connor L, Siddiqi M. Are osteoporotic fractures being adequately investigated? A questionnaire of GP \& orthopaedic surgeons. BMC Fam Pract. 2006;7:7.

11. Freedman KB, Kaplan FS, Bilker WB, Strom BL, Lowe RA. Treatment of osteoporosis: are physicians missing an opportunity? J Bone Joint Surg Am. 2000 Aug;82-A(8):1063-70.

12. Hajcsar EE, Hawker G, Bogoch ER. Investigation and treatment of osteoporosis in patients with fragility fractures. Cmaj. 2000 Oct 3;163(7):819-22.

13. Rud B, Greibe R, Hyldstrup L, Sorensen HA. Does a distal forearm fracture lead to evaluation for osteoporosis? A retrospective cohort study in 147 Danish women. J Clin Densitom. 2005 Spring;8(1):18-24.

14. Elliot-Gibson V, Bogoch ER, Jamal SA, Beaton DE. Practice patterns in the diagnosis and treatment of osteoporosis after a fragility fracture: a systematic review. Osteoporos Int. 2004 Oct;15(10):767-78.

15. Prevention and management of osteoporosis: WHO Scientific Group. 2003.

16. Feldstein A, Elmer PJ, Orwoll E, Herson M, Hillier T. Bone mineral density measurement and treatment for osteoporosis in older individuals with fractures: a gap in evidence-based practice guideline implementation. Arch Intern Med. 2003 Oct 13;163(18):2165-72.

17. Astrand J TK, Tagil M. One fracture is enough! Experience with a prospective and consecutive osteoporosis screening program with 239 fracture patients. Acta Orthopaedica. 2006 3/4/2006;77(1):3-8.

18. Bogoch ER, Elliot-Gibson V, Beaton DE, Jamal SA, Josse RG, Murray TM. Effective initiation of osteoporosis diagnosis and treatment for patients with a fragility fracture in an orthopaedic environment. J Bone Joint Surg Am. 2006 Jan;88(1):25-34.

19. Harrington JT, Barash HL, Day S, Lease J. Redesigning the care of fragility fracture patients to improve osteoporosis management: a health care improvement project. Arthritis Rheum. 2005 Apr 15;53(2):198-204.

20. Hawker G, Ridout R, Ricupero M, Jaglal S, Bogoch E. The impact of a simple fracture clinic intervention in improving the diagnosis and treatment of osteoporosis in fragility fracture patients. Osteoporos Int. 2003 Apr;14(2):171-8.

21. Hegeman JH, Willemsen G, van Nieuwpoort J, Kreeftenberg HG, van der Veer E, Slaets $\mathrm{JP}$, et al. [Effective tracing of osteoporosis at a fracture and osteoporosis clinic in Groningen; an analysis of the first 100 patients]. Ned Tijdschr Geneeskd. 2004 Oct 30;148(44):2180-5.

22. Cummings SR, Black DM, Thompson DE, Applegate WB, Barrett-Connor E, Musliner TA, et al. Effect of alendronate on risk of fracture in women with low bone density but without vertebral fractures: results from the Fracture Intervention Trial. Jama. 1998 Dec 23-30;280(24):2077-82. 


\section{CHAPTER 4}

Bone and fall related fracture risks in women and men with a recent clinical fracture

Svenhjalmar van Helden, Antonia CM van Geel, Piet P Geusens, Alfons Kessels, Arie C Nieuwenhuijzen Kruseman, Peter R G Brink

J Bone Joint Surg Am, 2008; 90(2):241-8 


\section{ABSTRACT}

Background. The number of fractures is increasing as a result of the growing ageing population and prevention (primary and secondary) is an important public health goal worldwide. Unfortunately, the tools for preventing fractures that are currently available are not well applied. A better understanding of the numerous risk factors that contribute to fractures is needed in order to improve the implementation of preventive, diagnostic and treatment modalities in patients with a recent fracture. We therefore systematically analysed risk factors in subjects with a recent clinical fracture.

Methods. All men and women older than 50 years of age that had been admitted for a recent fracture during a one-year period were offered an evidencebased bone and fall related risk factor assessment and bone densitometry.

Results. Of the 940 consecutive patients, 797 (85\%) were eligible for this study and $568(60 \%)$ agreed to participate. The prevalence of fall related risk factors (75\% [95\% Cl:71\%-78\%]; $n=425)$, and the prevalence of bone related risk factors $(53 \%$ [95\%Cl:49\%-57\%]; $n=299)$ at the time of fracture were higher than the prevalence of osteoporosis (DXA T score $<-2.5$ in spine and/or hip, (35\% [95\%Cl:31\%-39\%]; $n=201$ ). The fall and bone related risk factors were present irrespective of the fracture location, patient age , or gender. An overlap between bone and fall related risk factors was found in $50 \%$ of the patients.

After adjusting for age, weight, and height, we found that women with a fracture more frequently had a diagnosis of osteoporosis (OR $2.9 ; 95 \% \mathrm{Cl}: 2.0-4.1$ ) and had a more extensive history of falls (OR 4.0;95\%Cl:2.7-5.9) than did the postmenopausal women without a fracture history.

Conclusions. Men and women over 50 years of age who had recently sustained a clinical fracture had, at the time of their fracture, bone and fall related risk factors that were greater than the risk predicted by the presence of osteoporosis. Risk factors were overlapping, heterogeneous, and found in multiple combinations. This was the case regardless of the patient's age, fracture location or gender. The findings suggest that an integrated bone and fall related risk factor assessment is a preferable means for identifying elderly subjects at risk for fracture. Integrated bone and fall related risk assessment and treatment studies are needed to document this proposal.

Level of evidence. Systematic cross-sectional observational study. 


\section{INTRODUCTION}

Worldwide fracture rates are increasing as a result of the ageing population and prevention both primary and secondary is an important public health goal. Unfortunately, the tools currently available for preventing fractures are not well applied. A better understanding of the numerous risk factors that contribute to fractures is needed in order to improve the implementation of preventive, diagnostic and treatment modalities for patients with a recent fracture.

For both men and women, the prevalence of osteoporosis and falls increases with age ${ }^{1}$ and one to five percent of falls result in a fracture ${ }^{2}$.

In order to address this problem, numerous guidelines for evaluation of risk factors have been developed in various countries ${ }^{3}$. Although these guidelines have been available for many years, several reports indicate that case finding and patient treatment after a fracture are poorly implemented in daily practice, ${ }^{5}$. Primary and secondary prevention is important for patients who are at high risk for fractures, even in the short term ${ }^{6,7}$. Currently, most secondary prevention programs concentrate on measures that correct causes of osteoporosis. These include correcting disturbed calcium homeostasis and increasing the resistance to fractures in patients with low bone mineral density and/or vertebral fractures. However, many patients with a clinical fracture do not have a low bone mineral density but rather are vulnerable to fracture because of other risk factors that are applicable in the clinical context ${ }^{8}$. Several investigators have conducted a baseline risk assessment in a population and then followed the patients to measure fracture rates ${ }^{8-11}$. To our knowledge, no one has previously conducted a baseline risk assessment of both bone and fall related risks in patients with a recent fracture.

Using two evidence based guidelines produced by the National Institute of Health Care in The Netherlands, we performed, over the course of one year, a systematic screening program for risk factors in all men and women over 50 years of age who were seen with a clinical fracture at the emergency of our hospital ${ }^{12,13}$. We analysed the relative presence of risk factors in these patients, determined how many patients could have been identified with use of case finding prior to their current fracture and explored the medical consequences in reference to the risk factor profile.

\section{METHODS}

This study was a pre-planned systematic cross-sectional observational investigation and was approved by the medical ethical committee. Over the course of 
one year, subjects over 50 years of age who had attended the surgical emergency clinic or who had been admitted to our hospital because of a clinical fracture were invited to participate in the study. Those who agreed to participate received a bone and fall related risk factor assessment and bone densitometry. These investigations were done in conjunction with the fracture treatment. Patients were excluded from this study if they did not provide informed consent, did not undergo bone densitometry, were receiving treatment for osteoporosis, resided in a different region, were unavailable for the next consultation or had a pathologic fracture as confirmed on radiographs.

Fractures were classified according to the International Classification of Disease, Ninth revision, Clinical modification (ICD-9) into skull; spine; thorax and/or clavicle; pelvis; humerus; radius and/or ulna; hand; hip and femur; tibia, fibula and/or patella; and foot categories. For further analyses, these categories were clustered into four groups: upper limb, lower limb, other fractures and multiple fractures (two or more fractures at the same time).

Three assessments for fracture risk were performed:

Type A: The bone mineral density of the spine and the left hip (or at the nonfracture site in case of unilateral hip fracture) were measured by dual X-ray absorptiometry with the Hologic QDR 4500 Elite densitometer (Waltham Massachusetts / coefficient of variation $0.4 \%$ ). Three patient groups were determined on the basis of the T scores: osteoporosis (T score $\leq-2.5)$, osteopenia (lower T score in the hip or spine in the range of -2.5 to -1 ) and normal (T score of $\geq-1)$.

Type B: Clinical bone related risk factors for fractures including a previous fracture after the age of 50 , a vertebral fracture after the age of 50 , a mother with a fracture history, a body weight of $<60 \mathrm{~kg}$, severe immobility, and the use of glucocorticoids, were determined.

Type $C$ : fall related risk factors for fractures including more than one fall in the past year, the use of psychoactive drugs, a low level of activities of daily living before the current fracture, articular symptoms, impaired vision, urin incontinence, and Parkinson disease, were determined.

The assessment of risk factors for fractures was based on the Dutch guidelines for the prevention of osteoporosis and falls ${ }^{12-14}$ (Table 1). These guidelines recommend case finding using Type B risk factors. Pharmaceutical treatment is recommended for individuals with a preexisting vertebral fracture or when other risk factors are present and the T-score $\leq-2.5$ (Table 1). According to the fall prevention guideline, Type $\mathrm{C}$ risk factors are the most important for assessment. 
A specialist nurse, trained in osteoporosis management and fall risk assessment evaluated all of the patients included in this study. During the first consultation, the patient was provided with information about the study and an informed consent form. If the patient agreed to participate, a dual X-ray adsorptiometry measurement of the spine and hip and an investigation of bone and fall related fracture risks were included in the second consultation. This was usually completed within two months following the fracture. The fall risk assessment included an assessment of the ability to carry out activities of daily living with use of the Groningen Activity Restriction Scale (status before the fracture) ) $^{15-18}$ and an assessment of the patient's vision with use of the Snellen eye chart ${ }^{18-21}$. In addition, the examination included documentation of any history of falls ${ }^{16,18,20,}$ ${ }^{22-24}$, use of psychoactive drug (benzodiazepines, antipsychotics, antidepressants or neuroleptics $)^{15,18,24-27}$, osteoarthritis ${ }^{19,20,23,25}$; urin incontinence ${ }^{18,24}$ and Parkinson's disease ${ }^{19,20}$. Both the entire group and a group that had fallen from a standing height or less were analysed.

A control group was included in the analyses as well. The control group was derived from a cohort of 759 female postmenopausal subjects and comprised 492 women over the age of 50 years who had no previous fracture. All control group subjects were recruited from the practices of general practitioners. The only criterion for serving as a control subject was the absence of a fracture and an age above 50 years. The settings and methodology of this cohort have been described elsewhere ${ }^{28}$.

\section{STATISTICAL ANALYSIS}

The comparison of proportions was conducted with a chi-square test. To investigate differences between patients, univariate analyses were performed with use of binary logistic regression. Additionally, to determine the independent contributions of these risk factors, a stepwise logistic regression analysis was performed with sex, age, weight, height, and type of trauma.

The comparisons of the female patients in this cohort with those in the control group were also performed using univariate and multivariate binary logistic regression. Interaction was tested with use of multivariate analyses.

Odds ratio's (OR) and 95\% confidence intervals $(\mathrm{Cl})$ were calculated. Observations were considered significant if $p$ was $<0.05$ (two-tailed). 


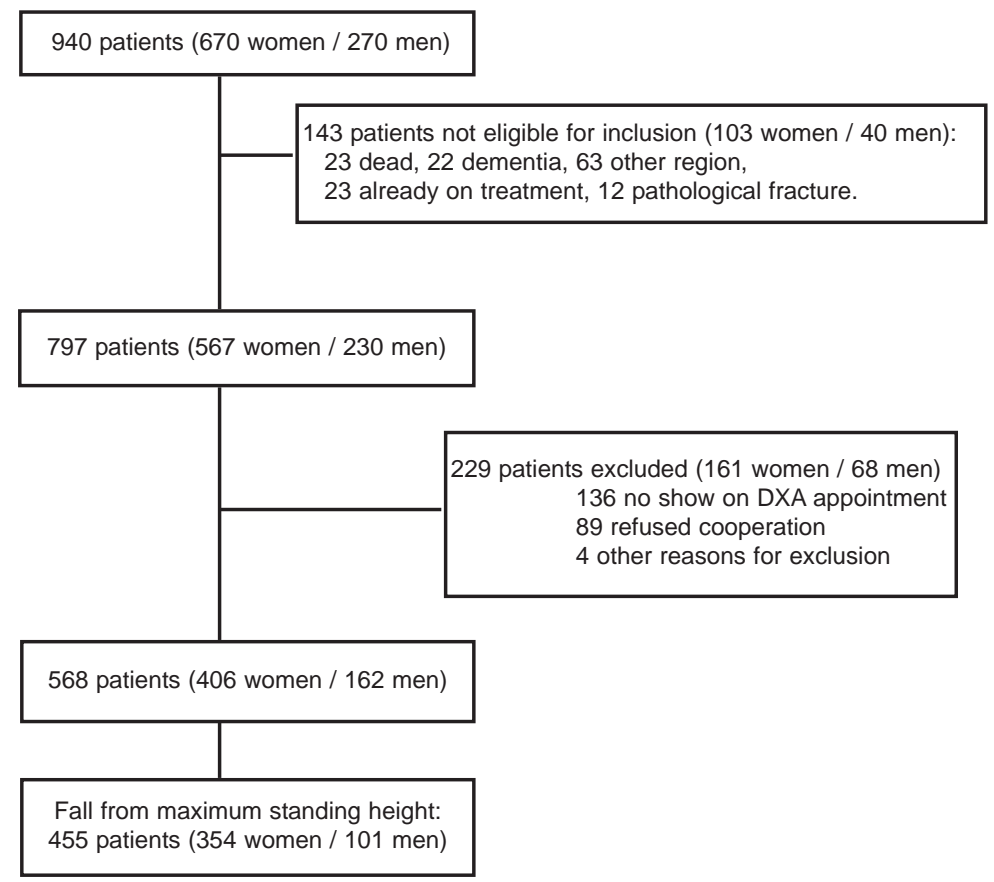

Figure 1. Flowchart of patient inclusion

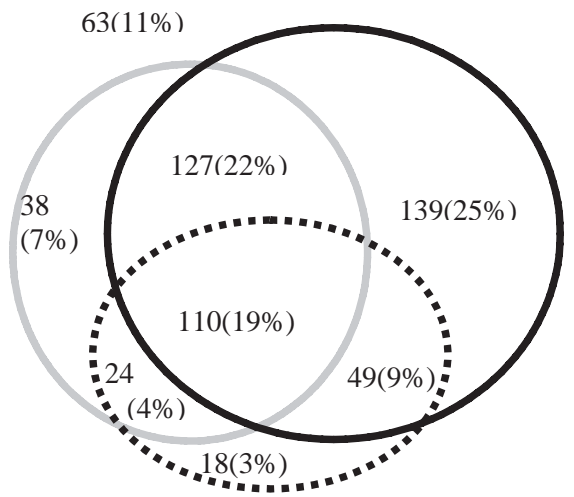

$\ldots . .$. Osteoporosis (T score $<-2.5$ )

Bone related risk factors

Fall related risk factors

Figure 2. Distribution of bone related risk factors, fall related risk factors and osteoporosis distribution in the fracture population in $(n=568)$ the last fracture of each patient is excluded) 


\section{RESULTS}

Over the course of the year-long study period, 940 subjects over the age of 50 years presented to our emergency clinic with a fracture. Of these subjects, 229 were excluded on the basis of previously mentioned criteria (failure to obtain a bone mineral density study, refusal to provide informed consent, etc.) and 143 were not eligible for inclusion for various other reasons (Figure 1). As a result, 568 subjects participated in the study, giving an inclusion rate of $71 \%$ (568 of 797).

The 229 patients who chose not to participate tended to be older than those who did participate (76 versus 67 years; $p<0.001)$. They also more frequently had a hip fracture $(27 \%$ compared with $13 \%$; $p<0.001)$, less frequently had a tibia-fibular and/or patellar fracture $(6 \%$ compared with $15 \% ; p=0.001)$ and less frequently had multiple fractures $(1 \%$ compared with $5 \% ; p=0.02)$ than the participants in this study.

The group that received a risk assessment consisted of 406 women and 162 men. This group has a total of 600 recent clinical fractures. A fall from standing height or less was the cause of the fracture in $455(80 \%)$ of the subjects (Figure 1). Other causes included falls from more than a standing height $(6.5 \%)$, traffic injuries (8.5\%), entrapment of the arm or leg (3.5\%) and a small group of rare causes such as skating injuries (1.4\%). Analyses of the total group are reported because the results found for the entire group were similar to those found when separate analyses were conducted for the group that had fallen from a standing height or less.

The mean age was 68 years among the women compared with 65 years among the men $(p=<0.001)$. An upper limb fracture (humerus, radius and/or ulna, or hand) was sustained by $49 \%$ of the patients; a lower limb fracture (hip and femur, tibia, fibula, and/or patella, or foot) by $37 \%$, a clinical vertebral fracture by $3 \%$; and multiple simultaneous fractures, by $5 \%$ of the patients (Table 2 ).

Osteoporosis of the hip and/or spine (a T score $\leq-2.5$ ) was found in 201 subjects (35\%, 95\% Cl: 31\% - 39\%), osteopenia in 250 (44\%, 95\% Cl: 40\% - 48\%) and normal bone mineral density, in 117 (21\%, 95\% Cl: 17\% - 24\%) (Table 3).

At least one bone related risk factor was found in 299 of the subjects $(53 \%$, $95 \% \mathrm{Cl}: 49 \%-57 \%$ ) (Table 3). Of these 299 subjects, $14 \%$ had two risk factors, $3 \%$ had three risk factors, and one patient had four risk factors. In total, 131 $(23 \%)$ subjects had a previous fracture after the age of fifty years.

Women and men had similar prevalences of bone related risk factors, except for low body weight $(20 \%$ compared with $12 \%$, respectively, $\mathrm{p}<0.05)$ and a previous fracture after the age of fifty (27\% compared with $13 \%$, respectively, $p<$ $0.05)$ which were more frequently found in women. 
At least one fall related risk factor was found in $425(75 \%)$ of the subjects (Table 3): $33 \%$ had one risk factor, $22 \%$ had two risk factors, $10 \%$ had three risk factors, and $10 \%$ had four or more risk factors.

Fall related risk factors were more frequently seen in women, with the exception of impaired vision, which was found in $25 \%$ of women and $31 \%$ of men. This difference was not significant.

When all risk factors were incorporated into one figure, it became apparent that the fracture population could be divided into eight groups (Figure 2). Roughly one-quarter had only fall related risk factors, one-fifth had both fall and bone related risk factors, and one-fifth had fall and bone related risk factors as well as osteoporosis.

Compared with patients without any risk factors, patients with bone and fall related risk factors as well as osteoporosis were more likely to be female $(81 \%$ compared with $56 \% ; p<0.001)$, had a lower mean body weight ( $77 \mathrm{~kg}$ compared with $62 \mathrm{~kg} ; p<0.001)$, were shorter $(155 \mathrm{~cm}$ compared to $170 \mathrm{~cm} ; \mathrm{p}=0.001)$, and were more likely to have fallen from a standing height more often $(93 \% \mathrm{com}$ pared with ; $60 \% ; p<0.001)$. The distribution of fracture locations was similar.

Multivariate analyses showed that lower weight (OR 1.1 per $\mathrm{kg} ; \mathrm{p}<0.001$; $95 \% \mathrm{Cl} 1.05-1.15$ ), older age (OR 1.1 per year; $p<0.001 ; 95 \% \mathrm{Cl} 1.06-1.16$ ) and type of trauma (in favour of a fall from standing height) (OR 3.6; $p=0.03$; $95 \% \mathrm{Cl} 1.1-11.6)$ were significantly associated with the presence of all three types of fracture risk.

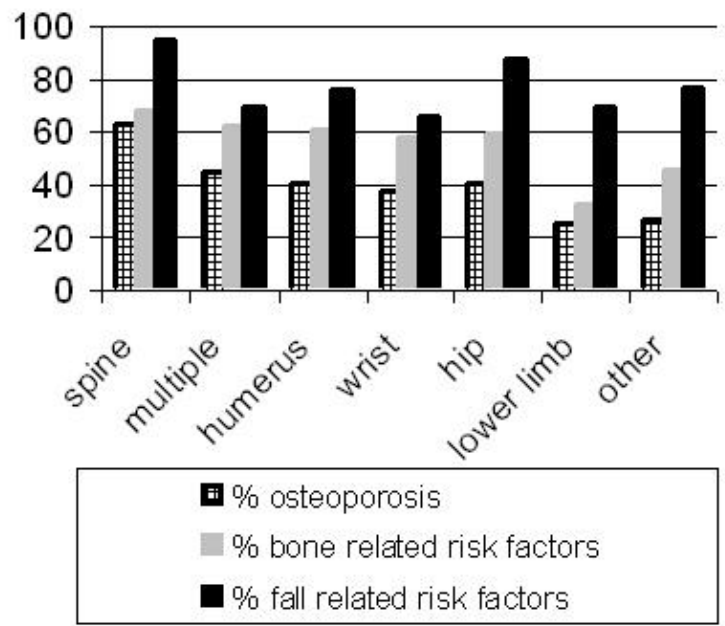

Figure 3. Risk factors by fracture location $(n=568)$ 
Regardless of the fracture location, fall related risk factors were more frequent than bone related risk factors, which in turn were more frequent than osteoporosis (Figure 3). The prevalence of osteoporosis was highest in patients with clinical vertebral fractures (63\%) and in those with multiple fractures $(45 \%)$. Compared with patients with osteoporosis, patients with osteopenia (lower T score in the hip or spine in the range -2.5 to -1 ) were younger (67 years compared with 70 years; $p<0.01$ ) and had a lower prevalence of clinical bone related risk factors ( $48 \%$ compared with $67 \%$; $p<0.01$ ). The distribution of fracture location was the same in patients with osteopenia and those with osteoporosis, with the exception of vertebral fractures, which were slightly more frequent in the osteoporosis group ( $6 \%$ compared with $2 \%=0.05)$.

Table 1: Dutch oste oporosis guideline recommendations

\begin{tabular}{|c|c|c|}
\hline Dutch osteoporosis guideline & recomm & $\begin{array}{l}\text { ndation } \\
\text { DXA }\end{array}$ \\
\hline & start medication & measurement $^{*}$ \\
\hline vertebral fracture & $\mathrm{x}$ & \\
\hline $\begin{array}{l}\text { On glucocorticoids for } 3 \text { months or more } \\
\text { (> } 7.5 \mathrm{mg} \text { prednisone /day) }\end{array}$ & $\mathrm{x}$ & \\
\hline clinical fracture after $50 \mathrm{yr}$ & & $\mathrm{x}$ \\
\hline $\begin{array}{l}\text { Women without fracture history } \geq 60 \text { years } \\
\text { with } 3 \text { risk factors * } \\
\text { women without fracture history } \geq 70 \text { years } \\
\text { with } 2 \text { risk factors * }\end{array}$ & & $x$ \\
\hline
\end{tabular}

* mother with fract ure history / body weight $<60 \mathrm{~kg}$ / severe immobility

${ }^{* *}$ start medication if $\mathrm{T}$ score $\leq-2.5$

Table 2: Age and distribution of fracture location

\begin{tabular}{lllllll}
\hline age & \multicolumn{2}{l}{ total group } & \multicolumn{2}{l}{ female gender } & male gender \\
\hline Mean * & 67 & & 68 & & 65 & \\
median & 67 & & 68 & & 62 & \\
Range & $50-95$ & & $50-95$ & & $50-90$ & \\
& & & & & & \\
fracture location & $\mathbf{n}$ & $\%$ & $\mathbf{n}$ & $\%$ & $\mathbf{n}$ & $\%$ \\
\hline skull & 1 & & 1 & & 0 & \\
spine & 19 & $(3)$ & 12 & $(3)$ & 7 & $(4)$ \\
thorax / clavicle * & 21 & $(4)$ & 7 & $(2)$ & 14 & $(9)$ \\
pelvis & 11 & $(2)$ & 7 & $(2)$ & 4 & $(3)$ \\
humerus & 92 & $(16)$ & 72 & $(18)$ & 20 & $(12)$ \\
radius/ulna * & 125 & $(22)$ & 105 & $(26)$ & 20 & $(12)$ \\
hand & 60 & $(11)$ & 41 & $(10)$ & 19 & $(12)$ \\
hip + femur & 76 & $(13)$ & 51 & $(13)$ & 25 & $(15)$ \\
tibia/fibula/patella & 84 & $(15)$ & 65 & $(16)$ & 19 & $(12)$ \\
foot & 50 & $(9)$ & 28 & $(7)$ & 22 & $(14)$ \\
multiple & 29 & $(5)$ & 17 & $(4)$ & 12 & $(7)$ \\
\hline${ }^{*}$ p<0.05 men vs women & & & & &
\end{tabular}


Table 3: Prevalence of risk factors in the total group and sex specific

\begin{tabular}{|c|c|c|c|c|c|c|}
\hline \multirow[t]{3}{*}{ Risk factors: prevalence } & \multicolumn{6}{|c|}{ total group } \\
\hline & \multicolumn{2}{|c|}{$\begin{array}{c}\text { All } \\
(n=568)\end{array}$} & \multicolumn{2}{|c|}{$\begin{array}{l}\text { Women } \\
(n=406)\end{array}$} & \multicolumn{2}{|c|}{$\begin{array}{c}\text { Men } \\
(n=162)\end{array}$} \\
\hline & $\%$ & $\mathrm{n}$ & $\%$ & $\mathrm{n}$ & $\%$ & $\mathrm{n}$ \\
\hline \multicolumn{7}{|l|}{ I. BMD (DXA) } \\
\hline Spine & 39 & 220 & 39 & 159 & 38 & 61 \\
\hline & 46 & 255 & 48 & 192 & 40 & 63 \\
\hline Spine and hip (lowest $T \leq-1$ and $>-2.5$ ) & 44 & 250 & 44 & 179 & 44 & 71 \\
\hline \multicolumn{7}{|l|}{ T score $\leq-2.5$} \\
\hline Spine & 30 & 172 & 32 & 131 & 25 & 41 \\
\hline Нiр & 17 & 92 & $20^{*}$ & 80 & 8 & 12 \\
\hline Spine or hip & 35 & 201 & $38^{*}$ & 156 & 28 & 45 \\
\hline \multicolumn{7}{|l|}{ II. Bone related risk factors } \\
\hline \multicolumn{7}{|l|}{ Fracture history $\S$} \\
\hline - clinical fracture after $50 \mathrm{yr}$ & 23 & 131 & $27^{*}$ & 110 & 13 & 21 \\
\hline - clinical vertebral fracture & 5 & 28 & 5 & 21 & 4 & 7 \\
\hline Mother with fracture history & 21 & 117 & 20 & 83 & 21 & 34 \\
\hline Body weight $<60 \mathrm{~kg}$ & 17 & 99 & 20 * & 80 & 12 & 19 \\
\hline Severe immobility & 6 & 34 & 7 & 28 & 4 & 6 \\
\hline On glucocorticoids & 1 & 8 & 2 & 6 & 1 & 2 \\
\hline At least 1 of the bone related risk factors & 53 & 299 & $56^{*}$ & 227 & 44 & 72 \\
\hline \multicolumn{7}{|l|}{ III. Fall related risk factors } \\
\hline$>1$ fall last year & 28 & 158 & $31^{*}$ & 124 & 21 & 34 \\
\hline On psychopharmaca & 23 & 128 & $25^{\star}$ & 102 & 16 & 26 \\
\hline Low ADL (before fracture) & 26 & 140 & $29 *$ & 113 & 17 & 27 \\
\hline Articular complaints & 32 & 183 & $37^{\star}$ & 151 & 20 & 32 \\
\hline Impaired vision & 27 & 153 & 25 & 103 & 31 & 50 \\
\hline Urinary incontinence & 14 & 82 & $18^{*}$ & 74 & 5 & 8 \\
\hline Parkinson's disease & 0.4 & 2 & 0.5 & 2 & 0 & 0 \\
\hline At least 1 of the fall related risk factors & 75 & 425 & $78^{*}$ & 315 & 68 & 110 \\
\hline
\end{tabular}

The 406 women in this cohort and a cohort of 492 women with no fracture history were compared with regard to age, height, weight, prevalence of osteoporosis of the spine and/or hip, maternal fracture, steroid use, Parkinson disease, use of sedatives, and the occurrence of two or more falls in the previous 12 months. When compared with the control group, the patients with a recent fracture tended to be slightly older (68 compared with 65 years; $p<.0001$ ), weigh less (69 kg compared with $71 \mathrm{~kg} ; \mathrm{p}=0.03$ ), have a higher prevalence of osteoporosis in the spine and/or hip more often (38\% compared with 19\%; $p<$ 0.0001 ), and have a higher prevalence of two or more falls in the previous 12 months $(31 \%$ compared with $11 \% ; p<.0001)$. Multivariate logistic regression 
analyses showed that, when adjusted for age, weight, and height, the above mentioned differences were independent for presence of osteoporosis (OR 2.9; $95 \% \mathrm{Cl} 2.0-4.1$ ) and the history of falls (OR 4.0; 95\% Cl $2.7-5.9)$. Interaction was only significant for age and the presence of osteoporosis $(p=0.02)$.

Using the Dutch osteoporosis guideline ${ }^{12}$, we determined that $83 \%$ of the women with a clinical fracture would not have been identified as being at risk for a fracture before they had the recent fracture.

\section{DISCUSSION}

In a cohort of patients over 50 years of age who had been admitted to the emergency clinic of our hospital for a recent clinical fracture, a heterogeneous mixture of bone and fall related risks for fractures was found in both sexes, in association with all fracture locations and irrespective of the patient's age, even when the analyses were limited to patients who had sustained the fracture in a simple fall. Osteoporosis (T-score $\leq-2.5$ ) was present in one third of the patients, while half of the patients had at least one bone related risk factor and three-quarters of the patients had at least one fall related risk factor before the current fracture. The majority $(71 \%)$ of this study population were women, and therefore the conclusions are predominantly based on results found in women. These results highlight two important issues.

First, most guidelines focus on identifying osteoporosis, as opposed to risk factors for fractures, and therefore they fail to prospectively identify most individuals at risk for fractures.

Only a limited number of the patients in our study, could have been identified before their current clinical fracture, with use of the Dutch guideline. This indicates the need for additional approaches to identify patients at risk for clinical, and usually nonvertebral fractures. Such an initiative is under way with the World Health Organisation (WHO) initiative to calculate the absolute fracture risk on the basis of bone mineral density and a group of clinical bone related risk factors that is larger than that included in the Dutch guideline. The WHO list of bone related risk factors includes use of multiple medications, cigarette smoking, excessive alcohol intake, rheumatoid arthritis and self-rated poor health status ${ }^{29}$. WHO acknowledges that it chose to include only bone related risks in this initiative. It identified the importance of fall risks but excluded them. In view of our results the algorithms proposed by WHO could therefore underestimate fracture risk in patients with a higher risk of falls. To what extent such algorithms could overestimate the fracture risk in patients who have a lower risk of falls is also unclear and needs to be addressed in large scale prospective 
population studies integrating both bone- and fall-related risks. Indeed Nguyen et al. reported that both bone- and fall-related risk factors were predictive of hip fractures, the most important clinical fractures, over a period of 14 years $^{30}$. A recent review on osteoporosis by Sambrook and Cooper supported the view that case finding and therapeutic strategies will shift from an approach primarily based on bone mineral density measurements to an approach in which both fall and bone related fracture risk factors are used to predict the absolute fracture risk ${ }^{31}$. Our data support this view and indicate that this approach may be particularly valuable in the context of patients entering the hospital for the treatment of a fracture.

The second important finding of our study is that most patients with a recent clinical fracture do not have osteoporosis. Thus, simply ordering a dual X-ray absorptiometry scan to select patients for treatment means that many patients with a high fracture risk will be discharged without further treatment. In these cases, the bone-related risk factors independent of bone mineral density and the fall-related risk factors will persist and will therefore need to be addressed and corrected whenever possible. Indeed, in our study $53 \%$ of patients had bone related risk factors other than low bone mineral density, for which there are potentially several structural and material bone-related reasons, including structural features (micro-architecture and macro-architecture), high bone turnover and material characteristics such as hypomineralisation in the context of high bone turnover and osteomalacia, genetic polymorphisms (e.g. of collagen type-I) and changes in collagen cross-linking ${ }^{32-34}$. As most patients in our study had had a fall, the high prevalence of fall related risk factors was not unexpected. However, the frequent combination of fall and bone related risk factors indicates that, in the context of case finding, those who fall need to be evaluated for bone related risk factors and low bone mineral density ( 2 of 3 patients who had fallen also had bone related risk factors and /or low bone mineral density) and patients with bone related risk factors and/or low bone mineral density need to be evaluated for fall related risk factors (4 of 5 patients had also fall related risk factors). However, the clinical relevance of fall risk evaluation and prevention in these patients remains unclear. Various studies have demonstrated a beneficial effect of focused or multifactorial fall prevention programs on the incidence of falls, but none have shown that this leads to fracture reduction ${ }^{2,35,36}$.

This study has several shortcomings.

The number of patients included could be interpreted as small when compared with the numbers in prospective studies in which bone and fall related risks were evaluated in several thousands subjects ${ }^{37,38}$. However, our study is 
by far the largest evaluating both bone and fall related risk factors in patients with a recent clinical fracture.

McLellan et al. conducted a study of 4600 patients with a recent fracture, but they only evaluated bone mineral density ${ }^{39}$. Becker et al. described 185 men and women with a recent fracture, but they focused mainly on causes of secondary osteoporosis and the influence of ethnicity. They found a mean of 3.2 fall related risk factors and a history of fracture in $40 \%$ of their patients ${ }^{40}$. However, their study was based on a retrospective chart review.

A second shortcoming of our study is that blood sampling was not performed, as it was in the study by Streeten et al. . Blood sampling may be important for diagnosing secondary causes of low bone mineral density ${ }^{41}$.

Third, some bone related risk factors (excessive alcohol intake, smoking , rheumatoid arthritis and self-rated poor health status )were not included in our study because they are not included in the Dutch osteoporosis guideline. Miller et al. reported that an algorithm that included self-reported poor health for assessment of women with osteopenia correctly classified $74 \%$ of those who had sustained a fracture. As self-reported poor health was not part of our evaluation, it remains to be determined if this additional information could have increased the proportion of patients who could have been identified as at risk ${ }^{8}$.

Fourth, $15 \%$ of the patients were not eligible for assessment and, of those who were eligible, $29 \%$ did not provide informed consent or failed to return for the bone mineral density study. Therefore, the conclusions drawn from these data are applicable only to those patients who are willing to cooperate with an assessment for fracture risk. The results show that older patients and patients with hip fractures were less willing to participate in such a program.

Fifth, risk factor assessment was conducted during the fracture treatment period in a study with a cross-sectional design. This may have affected recall regarding these risk factors. However, the evaluation was performed within two months after the fracture for most patients. As a result, recall bias was probably quite low.

Sixth, a control group was available only for the female subjects in this study. Lastly, we must consider that not all clinical vertebral fractures are treated at the emergency department and that two of every three fractures do not have the clinical picture of an acute fracture. Therefore, no data on nonclinical morphometric vertebral fractures were obtained.

In summary fracture prevention is essential to improve the quality of life for our growing elderly population. In order to be successful we need to move beyond using bone-related or fall-related risk factors as the only, or as separate risk factors for clinical fractures and we must develop screening tools that combine 
bone- and fall-related risk factors in prospective population studies to better identify a greater proportion of the at-risk population.

\section{REFERENCES}

1. Francis RM. Falls and fractures. Age Ageing. 2001 Nov;30 Suppl 4:25-8.

2. Tinetti ME. Preventing falls in elderly persons. N Engl J Med. 2003 Jan 2;348(1):42-9.

3. Geusens P, Milisen K, Dejaeger E, Boonen S. Falls and fractures in postmenopausal women: a review. J Br Menopause Soc. 2003 Sep;9(3):101-6.

4. Dreinhofer KE, Anderson M, Feron JM, Herrera A, Hube R, Johnell $O$, et al. Multinational survey of osteoporotic fracture management. Osteoporos Int. 2005 Mar;16 Suppl 2:S44-53.

5. Hegeman JH, Willemsen G, van Nieuwpoort J, Kreeftenberg HG, van der Veer E, Slaets $\mathrm{JP}$, et al. Effective tracing of osteoporosis at a fracture and osteoporosis clinic in Groningen; an analysis of the first 100 patients. Ned Tijdschr Geneeskd. 2004 Oct 30;148(44):2180-5.

6. van Helden S, Cals J, Kessels F, Brink P, Dinant GJ, Geusens P. Risk of new clinical fractures within 2 years following a fracture. Osteoporos Int. 2006 Mar; 17(3):348-54.

7. Johnell O, Kanis JA, Odén A, Sernbo I, Redlund-Johnell I, Petterson C, et al.: Fracture risk following an osteoporotic fracture. : Osteoporos Int. 2004;15(3):175-9.

8. Miller PD, Barlas S, Brenneman SK, Abbott TA, Chen YT, Barrett-Connor E, et al. An approach to identifying osteopenic women at increased short-term risk of fracture. Arch Intern Med. 2004 May 24;164(10):1113-20.

9. Cummings SR, Nevitt MC, Browner WS, Stone K, Fox KM, Ensrud KE, et al. Risk factors for hip fracture in white women. Study of Osteoporotic Fractures Research Group. N Engl J Med. 1995 Mar 23;332(12):767-73.

10. Nevitt MC, Cummings SR, Stone KL, Palermo L, Black DM, Bauer DC, et al. Risk factors for a first-incident radiographic vertebral fracture in women $>$ or $=65$ years of age: the study of osteoporotic fractures. J Bone Miner Res. 2005 Jan;20(1):131-40.

11. Siris ES, Chen YT, Abbott TA, Barrett-Connor E, Miller PD, Wehren LE, et al. Bone mineral density thresholds for pharmacological intervention to prevent fractures. Arch Intern Med. 2004 May 24;164(10):1108-12.

12. CBO kvdg. tweede herziene richtlijn osteoporose 2002. available at: http://wwwcbonl/product/richtlijnen/folder20021023121843/osteoporosepdf/view accessed august 17, 2005.

13. CBO kvdg. Preventie van valincidenten bij ouderen 2004. available at: http://wwwcbonl/product/richtlijnen/folder20021023121843/val-richtlijn2004pdf/view accessed june 5, 2006.

14. Geusens PP, Lems WF, Verhaar HJ, Leusink G, Goemaere S, Zmierczack H, et al. Review and evaluation of the Dutch guidelines for osteoporosis. J Eval Clin Pract. 2006 Oct; 12(5):539-48.

15. Tinetti ME, Speechley M, Ginter SF. Risk factors for falls among elderly persons living in the community. N Engl J Med. 1988 Dec 29;319(26):1701-7. 
16. Jaglal SB, Mclsaac WJ, Hawker G, Carroll J, Jaakkimainen L, Cadarette SM, et al. Information needs in the management of osteoporosis in family practice: an illustration of the failure of the current guideline implementation process. Osteoporos Int. 2003 Aug;14(8):672-6.

17. O'Loughlin JL, Robitaille Y, Boivin JF, Suissa S. Incidence of and risk factors for falls and injurious falls among the community-dwelling elderly. Am J Epidemiol. 1993 Feb $1 ; 137(3): 342-54$.

18. Tromp AM, Pluijm SM, Smit JH, Deeg DJ, Bouter LM, Lips P. Fall-risk screening test: a prospective study on predictors for falls in community-dwelling elderly. J Clin Epidemiol. 2001 Aug;54(8):837-44.

19. Nevitt MC, Cummings SR, Kidd S, Black D. Risk factors for recurrent nonsyncopal falls. A prospective study. Jama. 1989 May 12;261(18):2663-8.

20. Northridge ME, Nevitt MC, Kelsey JL. Non-syncopal falls in the elderly in relation to home environments. Osteoporos Int. 1996;6(3):249-55.

21. Lord SR, Dayhew J. Visual risk factors for falls in older people. J Am Geriatr Soc. 2001 May;49(5):508-15.

22. Luukinen H, Koski K, Kivela SL, Laippala P. Social status, life changes, housing conditions, health, functional abilities and life-style as risk factors for recurrent falls among the home-dwelling elderly. Public Health. 1996 Mar;110(2):115-8.

23. Stalenhoef PA, Diederiks JP, Knottnerus JA, Kester AD, Crebolder HF. A risk model for the prediction of recurrent falls in community-dwelling elderly: a prospective cohort study. J Clin Epidemiol. 2002 Nov;55(11):1088-94.

24. Luukinen H, Koski K, Laippala P, Kivela SL. Predictors for recurrent falls among the home-dwelling elderly. Scand J Prim Health Care. 1995 Dec;13(4):294-9.

25. Campbell AJ, Borrie MJ, Spears GF. Risk factors for falls in a community-based prospective study of people 70 years and older. J Gerontol. 1989 Jul;44(4):M112-7.

26. Schwartz AV, Villa ML, Prill M, Kelsey JA, Galinus JA, Delay RR, et al. Falls in older Mexican-American women. J Am Geriatr Soc. 1999 Nov;47(11):1371-8.

27. Weiner DK, Hanlon JT, Studenski SA. Effects of central nervous system polypharmacy on falls liability in community-dwelling elderly. Gerontology. 1998;44(4):217-21.

28. van Geel AC, Geusens PP, Nagtzaam IF, Schreurs CM, van der Voort DJ, Rinkens PE, et al. Timing and risk factors for clinical fractures among postmenopausal women: a 5year prospective study. BMC Med. 2006;4:24.

29. Kanis JA, Borgstrom F, De Laet C, Johansson H, Johnell O, Jonsson B, et al. Assessment of fracture risk. Osteoporos Int. 2005 Jun;16(6):581-9.

30. Nguyen ND, Pongchaiyakul C, Center JR, Eisman JA, Nguyen TV. Identification of highrisk individuals for hip fracture: a 14-year prospective study. J Bone Miner Res. 2005 Nov;20(11):1921-8.

31. Sambrook P, Cooper C. Osteoporosis. Lancet. 2006 Jun 17;367(9527):2010-8.

32. Bouxsein ML, Karasik D. Bone geometry and skeletal fragility. Curr Osteoporos Rep. 2006 Jun;4(2):49-56.

33. Garnero P. Markers of bone turnover for the prediction of fracture risk. Osteoporos Int. 2000;11 Suppl 6:S55-65. 
34. Uitterlinden AG, Weel AE, Burger H, Fang Y, van Duijn CM, Hofman A, et al. Interaction between the vitamin $D$ receptor gene and collagen type lalpha1 gene in susceptibility for fracture. J Bone Miner Res. 2001 Feb;16(2):379-85.

35. Close J, Ellis M, Hooper R, Glucksman E, Jackson S, Swift C. Prevention of falls in the elderly trial (PROFET): a randomised controlled trial. Lancet. 1999 Jan 9;353(9147):93-7.

36. Chang JT, Morton SC, Rubenstein LZ, Mojica WA, Maglione M, Suttorp MJ, et al. Interventions for the prevention of falls in older adults: systematic review and metaanalysis of randomised clinical trials. Bmj. 2004 Mar 20;328(7441):680.

37. Nguyen TV, Center JR, Sambrook PN, Eisman JA. Risk factors for proximal humerus, forearm, and wrist fractures in elderly men and women: the Dubbo Osteoporosis Epidemiology Study. Am J Epidemiol. 2001 Mar 15;153(6):587-95.

38. Sambrook PN, Cameron ID, Chen JS, Cumming RG, Lord SR, March LM, et al. Influence of fall related factors and bone strength on fracture risk in the frail elderly. Osteoporos Int. 2007 May;18(5):603-10.

39. McLellan AR, Gallacher SJ, Fraser M, McQuillian C. The fracture liaison service: success of a program for the evaluation and management of patients with osteoporotic fracture. Osteoporos Int. 2003 Dec;14(12):1028-34.

40. Becker C, Crow S, Toman J, Lipton C, McMahon DJ, Macaulay W, et al. Characteristics of elderly patients admitted to an urban tertiary care hospital with osteoporotic fractures: correlations with risk factors, fracture type, gender and ethnicity. Osteoporos Int. 2006;17(3):410-6.

41. Streeten EA, Mohamed A, Gandhi A, Orwig D, Sack P, Sterling R, et al. The inpatient consultation approach to osteoporosis treatment in patients with a fracture. Is automatic consultation needed? J Bone Joint Surg Am. 2006 Sep;88(9):1968-74. 


\section{CHAPTER 5}

Evaluation of patients with a recent clinical fracture and osteoporosis A multidisciplinary approach

B. Dumitrescu, S.H. van Helden, R ten Broeke A. Nieuwenhuijzen-Kruseman, C. Wyers, G. Udrea, S. van der Linden, P. Geusens 


\section{ABSTRACT}

The aetiology of fractures is multifactorial, but little is known about the way to evaluate patients with a recent clinical fracture.

The aim of the study was to evaluate in these patients referred by the surgeons to the rheumatologist, in collaboration with the endocrinologists, the presence of contributors to secondary osteoporosis, clinical bone- and fall-related risks for fractures and morphometric vertebral fractures (MVF). One hundred consecutive men and women, over 50 years of age who presented at the hospital with a recent clinical fracture and a T-score $\leq-2.5$ had clinical and laboratory assessments and vertebral fracture assessment by densitometry.

In 73 women and 27 men (mean age:68 years) contributors to secondary osteoporosis were known in 27 patients, 50 patients had newly diagnosed contributors (mainly vitamin D deficiency), 14 needed further exploration because of laboratory abnormalities, 54 had bone- and 79 had fall-related fracture risks and 53 had previously undiagnosed MVF.

We conclude that among 100 women and men over 50 years of age with a recent clinical fracture and osteoporosis, referred by the surgeons, many have contributors to secondary osteoporosis (or need further exploration), clinical bone- and fall-related fracture risks and MVF. These results suggest that patients with a recent clinical fracture and osteoporosis require broad spectrum evaluation that includes a search for contributors to osteoporosis and MVF. 


\section{INTRODUCTION}

Osteoporosis is defined as a skeletal disorder characterized by low bone mass and micro architectural deterioration of bone tissue, resulting in decreased bone strength and in an increased risk for fragility fractures ${ }^{1,2}$.

According to the World Health Organisation (WHO) the diagnosis of osteoporosis is made on the results of bone densitometry (T-score below -2.5$)^{1,3}$. However, many risk factors are related to fracture risk, independently of BMD, such as clinical risk factors ${ }^{4}$, fall risks ${ }^{5}$ and the presence of morphometric vertebral fractures (MVF) ${ }^{6}$, as acknowledged by the $\mathrm{NIH}^{2}$. The $\mathrm{WHO}$ is therefore on the way to develop clinical algorithms to calculate the absolute fracture risk based on a combination of clinical risks and BMD, but not including the presence of fall risks or the presence of MVF. In addition there is increasing evidence that secondary osteoporosis is more prevalent than initially thought, not only in males, but also in females ${ }^{7}$. The true prevalence of contributors to secondary osteoporosis is unknown and no consensus regarding its evaluation is available . $^{8}$

Published data from referral centres for evaluation of osteoporosis indicate that 32 to $37 \%$ of women with low BMD have a history of other diseases or medications known to cause osteoporosis. ${ }^{9,10}$ From $20 \%$ up to $64 \%$ of patients have unknown secondary causes of osteoporosis that were only identified by laboratory testing ${ }^{11}$, but in these studies no data were presented on fall risks or the presence of MVF.

In a study of patients with a recent clinical fracture, a high prevalence of contributors to secondary osteoporosis (77\%) and of fall risks (a mean of 2.5 to 3.5 per patient) was reported, but the study included only a limited number of patients with measured low BMD and did not report on the presence of MVF'12. In another study, the reported prevalence of semi-quantitatively determined MVF in patients with a recent fracture was $25 \%$, but secondary osteoporosis was not investigated ${ }^{13}$. These studies indicate that patients with a recent clinical fracture are a heterogeneous group in terms of associated diseases, bone- and fall-related fracture risks and the presence of MVF.

The aim of this study was to evaluate the prevalence of contributors to secondary osteoporosis, bone- and fall-related fracture risks and MVF in 100 consecutive patients with a recent clinical fracture and osteoporosis, referred by the surgeons to the rheumatologists in collaboration with the endocrinologists. 


\section{PATIENTS AND METHODS}

This is an observational study on 100 consecutive and consenting patients over the age of 50, who presented with a clinical fracture at Maastricht University Hospital in the Netherlands. After receiving medical treatment for the fracture, patients had a consultation with the osteoporosis nurse. The nurse provided the patients with information about the study and invited them to join the Fracture and Osteoporosis Outpatient Clinic. All eligible patients who agreed to participate between April 2005 and April 2006 were further referred to the program. Only patients with osteoporosis according to World Health Organization (WHO) criteria for $\mathrm{BMD}^{1}$ and in whom all laboratory data were available were included in the present study (Figure 1). Patients already on osteoporosis treatment $(44 / 1246,4 \%$ of all) were excluded from the analysis. The local medical ethical committee approved the study.

Bone mineral density (BMD) in the left or right hip and the lumbar spine was determined using dual X-ray absorptiometry (DXA) with Hologic QDR 4500 Elite. The diagnosis of osteoporosis was based on the WHO criteria for BMD'. The patients were classified according to the lowest value of T-score in either hip or spine.

All patients were interviewed for bone-related risk factors for fracture (previous non-vertebral and vertebral fractures, mother with fracture, body weight $<60 \mathrm{~kg}$, severe immobility, use of glucocorticoids) and fall-risk factors (falls in the past 12 months, use of assistive devices, sedative medication, activities of daily living, mobility, impaired vision, articular complaints, urinary incontinency), according to the Dutch guidelines on osteoporosis and fall prevention ${ }^{5,14}$. Additional, data about vitamin D status (regular sun exposure, dietary intake and supplements), calcium intake ${ }^{15,16}$, height, history of height loss ${ }^{17}$, description of how the fracture occurred (fall from a standing height or other trauma) were recorded.

Patients with T-scores $\leq-2.5$ were given a pre-planned battery of laboratory tests that included erythrocyte sedimentation rate (ESR), haemoglobin, leucocytes, serum creatinine, calcium, albumin, alkaline phosphatase, 25-OHD3, and $\mathrm{TSH}$. Calcium and creatinin were measured in a 24-hour urine collection. On the basis of the test results and the data collected by the osteoporosis nurse at the second meeting, a consultation with either a rheumatologist or an endocrinologist was scheduled. The specialist decided about further investigation and treatment. When clinically appropriate, additional tests were performed. The diagnose of contributors to secondary osteoporosis was based on all data from the medical files. Renal insufficiency was defined with the cut-off value of creatinine clearance 40 using the Cockroft Gault formula ${ }^{18}$. Vitamin D deficiency was defined when serum $25-\mathrm{OHD}_{3}$ values were $50 \mathrm{nmol} / \mathrm{L}$. Patients were considered 
to be severely deficient when values were $30 \mathrm{nmol} / \mathrm{L}$, insufficient when values were $75 \mathrm{nmol} / \mathrm{L}^{19,20}$. Patients with vitamin $\mathrm{D}$ level above $220 \mathrm{nmol} / \mathrm{L}$ were considered abnormal ${ }^{21}$.

Exploration for hypogonadism in men was considered when a morning serum testosterone level was below $12 \mathrm{nmol} / \mathrm{L}^{22}$ and for thyroid disorders when $\mathrm{TSH}$ were outside the reference ranges $(0.4-3.5 \mathrm{mU} / \mathrm{L})$. Hyperparathyroidism was diagnosed when PTH levels were above $5.5 \mathrm{pmol} / \mathrm{L}$. Further exploration for hypercalciuria was considered when the total urinary calcium in a 24 hours collection exceeded $7 \mathrm{mmol} / \mathrm{d}$ and creatinuria indicated an appropriate collection (between $4.5-13.3 \mathrm{mmol} /$ hour $^{23}$. Following clinical judgement patients were considered for lactose intolerance. This was confirmed by the lactose tolerance test ${ }^{24}$.

Vertebral fracture assessment (VFA ${ }^{25,26}$ by single X-ray absorptiometry on the lateral spine images was performed. Images were saved in a digital format. Physician Viewer software (Hologic, USA) provided the tools necessary to perform quantitative vertebral morphometry. Visual assessment and measurements of the anterior, posterior and mid heights from T4 to L4 were performed twice, by a trained rheumatologist (BD). These assessments were put into a database. The observer was blinded from the results of the first measurements. The intraobserver coefficient of variation (ICC) at vertebral level for heights was 0.917 (95\% confidence interval (Cl): 0.905-0.930, Cronbach's alpha 0.959). The arithmetic mean heights of the two measurements were used for calculation. The anterior-posterior ratio, the middle-posterior ratio, the posterior-posterior ratio were calculated. Prevalent morphometric vertebral fractures (MVF) were defined according to the Genant grading [27]. Vertebral fractures were classified into three types (wedge, biconcavity, crush) and three grades (mild (any ratio $<20 \%$ ), moderate (any ratio between $25-40 \%$ ), and severe (any ratio $>40 \%$ )).

Statistical analyses were performed using SPSS version 12.01. Categorical variables and proportions were analyzed using chi-square statistic. Reliability analyses were conducted for the intra-class correlation coefficient at vertebral level using an absolute agreement definition for heights. Odds ratio (OR) with $95 \%$ confidence intervals $(95 \% \mathrm{Cl})$ were calculated based on the chi squares. One way ANOVA was used to investigate differences between subgroups. Observations were considered significant if $p$-values were $<0.05$ (two-tailed).

\section{RESULTS}

We, together with the endocrinologists, evaluated 100 consecutive and consenting patients. Of these 73 were women and 27 were men. The mean and 
median age was 68 years (standard deviation \pm 10 years, range: 50 to 90 years). Demographic data are summarized in Table 1 . The majority of patients were Caucasian (97\%). Fractures were found at the following locations: spine (4), clavicle (3), pelvis (2), humerus (10), radius and/or ulna (24), hand (6), hip (17), tibia/fibula/patella (8) and foot (21). In our sample, 5 patients had multiple simultaneous fractures and 80 patients had fractures after a fall from standing height.

A total of 86 contributors to secondary osteoporosis were diagnosed in 57 patients (Table 2). Contributors were either known medical conditions (34 in 27 patients) or newly diagnosed (52 in 50 patients). Seven had only known contributors, 20 had known plus a newly diagnosed contributor and 30 had only newly diagnosed contributors.

Based on serum levels of $25-\mathrm{OHD}_{3}$, we determined that 11 patients were severely deficient in vitamin $D, 31$ were deficient and 31 had insufficient serum values. All were newly diagnosed. Serum levels of 25-OHD3 could not be predicted by any of the vitamin $D$ questions or the sum of those questions. Additionally, 86 patients reported a calcium intake below $1200 \mathrm{mg}$, so that only three patients had a calcium intake above $1200 \mathrm{mg}$ together with a serum 25-OHD3 level above $75 \mathrm{nmol}$ (Figure 2).

Table 1 Characteristics of the patient population $(\mathrm{N}=100)$

\begin{tabular}{ll}
\hline Variable & Median+/-SD \\
\hline Age (years) & $68+/-10$ \\
Weight (kg) & $66+/-13$ \\
Spine T-score & $-2,86+/-1,1$ \\
Hip T-score & $-1,88+/-0,9$ \\
Spine Z-score & $-1,14+/-1,1$ \\
Hip Z-score & $-0,62+/-0,8$ \\
BMD spine(g/sq cm) & $0.772+/-0.100$ \\
BMD hip(g/sq cm) & $0.795+/-0.395$ \\
Calcium intake(mg/day) & $852+/-432$ \\
& Number \\
\hline Gender -woman & 73 \\
$\quad-$ men & 27 \\
Caucasian ethnicity & 97 \\
Current clinical fractures & \\
Clinical Vertebral & 4 \\
Thorax & 3 \\
Pelvis & 2 \\
Humerus & 10 \\
Radius/ulna & 24 \\
Hand & 6 \\
Hip/femur & 17 \\
Tibia/fibula/patella & 8 \\
Foot & 21 \\
Multiple & 5 \\
Fracture after fall from standing height & 80 \\
\hline
\end{tabular}


Five patients had secondary hyperparathyroidism, of which four were newly diagnosed. Hyperparathyroidism was secondary to renal insufficiency in three cases and to low calcium intake in two cases. We found 14 patients with renal insufficiency, of whom 6 were newly diagnosed (Table 2). Three patients were known with hyperthyroidism, 1 new case of exogenous hyperthyroidism and 1 new case of hypothyroidism was detected. One new case of lactose intolerance was diagnosed. Further contributors included anorexia nervosa in two women, 1 man with documented hypogonadism, 5 with pulmonary diseases (chronic obstructive lung disease and asthma), 4 men with alcohol abuse, 3 patients with inflammatory rheumatic diseases (rheumatoid arthritis, giant cell arteritis) and 3 with severe immobility. Most of these patients did not receive preventive measures for osteoporosis prior to the fracture and were thus probably not recognized as having a contributor to secondary osteoporosis before the fracture occurred.

Other laboratory abnormalities that required further exploration were found in 14 patients (18 abnormalities in total), including exogenous hypervitaminosis $D$ in 1 , hypercalciuria in 3 , TSH outside normal ranges in 13 and low serum testosterone in one men (Table 3). Among the 9 patients being treated for hypothyroidism, one was over-treated while three were under-treated. Among the 3 patients being treated for hyperthyroidism, two were under-treated while one was overtreated (Table 3). In 43 patients no contributors were found, one contributor (of whom 26 were vitamin D deficient) was found in 32 and more than one contributor was found in 25. No differences were found in BMD between patients with or without documented contributors to secondary osteoporosis.

According to the Dutch guideline for osteoporosis 54 patients had clinical bonerelated risk factors for fractures in addition to their current fracture (Table 4). A history of an additional clinical fracture after the age of 50 was present in 31 patients (two with an earlier clinical spine fracture). Additionally, 12 had a mother that had suffered one or more fractures, 3 were severely immobilised, and 23 had a low body weight $(60 \mathrm{~kg})$. According to the Dutch guideline for fall prevention, we found fall related risk factors in 79 of the patients: 22 patients had one risk factor, 21 had two risk factors, and 36 had more than two risk factors. An overlap between clinical bone related risk factors and fall related risk factors was present in 45 patients. The prevalence of clinical bone-related and fallrelated risk factors was similar between patients that had documented contributors to secondary osteoporosis and those who did not $(50 \%$ versus $59 \%$ for clinical bone related risk factors and $79 \%$ versus $84 \%$ for fall-related risk factors for fractures).

VFA could be performed for 93 patients. Lateral spine images were not available in 7 cases due to severe scoliosis or other technical difficulties such as posi- 
tioning patients with humerus fracture on the DXA table. On VFA, $57 \%$ of patients had MVF, $31 \%$ had more than one MVF and $31 \%$ had moderate and severe MVF. The prevalence of MVF was $67 \%$ in those patients with secondary osteoporosis and $44 \%$ in the other patients ( $\mathrm{OR}=2.6,95 \% \mathrm{Cl}=1.1$ to 6.0$)$. Similar results were obtained if only patients with fractures after a fall from standing height were retained in the analysis.

Table 2 Contributors to secondary osteoporosis identified in men and women $>50$ years with a recent clinical fracture $(\mathrm{N}=100)$

\begin{tabular}{|c|c|c|}
\hline Contributors & Known & $\begin{array}{l}\text { Newly } \\
\text { diagnosed }\end{array}$ \\
\hline \multicolumn{3}{|l|}{ Endocrine disorders } \\
\hline Serum $25-\mathrm{OHD}_{3} \mathrm{~s}<50 \mathrm{nmol} / \mathrm{l}$ & 0 & 42 \\
\hline Hyperparathyroidism seco ndary to low calcium intake & 0 & 2 \\
\hline Hyperthyroidism & 3 & 0 \\
\hline Hypogonadism (in men) & 1 & 0 \\
\hline Anorexia nervosa (in women) & 2 & 0 \\
\hline \multicolumn{3}{|l|}{ Gastrointestinal disorders } \\
\hline Lactose intolerance & 0 & 1 \\
\hline \multicolumn{3}{|l|}{ Connective tissue disorders } \\
\hline Rheumatoid arthritis & 2 & 0 \\
\hline Giant-cell arteritis & 1 & 0 \\
\hline \multicolumn{3}{|l|}{ Renal disorders } \\
\hline $\begin{array}{l}\text { Renal insufficiency without secondary } \\
\text { hyperparathyroidism }\end{array}$ & 5 & 6 \\
\hline $\begin{array}{l}\text { Renal insufficiency with secondary } \\
\text { hyperparathyroidism }\end{array}$ & 3 & 0 \\
\hline Miscellaneous & 5 & 0 \\
\hline Severe immobility & 3 & 0 \\
\hline Pulmonary diseases & 5 & 0 \\
\hline \multicolumn{3}{|l|}{ Medication and life style } \\
\hline Exogenous hyperthyroidism & 0 & 1 \\
\hline Alcohol abuse & 4 & 0 \\
\hline
\end{tabular}

Table 3: Laboratory abnormalities that required further exploration in men and women more than 50 years of age with a recent clinical fracture $(\mathrm{N}=100)$

\begin{tabular}{ll}
\hline Laboratory abnormality & Total \\
\hline Exogenous hypervitaminosis D $(>220 \mathrm{nmol} / \mathrm{l})$ & 1 \\
Hypercalciuria in 24 hours urine & 3 \\
TSH 0.4-3.5mU/L & 13 \\
$->3.5 \mathrm{mU} / \mathrm{L}$ & 10 \\
- treated hypothyroidism & 9 \\
$-\mathrm{TSH}<0.4 \mathrm{mU} / \mathrm{L}$ & 1 \\
$-\mathrm{TSH}>3.5 \mathrm{mU} / \mathrm{L}$ & 3 \\
- treated hyperthyroidism & 3 \\
$-\mathrm{TSH}>3.5 \mathrm{mU} / \mathrm{L}$ & 1 \\
$-\mathrm{TSH}<0.4 \mathrm{mU} / \mathrm{L}$ & 2 \\
Serum testosteron in men $<12 \mathrm{nmol} / \mathrm{L}$ & 1 \\
(one measurement) & 14 \\
\hline Total number of patients &
\end{tabular}


Table 4. Clinical risks for fractures recorded in patients with a recent clinic fracture according to the Dutch guidelines

\begin{tabular}{llll}
\hline CLINICAL RISKS OF FRACTURE & Women(73) & Men(27) & Total(100) \\
\hline BONE RELATED RISK FACTORS & 42 & 12 & 54 \\
History of clinical fracture after 50 years & 23 & 8 & 31 \\
History of clinical vertebral fracture & 1 & 10 & 2 \\
Mother with fracture & 9 & 3 & 12 \\
Low body weight $(<60 \mathrm{~kg})$ & 20 & 3 & 23 \\
Severe immobility & 3 & 0 & 3 \\
Glucocorticosteroids user & 2 & 0 & 2 \\
$\quad$ No risk factor & 29 & 15 & 37 \\
$\quad$ risk factor & 31 & 10 & 41 \\
2 risk factors & 10 & 2 & 12 \\
More than 2 risk factors & 1 & 0 & 1 \\
FALL RELATED RISK FACTORS & 57 & 22 & 79 \\
Mobility: Timed Get up and Go test & 21 & 3 & 24 \\
Previous falls: 2 or more falls in the previous year & 22 & 5 & 27 \\
Medication use (benzodiazepines, antiepileptics) & 14 & 2 & 16 \\
Activities of daily living-climbing stairs, & 38 & 11 & 49 \\
walking outside independently, cutting own toenail: & 40 & 8 & 48 \\
Osteoarthritis & 8 & 8 & 16 \\
Snellen score -visual acuity less than 0.4 & 17 & 2 & 19 \\
Urinary incontinence & 13 & 5 & 18 \\
No risk factor & 11 & 11 & 22 \\
1 risk factor & 14 & 7 & 21 \\
2 risk factors & 32 & 4 & 36 \\
More than 2 risk factors & & &
\end{tabular}

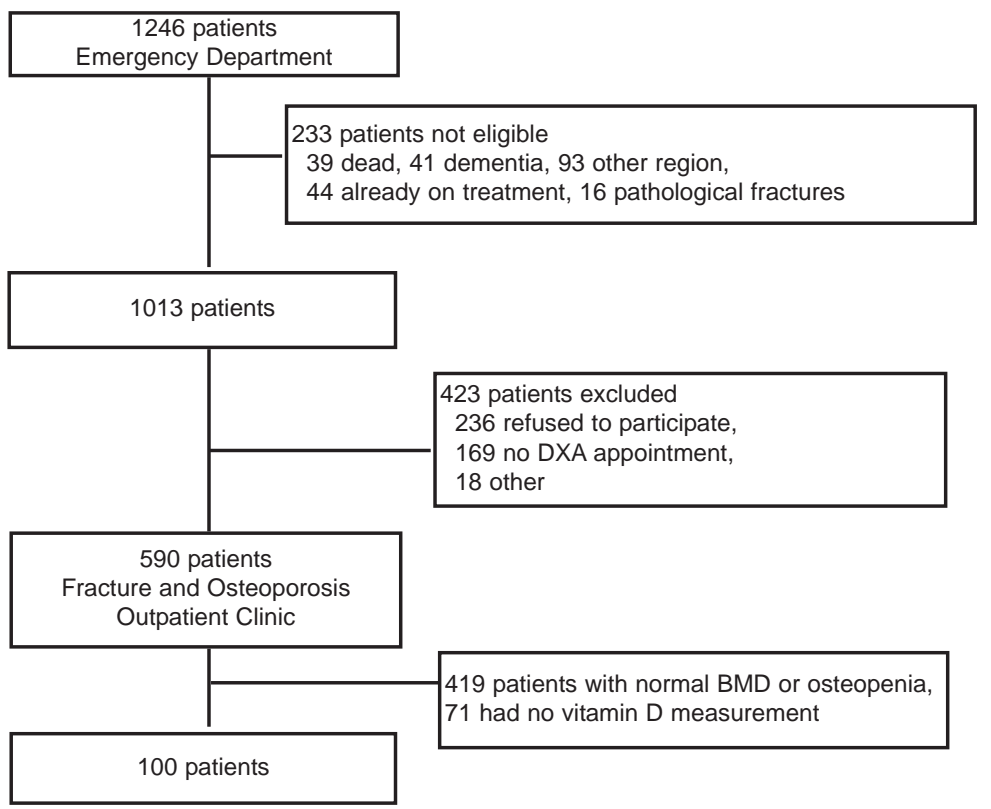

Figure 1. Flow chart of patients included in the study (see text for details) in one year 


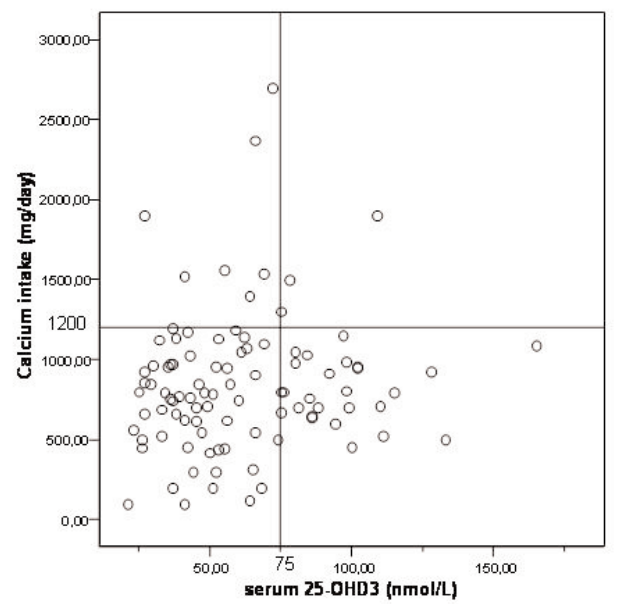

Figure 2. Calcium intake and serum serum levels of 25OHD3. Only 3 patients had sufficient intake of calcium and normal serum levels of 25-OHD3.

\section{DISCUSSION}

In this study 100 patients over 50 years of age presenting with a recent clinical fracture and osteoporosis and referred by the surgeons to the rheumatologists in collaboration with the endocrinologists were systematically evaluated for the presence of contributors to secondary osteoporosis and other risk factors for fractures. The prevalence of contributors to secondary osteoporosis was high: almost two out of three patients had one or more contributors and many had clinical risks for fractures and falls. In addition, patients with documented secondary osteoporosis had a 2.6 times higher risk for having MVF than those without documented contributors to secondary osteoporosis. These patients belong to a high risk group with therapeutic consequences linked to contributors to secondary osteoporosis.

Our results show that many patients (27\%) had known contributors to secondary osteoporosis, a percentage similar to that of Tannenbaum et all. in women with postmenopausal osteoporosis who were seen in an osteoporosis referral centre $(32 \%)^{10}$. The categories of known contributors to secondary osteoporosis were globally similar as reported by Tannennbaum ${ }^{10}$ (endocrine, gastrointestinal and inflammatory rheumatic and pulmonary diseases, severe immobility, alcohol abuse), One exception was glucocorticoid users who are presumably frequently referred to an osteoporosis clinic, but were not represented in our 
group of patients. In contrast to Tannenbaum, we performed the laboratory battery also in patients with already known contributors and 20 additional contributors were diagnosed in 20 patients (mainly low 25-OHD3, $n=13$ ). Presumably none of the patients with known contributors had received attention in the context of osteoporosis, as none had osteoporosis treatment.

In the other, presumably healthy patients without known contributors, laboratory testing identified newly diagnosed contributors to secondary osteoporosis in 31 more patients, mostly vitamin $\mathrm{D}$ deficiency and renal disorders. The number of patients with newly diagnosed contributors (50\%) was higher than reported by Tannenbaum et all. (33\%) and concerned mainly vitamin D deficiency and secondary hyperparathyroidism (to renal insufficiency and low calciumintake), malabsorption and exogenous hyperthyroidism were found ${ }^{10}$. In contrast to Tannenbaum, we performed TSH not only in patients with a history of thyroid diseases, but in all patients, and were able to diagnose one new case of hypothyroidism.

Vitamin D status could not be identified by history, despite including four specific questions regarding vitamin $D$ intake. It has been shown that there is only a modest relation $(r=0.24, p<0.001)$ between reported vitamin $D$ intake from an extensive dietary questionnaire and serum levels of $25-\mathrm{OHD}^{28}$. In our study a wide spectrum of levels of serum 25-OHD3 were found, from severely deficient to normal. There is still no consensus about how much vitamin D supplements are required to normalise serum levels. Some propose a unique dose of 800 $\mathrm{IU} /$ day together with $1000-1200 \mathrm{mg}$ calcium/day to achieve $50 \mathrm{nmol} / \mathrm{L}^{29,}{ }^{30}$. Others state that a unique dose of 800-1600 IU/day would normalize serum levels to $>75 \mathrm{nmol} / \mathrm{L}^{31,19}$. As patients with low serum levels of 25-OHD3 require, at least temporarily, high doses of vitamin $\mathrm{D}$ supplements while those with normal levels require less or none ${ }^{32}$, measuring serum 25-OHD3 levels is indicated in all patients with osteoporosis ${ }^{10}$.

The calcium homeostasis was further compromised by the low calcium intake $(<1200 \mathrm{mg} /$ day) in most patients, resulting in secondary hyperparathyroidism in 2 , so that only $3 \%$ of the patients had both adequate calcium intake and vitamin $\mathrm{D}$ status. Correcting these combined deficiencies has been demonstrated to reduce fracture risk, at least in institutionalized elderly women ${ }^{33}$ and to reduce the risk of fall ${ }^{34}$. However, supplementation with calcium and vitamin D alone is an insufficient measure in patients with osteoporosis, as drug therapy for osteoporosis has been shown to reduce the risk of fractures on top of correcting such deficiencies.

An additional 14 patients had laboratory abnormalities that required further investigation, mainly hypercalciuria, uncontrolled treatment of thyroid disorders and low testosterone (in one man). Hyperthyroidism, whether endogenous or 
exogenous, can increases bone turnover and contributes to secondary osteoporosis $^{35,36}$. Hypothyroidism on the other hand increases the risk of fractures hrough low bone turnover if untreated or high bone turnover if over treated ${ }^{37}$.

Thus fine-tuning thyroid treatment is indicated. The same is probably true for patients with hypercalciuria in whom thiazides are indicated ${ }^{38}$, and for hypogonadism in men that can be treated with testosterone supplementation ${ }^{39}$, although no fracture prevention data are available in these conditions.

Therefore, measuring serum $25-\mathrm{OHD}_{3}$, calcium in 24 hours urine, serum creatinine, TSH, PTH as proposed by Tannenbaum et all. is indicated in patients with osteoporosis and a recent clinical fracture, and enabled us to identify 47 $(96 \%)$ newly diagnosed contributors and 13 of the 14 laboratory abnormalities ${ }^{10}$. As many patients had endocrine diseases, collaborating with endocrinologists appeared to be highly valuable for diagnosis and treatment. The prevalence of clinical bone-related fracture risks in postmenopausal women, as evaluated by the Dutch guidelines, was similar between patients with and without documented contributors. It contributes to further specify the risk for fractures in all patients.

Nearly $80 \%$ of patients had fall-related risk factors for fractures, as reported by others ${ }^{12}$. Although it has not been shown until now that fall prevention strategies itself can prevent fractures, they reduce the risk of falls. ${ }^{40} \mathrm{~A}$ multidisciplinary, multifactorial interventionprogram reduces postoperative falls and injuries after femoral neck fracture and are therefore applied in our ongoing prevention program ${ }^{41}$.

An interesting finding was the prevalence of MVF which was more than twice as high among patients with documented contributors for secondary osteoporosis compared to those without contributors, in spite of similar low BMD in both groups. MVF, that are related to future fracture risk independent of $\mathrm{BMD}^{6}$, reflect bone failure independently of BMD and thus indicate other mechanisms of bone's decreased resistance to fracture than low BMD, such as changes in the bone turnover, alterations in micro architecture of bone and deficient mineralization, especially in the context of the high prevalence of calcium and vitamin D deficiency.

This study has several limitations. Smoking history, which is part of the WHO guideline, was not recorded as it is not part of the Dutch guideline. The sample size was relatively small, but the strength of the study was that consecutive patients were evaluated showing that even in a small group many contributors to secondary osteoporosis could be diagnosed. Some laboratory abnormalities needed further exploration, but were not followed up and so no definite diagnosis could be applied in these patients. VFA has several limitations. Not all ver- 
tebrae could be measured, mainly at the upper thoracic level. Identifying patients with MVF by VFA requires additional X-rays to differentiate deformities due to other conditions, such as Scheuerman's disease, degenerative changes or non-osteoporotic short vertebral height. However, the method has a high negative predictive value..$^{25}$

We conclude that the rheumatologist has a great responsibility in evaluating patients with a recent clinical fracture and a T-score $\leq-2.5$, as contributors to secondary osteoporosis are frequently present, even beyond vitamin $D$ deficiency. In more than $50 \%$ of the patients studied, new contributors, which were either correctable or preventable, were diagnosed. Half of the patients had undiagnosed MVF and nearly four out of every five patients had fall-related risk factors. These results suggest that patients with a recent clinical fracture and osteoporosis require a broad spectrum evaluation that includes the consideration of contributors to osteoporosis and the detection of undiagnosed MVF.

\section{REFERENCES}

1. Prevention and mana ement of osteoporosis. World Health Organ Tech Rep Ser 2003. 921: p. 1- 164 back cover.

2. NIH Consensus Development Panel on Osteoporosis Prevention, Dia nosis, and Therapy, March -29, 2000: hi hli hts of the conference. South Med J 2001. 94(6): p. 569-73.

3. Assessment of fracture risk and its application to screenin for postmenopausal osteoporosis. Report of a WHO Study Group. World Health Organ Tech Rep Ser 1994. 843: p. 1-129.

4. Kanis J.A. P. Geusens and . hristiansen Guidelines for clinical trials in osteoporosis. A position paper of the European Foundation for Osteoporosis and Bone Disease. Osteoporos Int 1991. 1(3): p. 182-8.

5. Richtlijn Preventie van valincidenten bij ouderen. 2004.

6. Siris E.S. et al. Enhanced prediction of fracture risk combinin vertebral fracture status and BMD. Osteoporos Int 2007. 18(6): p. 761-70.

7. Favus D.M.J. PRIMER on the Metabolic Bone Diseases and Disorders of the Mineral Metabolism. 12 ed. Best Pract Res lin Rheumatol. 2006: American Society for Bone and Mineral Research. 1.

8. Wagman R.B. and R. Marcus Beyond bone mineral density-navi atin the laboratory assessment of patients with osteoporosis. J lin Endocrinol Metab 2002. 87(10): p. 4429-30.

9. Deutschmann H.A. et al. Search for occult secondary osteoporosis: impact of identified possible risk factors on bone mineral density. J Intern Med 2002. 252(5): p. 389-97.

10. Tannenbaum et al. Yield of laboratory testin to identify secondary contributors to osteoporosis in otherwise healthy women. $\mathrm{J}$ lin Endocrinol Metab 2002. 87(10): p. 4431-7.

11. Fitzpatrick L.A. Secondary causes of osteoporosis. Mayo lin Proc 2002. 77(5): p. 453-68.

12. Becker et al. Characteristics of elderly patients admitted to an urban tertiary care hospital with osteoporotic fractures: correlations with risk factors, fracture type, ender and ethnicity. Osteoporos Int 2006. 17(3): p. 410-6. 
13. Gallacher S.J. et al. The prevalence of vertebral fracture amon st patients presentin with non- vertebral fractures. Osteoporos Int 2007. 18(2): p. 185-92.

14. Geusens P.P. et al. Review and evaluation of the Dutch uidelines for osteoporosis. J Eval lin Pract 2006. 12(5): p. 539-48.

15. The role of calcium in peri- and postmenopausal women: 2006 position statement of the North American Menopause Society. Menopause 2006. 13(6): p. 862-77; quiz 878-80.

16. Geusens P.P. Review of Guidelines for testin and treatment of osteoporosis. urr Osteoporos Rep 2003. 1(2): p. 59-65.

17. Ismail A.A. et al. Number and type of vertebral deformities: epidemiolo ical characteristics and relation to back pain and hei ht loss. European Vertebral Osteoporosis Study Group. Osteoporos Int 1999. 9(3): p. 206-13.

18. Saile P. et al. [Estimation of renal function in clinical routine: which is the best method?]. Dtsch Med Wochenschr 2007. 132(20): p. 1093-7.

19. Dawson-Hughes B. et al. Estimates of optimal vitamin D status. Osteoporos Int 2005. 16(7): p. 713-6.

20. Holick M.F. et al. Prevalence of Vitamin D inadequacy amon postmenopausal North American women receivin osteoporosis therapy. J lin Endocrinol Metab 2005. 90(6): p. 3215-24.

21. Heaney R.P. et al. Human serum 25-hydroxycholecalciferol response to extended oral dosin with cholecalciferol. Am J lin Nutr 2003. 77(1): p. 204-10.

22. Nieschlag E. et al. Investi ation, treatment and monitorin of late-onset hypo onadism in males: ISA, ISSAM, and EAU recommendations. Int J Androl 2005. 28(3): p. 125-7.

23. Bailie G.R. and S.G. Massry Clinical practice uidelines for bone metabolism and disease in chronic kidney disease: an overview. Pharmacotherapy 2005. 25(12): p. 1687-707.

24. Shaw A.D. and G.J. Davies Lactose intolerance: problems in dia nosis and treatment. J lin Gastroenterol 1999. 28(3): p. 208-16.

25. Lewiecki E.M. and A.J. Laster Clinical review: Clinical applications of vertebral fracture assessment by dual-ener y X-ray absorptiometry. J lin Endocrinol Metab 2006. 91(11): p. 4215- 22.

26. Genant H.K. et al. Vertebral fractures in osteoporosis: a new method for clinical assessment. J lin Densitom 2000. 3(3): p. 281-90.

27. Genant H.K. et al. Vertebral fracture assessment usin a semiquantitative technique. J Bone Miner Res 1993. 8(9): p. 1137-48.

28. McAlindon T.E. et al. Relation of dietary intake and serum levels of vitamin $D$ to pro ression of osteoarthritis of the knee amon participants in the Framin ham Study. Ann Intern Med 1996. 125(5): p. 353-9.

29. Boonen S. et al. Addressin the musculoskeletal components of fracture risk with calcium and vitamin D: a review of the evidence. alcif Tissue Int 2006. 78(5): p. 257-70.

30. Boonen S. et al. Calcium and vitamin $\mathrm{D}$ in the prevention and treatment of osteoporosis - a clinical update. J Intern Med 2006. 259(6): p. 539-52.

31. B D.-H. The role of vitamin D in fracture prevention BoneKEy-Osteovision 2005. 2(4): p. 6-10.

32. Heaney R.P. The Vitamin D requirement in health and disease. J Steroid Biochem Mol Biol 2005. 97(1-2): p. 13-9. 
33. Hapuy M. et al. Healthy elderly French women livin at home have secondary hyperparathyroidism and hi h bone turnover in winter. EPIDOS Study Group. J lin Endocrinol Metab 1996. 81(3): p. 1129-33.

34. Bischoff H.A. et al. Effects of vitamin D and calcium supplementation on falls: a randomized controlled trial. J Bone Miner Res 2003. 18(2): p. 343-51.

35. Bauer D. et al. Risk for fracture in women with low serum levels of thyroid-stimulatin hormone. Ann Intern Med 2001. 134(7): p. 561-8.

36. Vestergaard P. and L. Mosekilde Hyperthyroidism, bone mineral, and fracture risk--a meta- analysis. Thyroid 2003. 13(6): p. 585-93.

37. Vestergaard P. L. Rejnmark and L. Mosekilde Influence of hyper- and hypothyroidism, and the effects of treatment with antithyroid dru $s$ and levothyroxine on fracture risk. alcif Tissue Int 2005. 77(3): p. 139-44.

38. Liebman S.E. J.G. Taylor and D.A. Bushinsky Idiopathic hypercalciuria. urr Rheumatol Rep 2006. 8(1): p. 70-5.

39. Nieschlag E. et al. Investi ation, treatment, and monitorin of late-onset hypo onadism in males: ISA, ISSAM, and EAU recommendations. J Androl 2006. 27(2): p. 135-7.

40. Hang J.T. et al. Interventions for the prevention of falls in older adults: systematic review and meta-analysis of randomised clinical trials. Bmj 2004. 328(7441): p. 680.

41. Stenvall M. et al. A multidisciplinary, multifactorial intervention pro ram reduces postoperative falls and injuries after femoral neck fracture. Osteoporos Int 2007. 18(2): p. 167-75. 


\section{CHAPTER 6}

Prevalence of morphometric vertebral deformities determined by absorptiometry in patients presenting with a non-vertebral fracture.

Bianca Dumitrescu, Svenhjalmar van Helden, Sjef van der Linden, Gittie Willems, Gabriela Udrea, Rene ten Broeke, Piet Geusens 


\section{ABSTRACT}

Background. Vertebral fractures contribute to further fracture risk and their presence contributes to treatment decisions, but most are not recognized. We determined the prevalence of morphometric vertebral deformities (MVD) in patients presenting with a non-vertebral fracture and evaluated to what degree their presence could influence treatment decisions.

Methods. A prospective study in 695 consecutive consenting patients older than 50 years, presenting with a non-vertebral fracture who underwent morphometric X-ray absorptiometry (MXA) of the thoracic and lumbar spine using the quantitative Genant grading scale.

Results. $30 \%$ had osteoporosis and $27 \%$ had a MVD of $\geq 25 \%$ ( $17 \%$ of patients with normal BMD, $23 \%$ of those with osteopenia and $40 \%$ of those with osteoporosis). Fifty five percent of MVDs of $\geq 25 \%$ were found in patients without osteoporosis. A MVD of 20 to $24 \%$ was found in $22 \%$ of patients, at all levels of BMD. $51 \%$ of patients had no MVD (62\% of patients with normal BMD, $45 \%$ of those with osteopenia and $39 \%$ of those with osteoporosis).

Conclusions. Using MXA, many patients presenting with a non-vertebral fracture had a MVD of $\geq 25 \%$, also in the absence of a low BMD. MXA contributes to identifying patients in whom an X-ray of the spine is indicated to verify the presence of a radiographic morphometric vertebral fracture. This would result in treatment decisions that will be based on a better reflection of the patient's subsequent absolute fracture risk than when such decisions are based on low BMD and clinical risks alone and would provide information to identify pre-existing versus incident vertebral fractures during follow-up. 


\section{INTRODUCTION}

The presence, severity and number of morphometric vertebral fractures (MVF) contribute to fracture risk, from a deformity of $\geq 20 \%$ on and at any level of bone mineral density $(B M D)^{1-12}$. MVF are related to morbidity, decreased quality of life and increased mortality ${ }^{8,13-15}$. Furthermore, a prevalent MVF is an indication for drug treatment, as fracture reduction has been demonstrated in such patients, independent of $\mathrm{BMD}^{16}$.

Although MVF are the fractures with the highest incidence in population studies $^{17,18}$, most patients admitted to the emergency room consult with a non-vertebral fracture ${ }^{19}$. This is, at least partly, because two thirds of all MVF do not present with signs and symptoms of an acute fracture ${ }^{20}$. The majority of these fractures thus go undiagnosed until patients have symptoms or if they are evaluated for the presence of MVF ${ }^{17,18}$.

Patients with a non-vertebral fracture have an increased fracture risk, already within short term and are advised to have a bone densitometry in order to decide about treatment based on the level of BMD, ${ }^{2,321}$. However, most of these patients do not have osteoporosis ${ }^{22,23}$. In guidelines of osteoporosis, patients with a non-vertebral fracture are recommended for drug treatment to reduce fracture risk if their T-score is below a certain BMD threshold ${ }^{16}$.

Semi-quantitative and quantitative measurements of vertebral heights on lateral X-ray images of the spine are considered the standard method for diagnosis of $\mathrm{MVF}^{24}$. X-rays of the spine also allow differential diagnosis from other diseases and other circumstances that are related to changes in the shape of vertebrae, such as normal variations in height. However, there is no golden standard for the definition of $\mathrm{MVF}^{25}$ and no data are available on the presence of radiographic MVF in patients with a non-vertebral fracture.

Morphometric X-ray absorptiometry is yet another, patient convenient, fast, lowradiation, cost-effective method to detect morphometric vertebral deformities $(M V D)^{26,27}$. The negative predictive value of MXA to exclude the presence of radiographic MVF is high, indicating that MXA is a suitable method to evaluate in which patients an X-ray of the spine is indicated to verify the presence of MVF. Recent data indicate that $25 \%$ of 337 patients with a recent low trauma fracture had MVD as measured by MXA , and defined as a deformity of $>20 \%$ using the Genant semi-quantitative grading scale. In that study , $73 \%$ of vertebral fractures were of grade 2 or 3 and $53 \%$ of all vertebral fractures were found in patients without BMD-osteoporosis ${ }^{22}$. The authors concluded that diagnosing MVF in patients with a non-vertebral fracture contributed to treatment decisions 
that better reflected any given patients' future absolute fracture risk. We systematically evaluated the presence of quantitatively measured MVDs in 695 patients older than 50 years of age presenting with a non-vertebral fracture.

\section{PATIENTS AND METHODS}

All consecutive patients older than 50 years who presented at the orthopedic and trauma surgery department of the University Hospital Maastricht in the Netherlands with a fracture that came to clinical attention between September 2004 and March 2006 were proposed an extensive bone- and fall-related fracture risk assessment. This initiative of the Fracture and Osteoporosis Outpatient Clinic was based on the guidelines on osteoporosis and fall prevention of the Dutch Institute for Health Care Improvement ${ }^{28-30}$. It included the evaluation of clinical risks for fractures and measurement of BMD and was extended by MXA. The study was approved by the Medical Ethical Committee of the hospital.

Patients were not included if they died during hospitalization, had dementia, were from other regions than Limburg in the Netherlands, were already on antiosteoporotic treatment or had pathologic fractures, if they declined full evaluation, presented with a clinical vertebral fractures or if MXA could not be performed due to technical difficulties, such as positioning on the DXA table of patients with a humerus fracture.

During the treatment period for the fracture, patients had a consultation with a specialized osteoporosis nurse. Information about the study was provided and patients were invited to join the program. Those who agreed to participate signed an informed consent form. An appointment for bone densitometry and a follow-up consultation were scheduled.

BMD at the left or right hip and the lumbar spine was determined by DXA (Hologic QDR 4500 Elite) and results were expressed as T-scores following to the World Health Organization (WHO) criteria for $\mathrm{BMD}^{31,32}$. Patients were classified according to the lowest value of T-score in either the hip or spine.

MXA by single X-ray absorptiometry of the lateral spine was performed to evaluate the presence of MVD. Images were saved in a digital format. Physician Viewer Software (Hologic, USA) provided the tools to perform quantitative vertebral morphometry. Visual assessment was performed, followed by morphometric indication of the anterior, mid and posterior locations at the upper and lower vertebral plate and measurements of the anterior, posterior and mid heights from T4 to L4 in all patients by a trained rheumatologist (BD). For posterior-posterior ratios the posterior height of the vertebra below was used, 
except for L4 ( $L 4$ had the posterior-posterior calculated using the posterior height of L3). MVDs were defined according to the Genant grading (mild (20$24 \%$ deformity), moderate (25-39\% deformity) and severe (>39\% deformity) $)^{31}$ and classified by type (wedge, biconcave or crush).

During the second consultation with the osteoporosis nurse, risk factors for osteoporosis and for falls were recorded according to the Dutch guidelines ${ }^{27,28}$. Clinical bone-related risk factors for osteoporosis and fractures included previous history of non-vertebral or vertebral fractures, mother with a fracture, body weight $<60 \mathrm{~kg}$, severe immobility and current use of glucocorticoids. Risk factors for falls included two or more falls in the past 12 months, use of assistive devices, sedative medication (benzodiazepines and anti-epileptic drugs), activities of daily living score (ADL), reduced mobility, impaired vision, articular complaints and urinary incontinence. The circumstances of the fracture were specified (fall from standing height or other trauma). A low trauma fracture was defined as a fracture resulting from standing height or less.

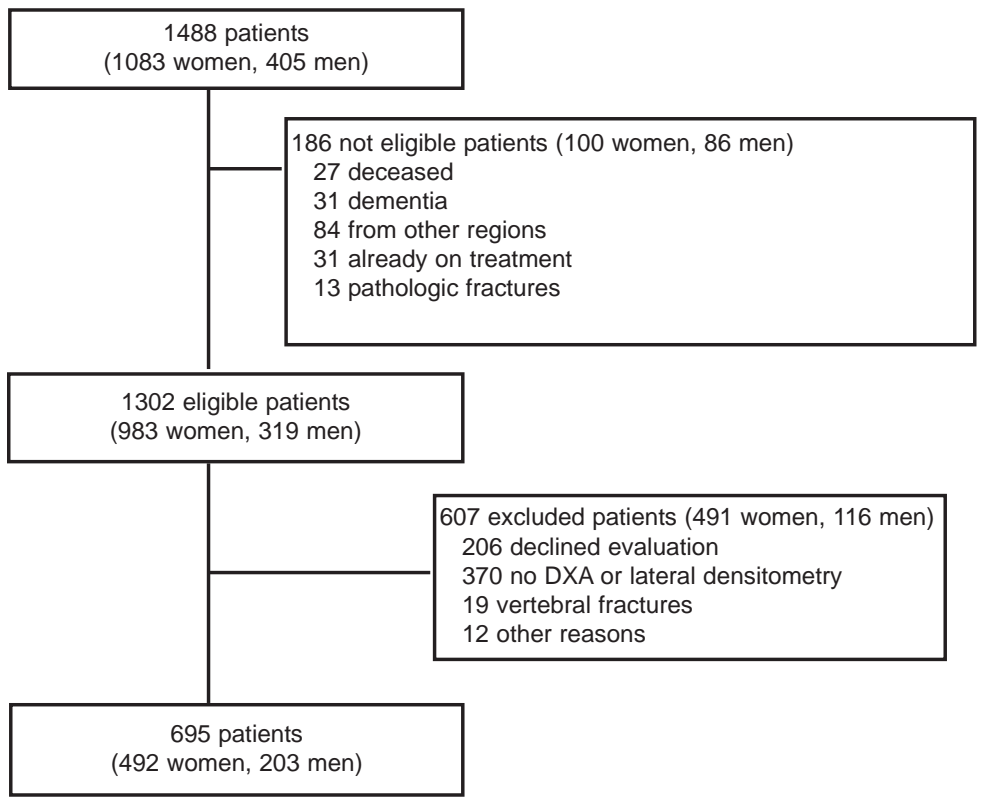

Figure1: Flow chart of patients included in the study 


\section{Statistical analysis}

SPSS version 12.01 and MedCalc version 8.2.1.0 were used for the statistical analysis. Multivariate analyses were conducted to investigate any relationships between clinical fracture risks and MVD. Chi-square test was used for categorical variables. Odd ratios (OR) and 95\% confidence intervals $(\mathrm{Cl})$ were calculated for comparisons between groups. Observations were considered significant if $p$-values were $<0.05$ (two tailed).

\section{RESULTS}

\section{Demographics}

Of the 1488 patients presenting with a clinical fracture, $1302(88 \%)$ patients were eligible. A total of $607(47 \%)$ of the eligible patients was not included for various reasons, resulting in $695(53 \%)$ patients who had full evaluation according to our protocol (Figure1) This group consisted of 492 women and 203 men, with a mean age of 65 years (standard deviation: 10 years, range: $50-95$ years).

Presenting fracture sites were the radius and/or ulna (24\%), tibia/fibula/patella $(16 \%)$, humerus $(14 \%)$, foot $(14 \%)$, hip $(13 \%)$, hand $(10 \%)$, clavicle $(2 \%)$, pelvis $(2 \%)$, thorax $(2 \%)$ rib, sternum and $4 \%$ had multiple simultaneous fractures (Figure 2). In the study group $77 \%$ had a low trauma fracture.

Osteoporosis of the spine and/or hip was found in 209 patients $(30 \%)$, osteopenia in 316 patients (46\%) and normal BMD in 170 patients (24\%).

Lumbar vertebrae were measurable by MXA in $99 \%$ of all patients, thoracic vertebrae in $71 \%$ of all patients (ranging from $27 \%$ at T4 to $98 \%$ at T12) (Figure 3 ). Superposition of ribs and vasculature at the thoracic level were the most important causes for measurement difficulties at the thoracic level.

Any moderate or severe MVD was found in 185 patients (27\%). MVDs included wedge deformities in 162 of patients (88\%), biconcave in 38 patients $(20 \%)$ and crush in 47 patients (25\%).

Any mild MVD was found in 154 patients (22\%). Mild MVDs included were wedge deformities in 107 of patients (70\%), biconcave in 27 patients (18\%) and crush in 35 patients (23\%).

The prevalence and number of all MVDs of $\geq 20 \%$ were similar across the locations of the presenting non-vertebral fracture. This prevalence was $49 \%$ in patients with upper or lower limb fractures and $48 \%$ in patients presenting with other locations. Multiple MVDs were found in $23 \%$ of the patients presenting with upper limb fractures, $22 \%$ of those with lower limb fractures and $25 \%$ of those with others fractures. 


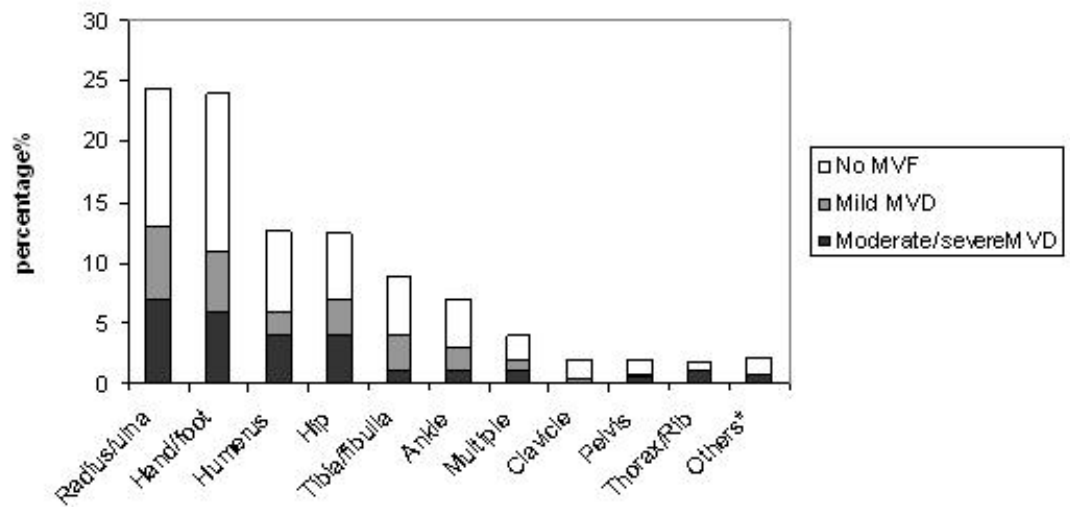

Figure 2: Fracture location and prevalence of morphometric vertebral deformities (MVD) for each type of presenting fracture. ( ${ }^{*}$ others includes olecranon, patella, scapula, shaft of femur)

\section{Measured vertebrae $(\%)$ of all patients}

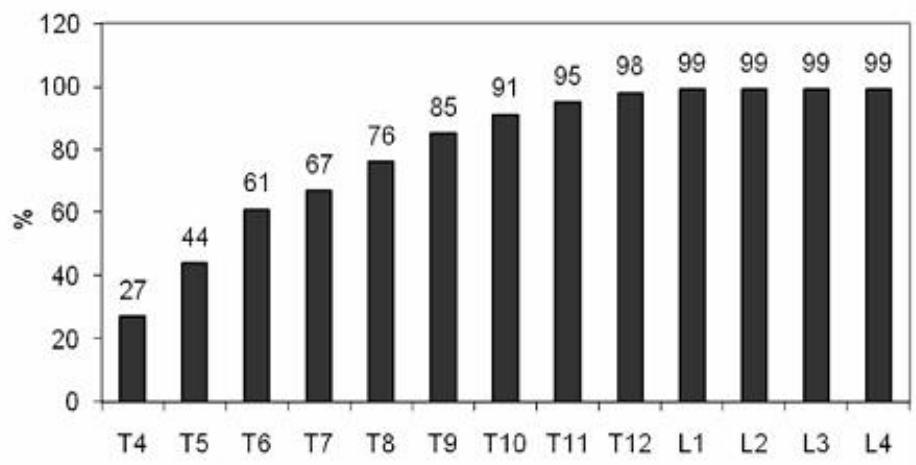

Figure 3: The percentages of all measurable vertrebrae in the total group of patients ( $n=695)$.

The prevalence of MVDs according to their severity differed according to BMD status (Figure 4). Patients with osteoporosis had significantly more of any MVD than patients with a normal BMD (OR: 2.6, Cl: 1.7-3.9, $\mathrm{p}<0.001$ ), mainly by having more moderate and severe MVF (OR: 3.8, Cl: 2.3-6.3, p<0.001).

In a multivariate analysis, MVDs were associated with increasing age (OR: 1.4, Cl: 1.3-1.6 per decade), osteoporosis (OR: 1.8, Cl: 1.2-2.5), clinical bonerelated risks (OR: 1.7, $\mathrm{Cl}: 1.2-2.3)$ and female gender (OR: 1.8, $\mathrm{Cl}: 1.3-2.6)$, but 


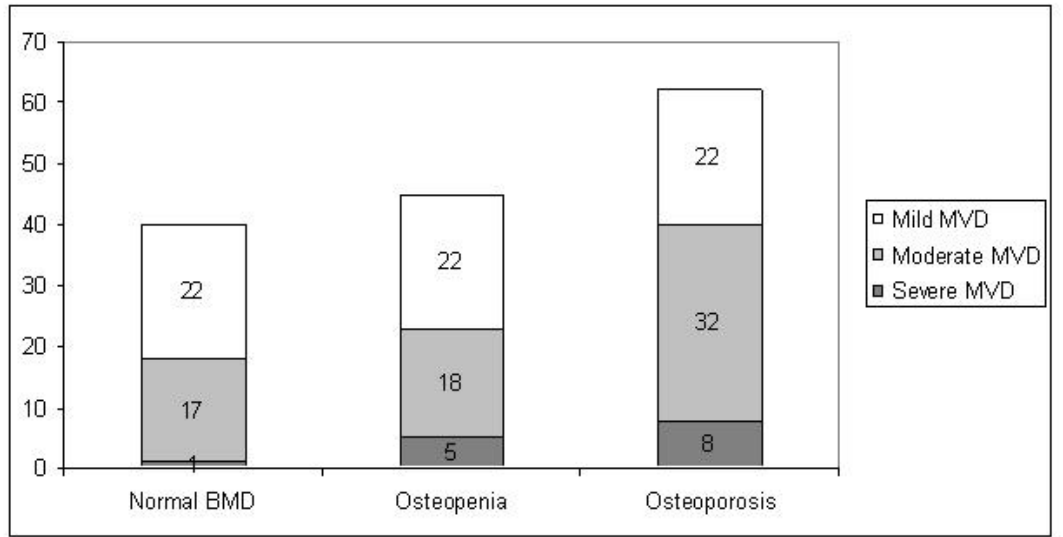

Figure 4:Prevalence of mild, moderate and severe morphometric vertebral deformities (MVD) according to normal BMD, osteopenia and osteoporosis

not with fall-related risks. The severity of MVD was associated with osteoporosis (OR: 2.0, Cl: 1.3-3.2) and fall risks (OR: 2.0, Cl: 1.2-3.3). The number of MVD was only associated with increasing age (OR:1.3, $\mathrm{Cl}$ : 1.1-1.5 per decade).

In the subgroup of non-osteoporotic patients $(n=486)$, multivariate analysis showed that the presence of MVD was associated with increasing age (OR: 1.4, $\mathrm{Cl}$ : 1.2- 1.6 per decade) and female gender (OR:1.6, Cl: 1.1-2.3). The severity of MVD was associated with the presence of fall risks (OR: 1.9, Cl: 1.0-3.6) and the number of MVD only with increasing age (OR: 1.3, Cl: 1.0-1.6 per decade).

In the subgroup of non-osteoporotic patients with a low trauma fracture $(n=359)$, the presence of MVD was associated with increasing age (OR: 1.4, Cl: 1.2-1.6 per decade) and female gender (OR:1.6, Cl:1.0-2.6), but the severity and the number of MVF had no significant predictor.

\section{DISCUSSION}

Among 695 consecutive eligible and consenting patients, presenting with a nonvertebral fracture, $30 \%$ had BMD-osteoporosis in the spine and/or hip and $49 \%$ had a MVD, more than half of which were present in patients without osteoporosis defined by BMD. Of the patients without BMD-osteoporosis, $44 \%$ had one or more MVD.

Patients with a non-vertebral fracture have an increased risk for fractures even at short term and independent of $\mathrm{BMD}^{2,3,33}$. They therefore deserve atten- 
tion for evaluation for osteoporosis and fracture risk according to osteoporosis guidelines ${ }^{16}$. All guidelines advocate measurement of BMD and advocate drug treatment below a certain treatment level of BMD, $\leq-2.5$ in the Dutch guidelines up to $\leq-1.0$ in other guidelines.

As found in other studies, only a minority of these patients had osteoporosis (30\% in our study) and most had osteopenia ( $46 \%$ in our study). This results in a therapeutic challenge for patients presenting with a non-vertebral fracture and having a BMD above the treatment threshold. Identifying patients with MVD substantially increased the number of patients that were candidate for treatment.

Our results were similar to those reported by others who found that half of vertebral fractures were found in patients without BMD-osteoporosis ${ }^{22}$. In that study, the presence of vertebral fractures was evaluated by semi-quantitative visual analysis according to the Genant grading scale. The total number of MVD in our study (49\%) was higher than in Gallacher's study (25\%). One reason was that performing quantitative analysis identifies all patients with a mild fracture in contrast to a semi-quantitative approach. Our numbers of moderate and severe MVF fitted well with the moderate and severe of that study. We did choose the quantitative method because the technique is immediately available on the digital image, the use of quantitative methods provided a valid approach for defining vertebral deformities as found by others and increased identification of high risk patients ${ }^{34-36}$.

The presence of MVDs was difficult to predict. Therefore the results of this study indicate that evaluation for the presence of MVF requires a systematic approach by including imaging of the spine and should be considered in all patients with a recent non-vertebral fracture, as suggested by others ${ }^{22}$.

Another way to calculate the fracture risk in patients is based on clinical risks in addition to BMD and fracture history. The ongoing WHO initiative includes clinical bone-related risk factors for fractures to calculate the absolute 5- and 10 -year fracture risk $^{37}$. Such approach should be helpful in identifying nonosteoporotic patients at high risk being candidate for treatment.

The major limitation of MXA is that Identifying patients with MVD by MXA requires additional $\mathrm{X}$-rays to differentiate deformities due to other conditions, such as Scheuerman's disease ${ }^{38}$, degenerative changes ${ }^{36}$ or non-osteoporotic short vertebral height ${ }^{39}$, especially for mild MVDs. We preferred to use the term MXA for morphometric analysis and not vertebral fracture assessment (VFA), as this last term could suggest that no X-rays would be necessary to diagnose vertebral fractures. Indeed, other studies have indicated that MXA and X-rays can give different information, especially on the nature of the deformity, but also on the degree of deformity ${ }^{40}$. 
However, in view of the high negative predictive value of MXA, this method could be helpful to select patients for $\mathrm{X}$-ray ${ }^{38}$. Additional $\mathrm{X}$-rays of the spine could be restricted to patients in whom not all vertebrae are measurable by MXA and to patients in whom a deformity of $20 \%$ or more is found on MXA.

Other limitations are that only $53 \%$ of eligible patients were fully explored and that not all vertebrae could be measured, especially at the upper thoracic level. These results indicate that in daily clinical practice performing MXA in fracture patients strongly refines future fracture prediction in these patients and increases the number of patients who can be treated.

We conclude that, using MXA, many patients presenting with a non-vertebral fracture had a MVD of $25 \%$, also in the absence of a low BMD. MXA contributes to identifying patients in whom an X-ray of the spine is indicated to verify the presence of a radiographic morphometric vertebral fracture. This would result in treatment decisions that will be based on a better reflection of the patient's subsequent absolute fracture risk than when such decisions are based on low BMD and clinical risks alone. Furthermore it provides information to distinguish preexisting vertebral fractures from incident vertebral fractures during follow up.

\section{REFERENCES}

1. Gallagher JC, Genant HK, Crans GG, Vargas SJ, Krege JH. Teriparatide reduces the fracture risk associated with increasing number and severity of osteoporotic fractures. $J$ Clin Endocrinol Metab. 2005 Mar;90(3):1583-7.

2. Klotzbuecher CM, Ross PD, Landsman PB, Abbott TA, Berger M. : Patients with prior fractures have an increased risk of future fractures: a summary of the literature and statistical synthesis. : J Bone Miner Res. 2000;15(4):721-39.

3. Johnell O, Kanis JA, Odén A, Sernbo I, Redlund-Johnell I, Petterson C, et al.: Fracture risk following an osteoporotic fracture. : Osteoporos Int. 2004;15(3):175-9.

4. Siris ES, Genant HK, Laster AJ, Chen P, Misurski DA, Krege JH. Enhanced prediction of fracture risk combining vertebral fracture status and BMD. Osteoporos Int. 2007 Jun;18(6):761-70.

5. Black DM, Arden NK, Palermo L, Pearson J, Cummings SR. Prevalent vertebral deformities predict hip fractures and new vertebral deformities but not wrist fractures. Study of Osteoporotic Fractures Research Group. J Bone Miner Res. 1999 May;14(5):821-8.

6. Ismail AA, Cockerill W, Cooper C, Finn JD, Abendroth K, Parisi G, et al. Prevalent vertebral deformity predicts incident hip though not distal forearm fracture: results from the European Prospective Osteoporosis Study. Osteoporos Int. 2001;12(2):85-90.

7. Lindsay R, Silverman SL, Cooper C, Hanley DA, Barton I, Broy SB, et al.: Risk of new vertebral fracture in the year following a fracture. : Jama. 2001;285(3):320-3.

8. Hasserius R, Karlsson MK, Nilsson BE, Redlund-Johnell I, Johnell O. Prevalent vertebral deformities predict increased mortality and increased fracture rate in both men and 
women: a 10-year population-based study of 598 individuals from the Swedish cohort in the European Vertebral Osteoporosis Study. Osteoporos Int. 2003 Jan;14(1):61-8.

9. Delmas PD, Genant HK, Crans GG, Stock JL, Wong M, Siris E, et al. Severity of prevalent vertebral fractures and the risk of subsequent vertebral and nonvertebral fractures: results from the MORE trial. Bone. 2003 Oct;33(4):522-32.

10. Lindsay R, Pack S, Li Z. Longitudinal progression of fracture prevalence through a population of postmenopausal women with osteoporosis. Osteoporos Int. 2005 Mar;16(3):306-12.

11. Kanis JA, Johnell O, De Laet C, Johansson H, Oden A, Delmas P, et al. A meta-analysis of previous fracture and subsequent fracture risk. Bone. 2004 Aug;35(2):375-82.

12. Genant HK, Delmas PD, Chen P, Jiang Y, Eriksen EF, Dalsky GP, et al. Severity of vertebral fracture reflects deterioration of bone microarchitecture. Osteoporos Int. 2007 Jan;18(1):69-76.

13. Ismail AA, O'Neill TW, Cooper C, Finn JD, Bhalla AK, Cannata JB, et al. Mortality associated with vertebral deformity in men and women: results from the European Prospective Osteoporosis Study (EPOS). Osteoporos Int. 1998;8(3):291-7.

14. Lips P, Cooper C, Agnusdei D, Caulin F, Egger P, Johnell O, et al. Quality of life in patients with vertebral fractures: validation of the Quality of Life Questionnaire of the European Foundation for Osteoporosis (QUALEFFO). Working Party for Quality of Life of the European Foundation for Osteoporosis. Osteoporos Int. 1999;10(2):150-60.

15. O'Neill TW, Cockerill W, Matthis C, Raspe HH, Lunt M, Cooper C, et al. Back pain, disability, and radiographic vertebral fracture in European women: a prospective study. Osteoporos Int. 2004 Sep;15(9):760-5.

16. Geusens PP. Review of guidelines for testing and treatment of osteoporosis. Curr Osteoporos Rep. 2003 Sep;1(2):59-65.

17. Cooper C, O'Neill T, Silman A. The epidemiology of vertebral fractures. European Vertebral Osteoporosis Study Group. Bone. 1993;14 Suppl 1:S89-97.

18. Incidence of vertebral fracture in europe: results from the European Prospective Osteoporosis Study (EPOS). J Bone Miner Res. 2002 Apr;17(4):716-24.

19. Gallacher SJ. Setting up an osteoporosis fracture liaison service: background and potential outcomes. Best Pract Res Clin Rheumatol. 2005 Dec;19(6):1081-94.

20. Cooper C, Atkinson EJ, O'Fallon WM, Melton LJ, 3rd. Incidence of clinically diagnosed vertebral fractures: a population-based study in Rochester, Minnesota, 1985-1989. J Bone Miner Res. 1992 Feb;7(2):221-7.

21. van Helden S, Cals J, Kessels F, Brink P, Dinant GJ, Geusens P. Risk of new clinical fractures within 2 years following a fracture. Osteoporos Int. 2006 Mar;17(3):348-54.

22. Gallacher SJ, Gallagher AP, McQuillian C, Mitchell PJ, Dixon T. The prevalence of vertebral fracture amongst patients presenting with non-vertebral fractures. Osteoporos Int. 2007 Feb;18(2):185-92.

23. McLellan AR, Gallacher SJ, Fraser M, McQuillian C. The fracture liaison service: success of a program for the evaluation and management of patients with osteoporotic fracture. Osteoporos Int. 2003 Dec;14(12):1028-34.

24. Genant HK. Assessment of vertebral fractures in osteoporosis research. J Rheumatol. 1997 Jun;24(6):1212-4. 
25. Grados F, Roux C, de Vernejoul MC, Utard G, Sebert JL, Fardellone P. Comparison of four morphometric definitions and a semiquantitative consensus reading for assessing prevalent vertebral fractures. Osteoporos Int. 2001;12(9):716-22.

26. Schousboe JT, Ensrud KE, Nyman JA, Kane RL, Melton LJ, 3rd. Cost-effectiveness of vertebral fracture assessment to detect prevalent vertebral deformity and select postmenopausal women with a femoral neck T-score -2.5 for alendronate therapy: a modeling study. J Clin Densitom. 2006 Apr-Jun;9(2):133-43.

27. Genant HK, Li J, Wu CY, Shepherd JA. Vertebral fractures in osteoporosis: a new method for clinical assessment. J Clin Densitom. 2000 Fall;3(3):281-90.

28. CBO kvdg. Osteoporose. Tweede herziene richtlijn 2002. available at : http://wwwcbonl/product/richtlijnen/folder20021023121843/osteoporosepdf/view.accessed august 17, 2005.

29. CBO kvdg. Preventie van valincidenten bij ouderen 2004. . available at: http://wwwcbonl/product/richtlijnen/folder20021023121843/val-richtlijn2004pdf/view.accessed june 5, 2006.

30. Geusens PP, Lems WF, Verhaar HJ, Leusink G, Goemaere S, Zmierczack H, et al. Review and evaluation of the Dutch guidelines for osteoporosis. J Eval Clin Pract. 2006 Oct;12(5):539-48.

31. Prevention and management of osteoporosis. World Health Organ Tech Rep Ser. 2003;921:1-164, back cover.

32. Assessment of fracture risk and its application to screening for postmenopausal osteoporosis. Report of a WHO Study Group. World Health Organ Tech Rep Ser. 1994;843:1-129.

33. van Helden S, Wyers CE, Dagnelie PC, van Dongen MC, Willems G, Brink PR, et al. Risk of falling in patients with a recent fracture. BMC Musculoskelet Disord. 2007;8:55.

34. Black DM, Palermo L, Nevitt MC, Genant HK, Epstein R, San Valentin R, et al. Comparison of methods for defining prevalent vertebral deformities: the Study of Osteoporotic Fractures. J Bone Miner Res. 1995 Jun;10(6):890-902.

35. Olenginski TP, Newman ED, Hummel JL, Hummer M. Development and evaluation of a vertebral fracture assessment program using IVA and its integration with mobile DXA. J Clin Densitom. 2006 Jan-Mar;9(1):72-7.

36. Roux C, Fechtenbaum J, Kolta S, Briot K, Girard M. Mild prevalent and incident vertebral fractures are risk factors for new fractures. Osteoporos Int. 2007 Dec;18(12):1617-24.

37. Kanis JA, Borgstrom F, De Laet C, Johansson $H$, Johnell $O$, Jonsson B, et al. Assessment of fracture risk. Osteoporos Int. 2005 Jun;16(6):581-9.

38. Lewiecki EM, Laster AJ. Clinical review: Clinical applications of vertebral fracture assessment by dual-energy X-ray absorptiometry. J Clin Endocrinol Metab. 2006 Nov;91(11):4215-22.

39. Ferrar L, Jiang G, Armbrecht G, Reid DM, Roux C, Gluer CC, et al. Is short vertebral height always an osteoporotic fracture? The Osteoporosis and Ultrasound Study (OPUS). Bone. 2007 Jul;41(1):5-12.

40. Vosse D, Heijckmann C, Landewe R, van der Heijde D, van der Linden S, Geusens P. Comparing morphometric X-ray absorptiometry and radiography in defining vertebral wedge fractures in patients with ankylosing spondylitis. Rheumatology (Oxford). 2007 Nov;46(11):1667-71. 


\section{CHAPTER 7}

Risk of falling in patients with a recent fracture

Svenhjalmar van Helden, Caroline E Wyers, Pieter C Dagnelie, Martien C van Dongen, Gittie Willems, Peter RG Brink and Piet P Geusens

BMC Musculoskeletal Disorders 2007, 8:55 


\section{ABSTRACT}

Background: Patients with a history of a fracture have an increased risk for future fractures, even in short term. The aim of this study was to assess the number of patients with falls and to identify fall risk factors that predict the risk of falling in the first three months after a clinical fracture.

Methods: Prospective observational study with 3 months of follow-up in a large European academic and regional hospital. In 277 consenting women and men aged $\geq 50$ years and with no dementia and not receiving treatment for osteoporosis who presented to hospital with a clinical fracture, fall risk factors were assessed according to the guidelines on fall prevention in the Netherlands. Follow-up information on falls and fractures was collected by monthly telephone interview. Incidence of falls and odds ratio's (OR, with 95\% confidence intervals) were calculated.

Results: 512 consecutive patients with a fracture were regarded for analysis, 87 were not eligible for inclusion and 137 patients were excluded. No follow-up data were available for 11 patients. Therefore full analysis was possible in 277 patients. A new fall incident was reported by 42 patients (15\%), of whom five had a fracture. Of the 42 fallers, 32 had one new fall and 10 had two or more.

Multivariate analysis in the total group with sex, age, ADL difficulties, urinary incontinence and polypharmacy showed that sex and ADL were significant fall risk factors. Women had an OR of $3.02(95 \% \mathrm{Cl} 1.13-8.06)$ and patients with ADL-difficulties had an OR of $2.50(95 \% \mathrm{Cl} 1.27-4.93)$. Multivariate analysis in the female group with age, ADL difficulties, polypharmacy and presence of orthostatic hypotension indicated that polypharmacy was the predominant risk factor (OR $2.51 ; 95 \% \mathrm{Cl}: 1.19-5.28$ ). The incidence of falls was $35 \%$ in women with low ADL score and polypharmacy compared to $15 \%$ in women without these risk factors (OR 3.56: $\mathrm{Cl} 1.47-8.67$ ).

Conclusion: $15 \%$ of patients reported a new fall and 5 patients suffered a new fracture within 3 months. Female sex and low ADL score were the major risk factors and, in addition, polypharmacy in women. 


\section{BACKGROUND}

A history of fracture indicates a risk for future fractures. The absolute risk for fractures is highest in the first year after a clinical fracture (fracture with symptoms urging the patient to look for medical attention) ${ }^{1}$. Therefore, the prevention of new fractures should be a part of post-fracture treatment. Fall prevention interventions have been shown not only to reduce certain risk factors for falling, but also have successfully reduced falls ${ }^{2}$. No fall prevention intervention study so far has been large enough to determine whether reducing falls will also reduce the number of fractures.

One third of the people aged 65 years and above fall every year and in one to five percent the fall results in a fracture ${ }^{3-8}$. The prevalence of falls increases with age, and more in women than in men. It is expected that the number of persons who fall and the number of fractures will increase due to the sharp rising in the ageing population. Hip fractures, vertebral fractures and wrist fractures are the most common fractures, but most of the other fractures after the age of 50 are also associated with osteoporosis and falls ${ }^{8-10}$. Fractures after menopause and in elderly can have severe consequences in terms of mortality and morbidity, including admission to hospital or to a nursing home and a decrease in quality of life $e^{6,7,9,11}$.

Previous research identified the following fall risk factors: age of 65 years and above, female sex, mobility problems, previous falls, muscle weakness, visual impairment, disturbances of the equilibrium, low bone mineral density, multimedication use such as sedatives, previous fractures, low grip strength, low physical activity, impaired activities of daily living, depression, cognitive impairment, use of assistive devices, urinary incontinence, Parkinson's disease, fear of falling, living in a nursing home, diabetes mellitus, high blood pressure, orthostatic hypotension and others ${ }^{5-9,12,13,10,14-23}$. Certain fall risk factors are modifiable to prevent falls, including visual impairment, physical activity, mobility, and muscle strength $^{13}$. The fall risk factors examined in this study are used as predictors of new falls after a recent clinical fracture. To our knowledge there are no previous studies where fall risk factors were analysed in a cohort of fracture patients.

The aim of this study was to assess the number of patients with falls within 3 months after a recent clinical fracture, and to identify fall risk factors that predict the risk of falling within 3 months after a recent clinical fracture. 


\section{METHODS}

\section{Study design and participants}

In September 2004, based on the guideline of the Dutch Institute for Health Care Improvement (CBO) on osteoporosis and the guideline on fall prevention, a large European hospital initiated a fracture and osteoporosis outpatient clinic in which fracture patients aged 50 years and above are investigated for osteoporosis $[8,10]$. The aim of the outpatient clinic is to improve the care of patients with a clinical fracture, to diagnose osteoporosis, and to determine fall risk in fracture patients. Patients who present with a fracture either at the emergency department, at the outpatients clinic or who are hospitalized because of a facture were invited to the fracture and osteoporosis outpatient clinic.

For the present study, all patients with a clinical fracture that visited the hospital for fracture treatment between April and September 2005 were invited to participate. During the first consultation, the nurse specialized in osteoporosis and fall risk assessment informed and invited every patient individually. If the patient agreed to participate in the study, an informed consent form was signed and handed over to the osteoporosis nurse. The second consultation was combined with a dual-energy xray absorptiometry (DXA) measurement. During the second visit, patients were informed about the results of the DXA scan and anamnesis for fracture and fall risk assessment were performed. Patients were included if they were willing to undergo 1) a fall risk assessment and 2) a bone mineral density (BMD) measurement by DXA. Patients were excluded for the following reasons: not completing one of both assessments (fall risk and DXA), deceased, established dementia written down in medical history, living in another region, having a pathological (non - osteoporotic) fracture, no informed consent or no show on DXA appointment. Patients already receiving adequate treatment for osteoporosis were not invited to attend the fracture and osteoporosis clinic where the recruitment for the study occurred. The study was approved by the medical ethical committee of the hospital.

\section{Follow-up and outcome assessment}

Follow-up information on falls and fractures was collected by telephone interview, performed monthly for 3 months after the fracture. This three-month period was chosen to evaluate fall risk in the recovery period of the fracture. The osteoporosis nurse asked whether the patient had a fall, and if so, the number and timing of falls and whether the fall resulted in a fracture.

The primary outcome of this study is the incidence of patients who had a fall within the three months of follow up. Falls were defined as unintentional events 
which result in a person coming to rest on the floor or a lower level $8,9,22,24$. People who had fallen were classified as a faller or a recurrent faller. A faller was defined as someone who had fallen at least once within 3 months of follow-up, and a recurrent faller as someone who had fallen twice or more within 3 months of follow-up.

\section{Measurements of risk factors}

Fall risk was assessed by measuring balance, mobility, lower limb muscle strength, handgrip strength, cognitive status, activities of daily living, visual impairment and general measurement such as blood pressure. These risk factors were chosen based on their description in the Dutch guideline for prevention of falls in the elderly ${ }^{8}$. Balance was evaluated by the Four-Test Balance Scale, in which the patient was asked to perform feet together stand, semi-tandem stand, tandem stand and one leg stand ${ }^{25}$. If the patient was not able to hold at least one of these positions for 10 seconds, this counted as one fall risk.

Mobility was assessed by the Timed Get Up and Go Test, in which the patient is asked to rise from a chair, walk 3 meters, turn, walk back and sit down in the chair. If the patient was not able to perform the test within 12 seconds this was regarded as a reduced mobility and increased fall risk ${ }^{26,27}$.

Lower limb muscle strength was measured by the Chair Stand Test. In this test, the patient was asked to rise up and sit down from a chair as quickly as possible five times, while not using their arms if possible. If the patient was not able to complete the test within two minutes this was regarded as a fall risk ${ }^{28}$.

Handgrip strength was measured by the Jamar dynamometer (Jamar, Irvington, NY). The patient was asked to squeeze two times on a handgrip strength indicator with both hands separately. For each hand the maximum score (in $\mathrm{kg}$ ) was added up. If people squeezed with only one hand, the score of the other hand was replaced by the mean of the group that squeezed with both hands taking sex and dominant hand into account. For women, the cutoff point was $<30 \mathrm{~kg}$, for men the cut-off point was $<50 \mathrm{~kg}^{29}$.

The Abbreviated Mental Test, a questionnaire to test the cognitive status, was used to assess if patients were cognitive impaired. The cut-off point of this test is 8 (range: $0-10$ ), with a score less than 8 suggesting abnormal cognitive functioning ${ }^{30,31}$. The Groningen Activity Restriction Scale (GARS) was used to test disability in activities of daily living (ADL) ${ }^{32}$.

Patients were asked to answer the questions regarding their abilities just before the fracture. The patient was considered as having a fall risk if he or she had difficulties with a least two out of the three following questions of GARS: a) Can you, fully independently, go up and down the stairs; b) Can you, fully inde- 
pendently, walk outdoors (if necessary with a cane); and c) Can you, fully independently, take care of your feet and toenails? Visual impairment was measured by the Snellen eye chart. Patients viewed the eye chart at a distance of 3 meters. If the visual acuity was less than 0.4 , the patient was regarded as visually impaired and having a fall risk ${ }^{33,34}$.

Blood pressure was measured to determine if orthostatic hypotension was present ${ }^{35}$. It was measured both in lying and standing position (after one minute). Further, patients were asked for previous falls in the past 12 months, the ability to keep their balance, problems with walking, difficulties with rising from a chair, difficulties with dressing and undressing, the use of psychofarmaca, polypharmacy (taking 5 or more pills per day), osteoarthritis (patients were asked for previous medical attention for arthrosis of especially the joint in the lower limb), urinary incontinence (patient was asked for involuntary loss of urine), difficulties with reading the newspaper, and depression.

\section{Statistical analysis}

Statistical analyses were performed using SPSS for Windows version 12.0.1. Individuals without falls were compared with those with falls. First, univariate logistic regression models were fitted with all individual fall risk factors for the total group and women. If a risk factor had an Odds Ratio $(O R) \geq 2.0$ it was retained for subsequent multivariate analysis.

The logistic regression analysis was fitted by the "Forward Likelihood Ratio" method. To identify the relationship between the fall risk factors and falling, OR's and 95\% confidence intervals were calculated. Interaction was tested for all significant variables resulting from the univariate analysis.

\section{RESULTS}

During an inclusion period of 6 months, 512 patients over the age of 50 with a clinical fracture visited the emergency department or the outpatient clinic (Figure 1). Of

those patients, 87 were not eligible for inclusion. Of the resulting 425 patients who where eligible for inclusion, 137 patients were excluded for various reasons. No follow-up data were available for 11 patients. As a result, 277 patients were included with a total of 286 clinical fractures at baseline (inclusion rate $65.2 \%$ of all eligible patients). A fall from maximum standing height as the cause of the fracture was reported by 246 patients $(88.8 \%)$.

In this study the majority of patients were women (A fall within 3 months after a recent clinical fracture was reported by 42 of the patients $(15.2 \%)$; the num- 
ber of women with a fall was higher than the number of men (respectively 37 [18.5\%] and 5 [6.5\%]; $p=0.013$ ). Of the 42 fallers, 10 were recurrent fallers. The fall rate was 1.5 falls/patient year. In 5 patients a fall resulted in a fracture.

Mean age of female fallers was 69.9 years (range: $51-86$ ), and 66.6 years in male fallers (range: $51-78)(p=0.069)$.

All fallers reported that their baseline clinical fracture was the result of a fall from maximum standing height (Table 1). One in two fallers had difficulties with ADL before the clinical fracture, compared with one in four of the patients who had no falls during the follow-up $(p=0.003)$. The other characteristics were not significantly different between fallers and non-fallers (Table 1). At least one fall risk factor was present in $84 \%$ of the patients, $76(27 \%)$ had one fall risk factors, $62(22 \%)$ had two, $47(17 \%)$ three, and $49(18 \%)$ had four or more fall risk factors (table 2).

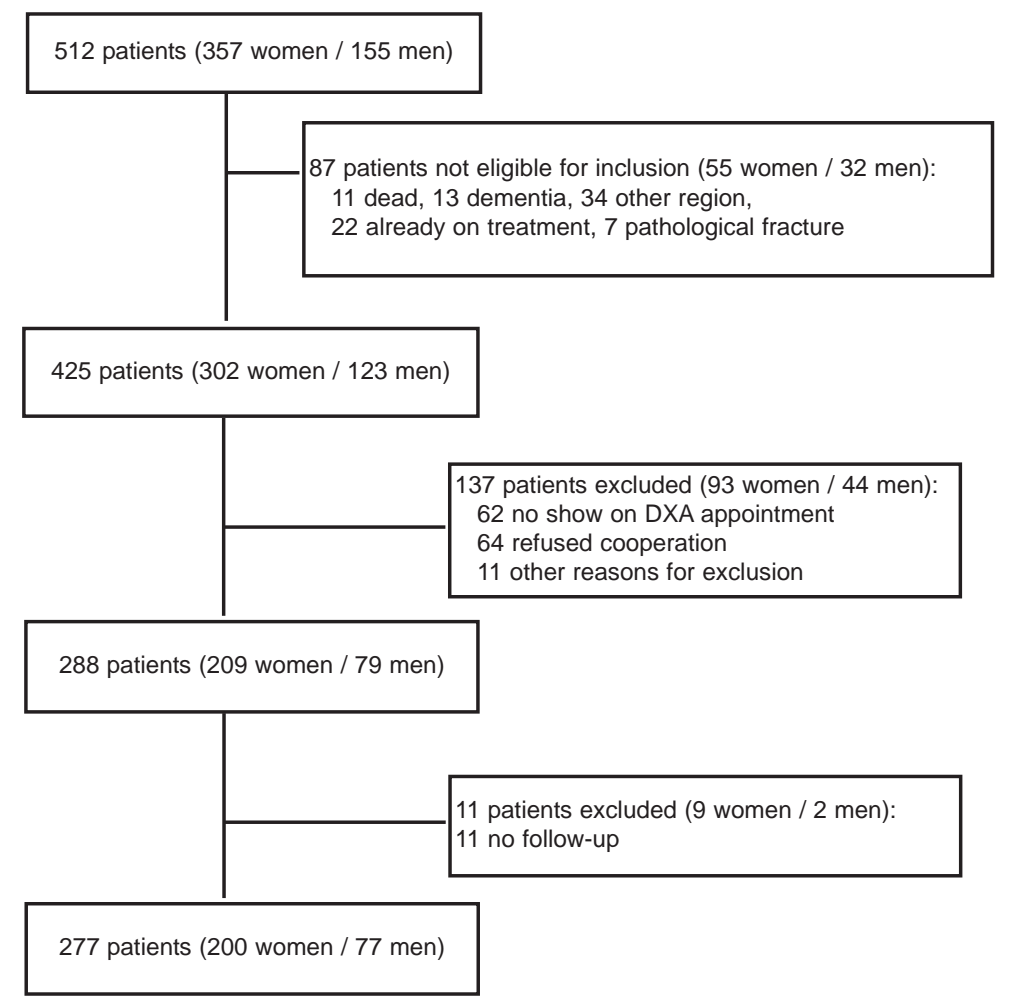

Figure 1. Flowchart with inclusion and exclusion of study participants 
Table 1: Characteristics of Study Population

\begin{tabular}{|c|c|c|c|c|c|c|c|}
\hline Characteristic & $\begin{array}{c}\text { Total group } \\
(\mathrm{n}=277) \\
\%\end{array}$ & $\mathrm{n}$ & $\begin{array}{c}\text { Fallers } \\
(n=42) \\
\%\end{array}$ & $\mathrm{n}$ & $\begin{array}{c}\text { Non fallers } \\
(\mathrm{n}=235) \\
\%\end{array}$ & $\mathrm{n}$ & p-value \\
\hline Sex (female) & 72 & 200 & 88 & 37 & 69 & 163 & $0.013^{*}$ \\
\hline Age, mean (range) years & $67.1(50-91)^{\dagger}$ & & $69.9(51-86)^{\dagger}$ & & $66.6(50-91)^{\dagger}$ & & 0.069 \\
\hline Living at home & 93 & 254 & 91 & 38 & 94 & 216 & 0.478 \\
\hline Low energy trauma & 89 & 246 & 100 & 42 & 87 & 204 & $0.012^{*}$ \\
\hline \multicolumn{8}{|l|}{ Bone Mineral Density $\S$} \\
\hline Normal (Tscore > -1) & 24 & 61 & 19 & 7 & 25 & 54 & 0.438 \\
\hline $\begin{array}{l}\text { Osteopenia (Tscore } \leq-1 \text { and } \\
>-2.5 \text { ) }\end{array}$ & 47 & 119 & 47 & 17 & 47 & 102 & 0.945 \\
\hline Osteoporosis (Tscore $\leq-2.5$ ) & 29 & 72 & 33 & 12 & 28 & 60 & 0.323 \\
\hline Weight, mean (range) kg & $71.8(40-120)^{\dagger}$ & & $71.9 \underset{+}{(45-115)}$ & & $71.8(40-120)^{\dagger}$ & & 0.945 \\
\hline \multicolumn{8}{|l|}{ Fracture type } \\
\hline Upper extremity & 43 & 119 & 36 & 15 & 44 & 104 & 0.430 \\
\hline Lower extremity & 48 & 134 & 57 & 24 & 47 & 110 & 0.305 \\
\hline Trunk & 5 & 15 & 5 & 2 & 6 & 13 & 0.922 \\
\hline Multiple fractures & 3 & 9 & 2 & 1 & 3 & 8 & 0.899 \\
\hline Diabetes & 17 & 47 & 24 & 10 & 16 & 37 & 0.200 \\
\hline Orthostatic hypotension ** & 12 & 33 & 19 & 8 & 11 & 25 & 0.235 \\
\hline \multicolumn{8}{|l|}{ Medication } \\
\hline Antihypertensive & 32 & 89 & 41 & 17 & 31 & 72 & 0.337 \\
\hline Benzodiazepines & 9 & 26 & 14 & 6 & 9 & 20 & 0.473 \\
\hline Antidepressive & 9 & 26 & 12 & 5 & 9 & 21 & 0.750 \\
\hline Anti-rheumatics & 5 & 13 & 7 & 3 & 4 & 10 & 0.649 \\
\hline \multicolumn{8}{|l|}{ Fall risk factors } \\
\hline Mobility (TGUGT) ${ }^{\ddagger}$ & 59 & 164 & 71 & 30 & 57 & 134 & 0.080 \\
\hline$\geq 2$ falls in previous year ${ }^{\ddagger}$ & 30 & 84 & 43 & 18 & 28 & 66 & 0.055 \\
\hline Use of benzodiazepines ${ }^{\ddagger}$ & 10 & 28 & 10 & 4 & 10 & 24 & 0.891 \\
\hline ADL difficulties ${ }^{\ddagger}$ & 31 & 85 & 50 & 21 & 27 & 64 & $0.003^{*}$ \\
\hline Osteoarthritis $^{\ddagger}$ & 34 & 95 & 31 & 13 & 35 & 82 & 0.620 \\
\hline Visual impairment $^{\ddagger}$ & 18 & 50 & 24 & 10 & 17 & 40 & 0.292 \\
\hline Urinary incontinence ${ }^{\ddagger}$ & 18 & 50 & 29 & 12 & 16 & 38 & 0.054 \\
\hline Parkinson's disease ${ }^{\ddagger}$ & 1 & 2 & 0 & 0 & 1 & 2 & 0.548 \\
\hline
\end{tabular}

* significant: $p<.05$

$\S$ results of 252 subjects

** $(20 \mathrm{mmHg}$ drop in systolic BP and/or $10 \mathrm{mmHg}$ drop in diastolic BP 1 minute after standing)

$\dagger$ Mean (range)

‡ Fall risk factor according to the Dutch guideline on fall prevention (TGUGT: Timed Get Up and Go Test: cut off at 12 seconds; ADL difficulties: fall risk if he or she had difficulties with a least two out of the three following questions of Gronigen Activity Restriction Scale: a) Can you, fully independently, go up and down the stairs; b) Can you, fully independently, walk outdoors (if necessary with a cane); and c) Can you, fully independently, take care of your feet and toenails?; Visual impairment: cut off at visual acuity less than 0.4 ; 
Table 2: Fall risk factors predicting the risk of falling within 3 months after a fracture: univariate analysis

\begin{tabular}{|c|c|c|c|c|}
\hline & & $\begin{array}{l}\text { Total } \\
n=277)\end{array}$ & & $\begin{array}{l}\text { Nomen } \\
n=200)\end{array}$ \\
\hline & $\mathrm{OR}^{*}$ & $95 \% \mathrm{Cl}$ & $\mathrm{OR}^{*}$ & $95 \% \mathrm{Cl}$ \\
\hline Sex (female) & 3.27 & $1.23-8.66$ & - & - \\
\hline Age (80+ yrs vs. $50-59)$ & 3.55 & $1.30-9.65$ & 2.88 & $0.99-8.40$ \\
\hline Mobility (TGUGT) & 1.88 & $0.92-3.86$ & 1.75 & $0.79-3.85$ \\
\hline$\geq 2$ falls in previous year ${ }^{\dagger}$ & 1.92 & $0.98-3.77$ & 1.76 & $0.86-3.64$ \\
\hline Use of benzodiazepines $^{\dagger}$ & 0.93 & $0.30-2.82$ & 1.11 & $0.35-3.55$ \\
\hline ADL difficulties ${ }^{\dagger \ddagger}$ & 2.67 & $1.37-5.22$ & 2.20 & $1.07-4.56$ \\
\hline Arthrosis $^{\dagger}$ & 0.84 & $0.41-1.70$ & 0.61 & $0.28-1.31$ \\
\hline Visual impairment $^{\dagger}$ & 1.52 & $0.69-3.35$ & 1.03 & $0.42-2.58$ \\
\hline Urinary incontinence $^{\dagger}$ & 2.07 & $0.98-4.41$ & 1.49 & $0.67-3.31$ \\
\hline Polypharmacy ( $>5$ pills / day) & 2.58 & $1.30-5.10$ & 2.51 & $1.19-5.28$ \\
\hline Orthostatic hypotension ${ }^{\ddagger}$ & 1.98 & $0.82-4.74$ & 2.22 & $0.88-5.60$ \\
\hline Cognitive impairment ${ }^{\ddagger}$ & 1.67 & $0.76-3.69$ & 1.33 & $0.55-3.21$ \\
\hline Handgrip strength ${ }^{\ddagger}$ & 1.95 & $0.94-4.05$ & 1.46 & $0.64-3.31$ \\
\hline FTBS feet together ${ }^{\ddagger}$ & 1.43 & $0.71-2.89$ & 1.48 & $0.68-3.21$ \\
\hline FTBS semi-tandem stand ${ }^{\ddagger}$ & 1.55 & $0.77-3.11$ & 1.61 & $0.75-3.45$ \\
\hline FTBS tandem stand $^{\ddagger}$ & 1.36 & $0.70-2.64$ & 1.39 & $0.68-2.85$ \\
\hline FTBS one leg stand $^{\ddagger}$ & 1.83 & $0.91-3.70$ & 1.79 & $0.81-3.95$ \\
\hline Chair stand test ${ }^{\ddagger}$ & 1.66 & $0.85-3.26$ & 1.77 & $0.85-3.68$ \\
\hline
\end{tabular}

*Values presented are crude OR's, significant OR's are printed in bold.

†Fall risk factors according to the Dutch guideline on fall prevention.

¥Abbreviations and cut off values: Timed Get Up and Go Test (TGUGT) cut off at 12 seconds.

Activities of Daily Living (ADL) difficulties: fall risk if he or she had difficulties with a least two out of the three following questions of Groningen Activity Restriction Scale: a) Can you, fully independently, go up and down the stairs; b)

Can you, fully independently, walk outdoors (if necessary with a cane); and c) Can you, fully independently, take care of your feet and toenails?

Visual impairment: cut off at visual acuity less than 0.4 .

Orthostatic hypotension: $20 \mathrm{mmHg}$ drop in systolic BP and/or $10 \mathrm{mmHg}$ drop in diastolic BP 1 minute after standing. Cognitive impairment : Abbreviated Mental Test score $\leq 8$.

Handgrip strength : For women, the cut-off point was $<30 \mathrm{~kg}$, for men the cut-off point was $<50 \mathrm{~kg}$.

Four Test Balance Scale (FTBS): If the patient was not able to hold at least one of these positions for 10 seconds, this counted as one fall risk.;

Chair stand test: If the patient was not able to complete the test within two minutes this was regarded as a fall risk.

Univariate analysis was carried out for 15 fall risk factors (Table 2). Significant fall risk factors for the total population were sex (OR 3.27/women vs. men; $95 \% \mathrm{Cl}$ 1.23-8.66), age (OR 3.55/80 + vs. 50-59 years; 95\% Cl 1.30-9.65), ADL-problems vs. no ADL problems (OR 2.67; 95\% Cl 1.37-5.22), and polypharmacy vs. no polypharmacy (use of $\geq 5$ pills per day) (OR 2.58; $95 \% \mathrm{Cl} 1.30-5.10)$. In women, ADL difficulties (OR 2.20;95\% Cl 1.07-4.56) and polypharmacy (use of $\geq 5$ pills per day) (OR $2.51 ; 95 \% \mathrm{Cl} 1.19-5.28)$ were significant fall risk factors. 
Multivariate analysis in the total group with sex, age, ADL difficulties, urine incontinence and polypharmacy showed that sex and ADL were significant fall risk factors.

Women had an OR of $3.02(95 \% \mathrm{Cl} 1.13-8.06)$ and patients with ADL-difficulties had an OR of 2.50 (95\% Cl 1.27-4.93).

Multivariate analysis in the female group with age, ADL difficulties, polypharmacy and presence of orthostatic hypotension indicated that polypharmacy was the predominant risk factor (OR 2.51; 95\% Cl: $1.19-5.28$ ). The incidence of falls was $35 \%$ in women with polypharmacy and low ADL score. This risk of falls was three times higher than in women without polypharmacy and with normal ADL score. (OR 3.56; 95\% Cl 1.47-8.67).

\section{DISCUSSION}

In this study of people over 50 presenting with a fracture, who were not already on osteoporosis treatment, who are not demented and who were able to give informed consent, the incidence of patients with a fall within three months after a clinical fracture was $18.5 \%$ in women and $6.5 \%$ in men. In $11.9 \%$ the fall resulted in a new fracture. The predominant fall risk factors that predicted a new fall were sex and difficulties in ADL in the total group. In line with other studies, women more often experienced a new fall compared to $\mathrm{men}^{3-8}$. Nearly one in three women with polypharmacy as a risk factor had a new fall, compared with one in ten women without this risk factor. The sample was too small to detect differences in fracture.

This study has several limitations. The male group was to small for separate analysis. The information of the main outcome variable, i.e. falls during followup, relied on patients recall of falls, so the possibility of incomplete or biased reports of falls cannot be excluded.

The sample may not be completely typical in view of the various exclusion criteria. Only significant risk factors chosen to measure were described, which by definition can not be exhaustive and some of these assessments were not of the kind that could be carried out within routine clinical practice, but only in a research context. The follow-up period of three months was short but chosen to evaluate fall risk in the time patients were recovering from their fracture.

Based on the results of our study, a health care provider can identify patients with the highest risk of falls after a fracture examining ADL in all patients, and polypharmacy in women. 
Future studies should be large enough to include sufficient numbers of men and perform subgroup analysis on different ages. Eventually a very large cohort analysis with fracture risk as endpoint would be most interesting.

\section{CONCLUSION}

Patients with a recent clinical fracture have a high risk for new falls. In a group of 277 patients, $15 \%$ reported a new fall and 5 patients suffered a new fracture within 3 months. Female sex and low ADL score were the major risk factors and, in addition, polypharmacy in women.

\section{REFERENCES}

1. van Helden S, Cals J, Kessels F, Brink P, Dinant GJ, Geusens P: Risk of new clinical fractures within 2 years following a fracture. Osteoporos Int 2006, 17(3):348-354.

2. Gillespie LD, Gillespie WJ, Robertson MC, Lamb SE, Cumming RG, Rowe BH: Interventions for preventing falls in elderly people. Cochrane Database Syst Rev 2003:CD000340.

3. Nevitt MC, Cummings SR, Kidd S, Black D: Risk factors for recurrent nonsyncopal falls. A prospective study. Jama 1989, 261(18):2663-2668.

4. Tinetti ME, Speechley M, Ginter SF: Risk factors for falls among elderly persons living in the community. N Engl J Med 1988, 319(26):1701-1707.

5. Tromp AM, Smit JH, Deeg DJ, Bouter LM, Lips P: Predictors for falls and fractures in the Longitudinal Aging Study Amsterdam. J Bone Miner Res 1998, 13(12):1932-1939.

6. Bloem BR, Boers I, Cramer M, Westendorp RG, Gerschlager W: Falls in the elderly. I. Identification of risk factors. Wien Klin Wochenschr 2001, 113(10):352-362.

7. Schwartz AV, Villa ML, Prill M, Kelsey JA, Galinus JA, Delay RR, Nevitt MC, Bloch DA, Marcus R, Kelsey JL: Falls in older Mexican-American women. J Am Geriatr Soc 1999, 47(11):1371-1378.

8. CBO kvdg: Preventie van valincidenten bij ouderen. 2004 [http://www.cbo.nl/ product/ richtlijnen/folder20021023121843/valrichtlijn2004. pdf/view]. accessed june 5, 2006.

9. Masud T, Morris RO: Epidemiology of falls. Age and Ageing 2001, 30(4):3-8.

10. CBO : Osteoporose. Tweede herziene richtlijn 2002. [http/ www.cbo.nl/product/richtlijnen/folder20021023121843/oste oporose. pdf/view]. Utrecht, Kwaliteitsinstituut voor de Gezondheidszorg CBO accessed august 17, 2005

11. Close JCT, Lord SL, Menz HB, Sherrington C: What is the role of falls? Best Practice \& Research Clinical Rheumatology 2005, 19(6):913-935.

12. Prevention and management of Osteoporosis. Geneva, World Health Organization; 2003.

13. Shaw FE, Bond J, Richardson DA, Dawson P, Steen IN, McKeith IG, Kenny RA: Multifactorial intervention after a fall in older people with cognitive impairment and 
dementia presenting to the accident and emergency department: randomised controlled trial. Bmj 2003, 326(7380):73.

14. Pils K, Neumann F, Meisner W, Schano W, Vavrovsky G, Van der Cammen TJM: Predictors of falls in elderly people during rehabilitation after hip fracture - who is at risk of a second one? Zeitschrift für Gerontologie und Geriatrie 2003, 36(1):16-22.

15. Wei TS, Hu CH, Wang SH, Hwang Departments of KL: Fall Characterictics, Functional Mobility and Bone Mineral Density as Risk Factors of Hip Fracture in the CommunityDwelling Ambulatory Elderly. Osteoporosis International 2001, 12(12):1050-1055.

16. Albrand G, Munoz F, Sornay-Rendu E, DuBoeuf F, Delmas PD: Independent predictors of all osteoporosis-related fractures in healthy postmenopausal women: The OFELY Study. Bone 2003, 32(1):78-85.

17. Solomon DH, Finkelstein JS, Polinski JM, Arnold M, Licari A, Cabral D, Canning C, Avorn J, Katz JN: A randomized controlled trial of mailed osteoporosis education to older adults. Osteoporos Int 2006, 17(5):760-767.

18. Close JCT, Hooper R, Glucksman E, Jackson SHD, Swift CG: Predictors of falls in a high risk population: results from the prevention of falls in the elderly trial (PROFET). Emerg Med J 2003, 20(5):421-425.

19. Francis RM: Falls and fractures. Age and Ageing 2001, 30(4):25-29. 20. Stalenhoef PA, Diederiks JP, Knottnerus JA, de Witte LP, Crebolder HF: The construction of a patient record-based risk model for recurrent falls among elderly people living in the community. Fam Pract 2000, 17(6):490-496.

21. Stalenhoef PA, Diederiks JP, Knottnerus JA, Kester AD, Crebolder HF: A risk model for the prediction of recurrent falls in community-dwelling elderly: a prospective cohort study. J Clin Epidemiol 2002, 55(11):1088-1094.

22. Geusens P, Milisen K, Dejaeger E, Boonen S: Falls and fractures in postmenopausal women: a review. J Br Menopause Soc 2003, 9(3):101-106.

23. Scott V, Votova K, Scanlan A, Close J: Multifactorial and functional mobility assessment tools for fall risk among older adults in community, home-support, long-term and acute care settings. Age Ageing 2007, 36(2):130-139.

24. Kenny RA, Rubenstein LZ, Martin FC, Tinetti ME: Guideline for the Prevention of Falls in Older Persons. Journal of the American Geriatrics Society 2001, 49(5):664-672.

25. Rossiter-Fornoff JE, Wolf SL, Wolfson LI, Buchner DM: A cross-sectional validation study of the FICSIT common data base static balance measures. Frailty and Injuries: Cooperative Studies of Intervention Techniques. J Gerontol A Biol Sci Med Sci 1995, 50(6):M291-7.

26. Podsiadlo D, Richardson S: The timed "Up \& Go": a test of basic functional mobility for frail elderly persons. J Am Geriatr Soc 1991, 39(2):142-148.

27. Bischoff HA, Stahelin HB, Monsch AU, Iversen MD, Weyh A, von Dechend M, Akos R, Conzelmann M, Dick W, Theiler R: Identifying a cut-off point for normal mobility: a comparison of the timed 'up and go' test in community-dwelling and institutionalised elderly women. Age and Ageing 2003, 32(3):315-321.

28. Guralnik JM, Simonsick EM, Ferrucci L, Glynn RJ, Berkman LF, Blazer DG, Scherr PA, Wallace RB: A short physical performance battery assessing lower extremity function: association with self-reported disability and prediction of mortality and nursing home admission. J Gerontol 1994, 49(2):M85-94. 
29. Tromp AM, Pluijm SM, Smit JH, Deeg DJ, Bouter LM, Lips P: Fall-risk screening test: a prospective study on predictors for falls in community-dwelling elderly. J Clin Epidemiol 2001, 54(8):837-844.

30. Hodkinson HM: Evaluation of a mental test score for assessment of mental impairment in the elderly. Age Ageing 1972, 1(4):233-238.

31. Jitapunkul S, Pillay I, Ebrahim S: The abbreviated mental test: its use and validity. Age Ageing 1991, 20(5):332-336.

32. Kempen GI, Miedema I, Ormel J, Molenaar W: The assessment of disability with the Groningen Activity Restriction Scale. Conceptual framework and psychometric properties. Soc Sci Med 1996, 43(11):1601-1610.

33. Lord SR, Dayhew J: Visual risk factors for falls in older people. J Am Geriatr Soc 2001, 49(5):508-515.

34. Sherman FT: Functional assessment. Easy-to-use screening tools speed initial office work-up. Geriatrics 2001, 56(8):36-40; quiz 43.

35. Carey BJ, Potter JF: Cardiovascular causes of falls. Age Ageing 2001, 30 Suppl 4:19-24. 


\section{CHAPTER 8}

\section{Implementation of guidelines for osteoporosis and fall prevention in patients with a recent clinical fracture reduces the risk of new fractures}

Svenhjalmar van Helden, Tineke CM van Geel, Piet P Geusens, Evelien Pijpers, Gittie Willems, Geert Jan Dinant, Alfons Kessels, Rene ten Broeke, Peter R G Brink 


\section{ABSTRACT}

Objectives: The effect on new fracture incidence of systematic implementation of guidelines for osteoporosis and fall prevention in patients with a recent clinical fracture.

Design: Prospective case control study with historic controls.

Participants and interventions: During one year a dedicated fracture nurse offered a bone- and fall-related risk factor evaluation and treatment program according to the guidelines in the Netherlands to all patients older than 50 years with a recent clinical fracture ( $n=940,670$ women and 270 men). One-year fracture incidence in this group was compared to the 6.5\% 1-year incidence in 2373 patients who were treated with a fracture in 1999-2001 in the same hospital before the guidelines were available and no special post-fracture risk assessment was performed. The procedure of tracking the incidence of new fractures was identical for controls and after intervention. Cox-regression with adjustments for age, sex and location of fractures was used to calculate the hazard ratio $(\mathrm{HR}$, with $95 \%$ confidence interval $(\mathrm{Cl}))$ of the program compared to historical controls.

Main outcome measures: Incidence of new radiographic confirmed clinical fractures within one year.

Results: After exclusion of patients with pathological fractures $(n=14)$ and from abroad $(n=22), 33$ out of 904 patients (3.7\%) in the total study group had a new clinical fracture within one year, indicating a risk reduction of $43 \%$ compared to controls (HR: $0.57, \mathrm{Cl}: 0.39$ to 0.83 ).

Fracture reduction was similar in women (HR: $0.58,0.38$ to 0.89 ) and men (HR: $0.52, \mathrm{Cl}: 0.23$ to 1.18 ), in patients younger (HR: $0.55, \mathrm{Cl}: 0.31$ to 1.09 ) and older than 70 years (HR: $0.55, \mathrm{Cl}: 0.35$ to 0.89 ) and after a hip fracture (HR: $0.34, \mathrm{Cl}: 0.12$ to 0.95$)$ compared to other fractures at baseline (HR: $0.62, \mathrm{Cl}$ : 0.41 to 0.94 ).

Conclusions: Systematic implementation, by a dedicated fracture nurse, of guidelines for osteoporosis and fall prevention immediately after a recent clinical fracture significantly reduce the risk for new clinical fractures within one year compared to previous incidence when no guidelines were available. 


\section{INTRODUCTION}

Women and men with a history of a clinical fracture are at increased risk for developing a new fracture, already within short term ${ }^{1234}$.

In the context of evaluation of bone's ability to resist fracturing, guidelines on osteoporosis advocate to evaluate patients with a recent clinical non-spine fracture for fracture risk, including bone densitometry by dual energy X-ray absorptiometry (DXA). The results are used to make appropriate decisions about therapy that has been shown to reduce fracture risk ${ }^{5-7}$.

In the context of fall risks, guidelines on osteoporosis and fall prevention also advocate to perform a fall risk evaluation in patients with a recent clinical nonspine fracture. The fall risk profile is then used to make decisions about targeted or multidimensional fall prevention that has been shown to reduce fall risk ${ }^{8-10}$.

However, the implementation of guidelines for osteoporosis and fall prevention and of validated case finding strategies in daily practice remains unsatisfactory ${ }^{511-21}$.

The reasons for deficient implementation of guidelines are not well defined and are dependent on factors related to doctors and patients ${ }^{11-18 ~ 21-23}$. Barriers included cost of diagnosis and therapy and concerns about medications. Another barrier is the lack of clarity regarding the responsibility to undertake osteoporosis care, even after a fracture has occurred ${ }^{24}$.

In patients with a recent fracture, the initiative should come from the treating surgeon or the general practitioner, but this is often not the case ${ }^{25}$. No studies are available about the impact of implementing guidelines on new fracture risk in patients with a recent fracture by filling up this gap of implementation with the introduction of nurse help to inform such patients about fracture risk and organising further diagnostic and therapeutic steps.

Therefore, we studied, as a primary endpoint, the effect of implementation by a dedicated osteoporosis nurse of guidelines for osteoporosis and fall prevention on fracture incidence in patients with a recent clinical fracture. We compared, in the same hospital, the new fracture rate within one year before and after implementation of the guidelines in all $50+$ women and men with a recent clinical fracture.

\section{MATERIALS AND METHODS}

This study is a prospective observational study comparing new clinical fractures in patients with a recent fracture during the next first year with historic controls before the intervention was available and implemented.

The intervention group consisted of all subjects older than 50 years that attended the surgical emergency clinic or were admitted because of a clinical 
fracture within a one-year period (September 2004 until September 2005). These patients were invited to participate in a program, which comprised a bone- and fall-related risk factors assessment and bone densitometry. Investigations were done in conjunction with the fracture treatment.

The consenting group of the intervention group comprised all individuals who gave informed consent and did get the full risk assessment.

The non-consenting group of the intervention group consisted of all $50+$ patients with a fracture who were not included for this fracture risk evaluation due to various reasons (no informed consent, informed consent but "no show" on DXA appointment, already on any treatment for osteoporosis, from other region, not able to come back for next consultation and pathologic fracture confirmed on X-ray).

All the intervention group patients were contacted by telephone and/or mail one year after their fracture to evaluate the number of patients with new fractures.

The control group consisted of 2373 patients with a recent fracture treated in the same hospital as the intervention group 3 . Treatment of these subjects was before the start of the fracture and osteoporosis outpatient clinic in the years 1999, 2000 and 2001, before the guidelines were available and at a time that no post-fracture follow up was performed.

To track new incident fractures, the patients completed questionnaires when they were alive and for non-responders or deceased patients the hospital database was searched. In all three groups the procedure was similar.

Fractures were classified according to the International Classification of Disease (ICD-9: into skull, vertebra, clavicle, thorax, pelvis, humerus, radius and/or ulna, hand, femur, tibia, fibula and/or patella or foot categories). For further analysis, categories were clustered into five groups: upper limb, lower limb, vertebral fractures, other fractures and multiple fractures (two or more fractures at the same time).

Three assessments for fracture risk were performed in the consenting group of the intervention group:

Type A: bone mineral density (BMD) of the spine and the left hip (or at the non-fracture site in case of unilateral hip fracture) measured by DXA with the Hologic QDR 4500 Elite densitometer (coefficient of variation $0.4 \%$ ). The definition of the World Health Organisation (WHO) was used for osteoporosis ( $\mathrm{T} \leq$ -2.5 ), osteopenia (lowest $T$ in range -2.5 to -1.0 ), and normal BMD ( $T \geq-1.0$ ).

Type B: clinical bone-related risk factors for fractures. These included a previous fracture after the age of 50 years, mother with fracture history, body weight $<60 \mathrm{~kg}$, severe immobility and use of glucocorticoids.

Type $C$ : fall related risk factors for fractures. These included more than one 
fall during the last year, use of psychoactive drugs, low activity in daily living (ADL) before current fracture, articular complaints, impaired vision, urinary incontinence and Parkinson's disease.

Assessment of risk factors for fracture were based on the Dutch guidelines for prevention of osteoporosis and falls ${ }^{5627}$. The osteoporosis guideline recommends case finding with the risk factors stated above as Type B. Pharmaceutical treatment is recommended in individuals with a prevalent vertebral fracture or in the presence of other risk factors and a T-score $\leq-2.5$. The fall prevention guideline proposed the risk factors stated above as Type $C$ as the most important for assessment.

A specialized nurse, trained in osteoporosis management and fall risk assessment, investigated all the patients. During the first consultation information about the investigation was given and a letter for informed consent was handed over to the patient. If the patient consented, the second consultation, which was usually within two months after the fracture, was combined with a DXA measurement of the spine and hip and investigations for bone and fall related fracture risks. Fall risk assessment comprised tests for the detection of ADL functions according to the Groningen Activity Restriction Scale (status before the fracture $)^{1528-30}$ and vision according to the Snellen eye chart ${ }^{30-33}$. In addition, a review was taken for history of falls ${ }^{15}{ }^{3032}{ }^{34-36}$, use of psychofarmaca (benzodiazepines, antipsychotics, antidepressants, neuroleptics) ${ }^{28}{ }^{30} 36-39$, osteoarthritis ${ }^{31}$ ${ }^{32} 3537$; urine incontinence ${ }^{30} 36$ and Parkinson disease ${ }^{3132}$.

The fracture nurse instructed all patients for an adequate intake of calcium and vitamin $D$ and gave general instructions about fall prevention, depending on the fall risk profile. All patients were instructed to visit their general practitioner regarding possible measures to prevent falls coming forth from the fall risk assessment. In addition, patients with osteoporosis were treated with drugs known to reduce fracture incidence (combination of calcium, vitamin $D$ and mostly a bisphosphonate). Investigations to elucidate contributors for secondary osteoporosis were done on indication.

\section{Statistical analysis}

Statistical analysis was performed using SPSS for Windows (version 12.0.1; SPSS Inc. Chicago, IL, USA) and MedCalc® version 8.2.1.0 for Windows XP. Comparison of proportions was done with chi-square test.

Cox regression analysis was used to detect differences in new fracture incidence comparing the intervention group (consenting and non-consenting group) with the control group. 
Hazard ratio's (HR) and 95\% confidence intervals $(\mathrm{Cl})$ were calculated. Reported HRs are corrected for sex, age and fracture location (upper limb, lower limb, vertebral, other and multiple). Observations were considered significant if $p$ was $<0.05$ (two tailed).

\section{REsULTS}

In the first year of the fracture and osteoporosis outpatient clinic 940 patients with a recent clinical fracture were treated (table I). In total, 36 patients were excluded from the analysis (14 pathologic fractures, 22 living abroad). Of the remaining 904 patients 869 had one fracture, 31 had two fractures and four patients had three fractures.

568 Patients $(63 \%)$ agreed to an assessment for fracture risk (= consenting group). The remaining 336 (37\%) patients did not/could not agree to this assessment: 22 deceased shortly after their fracture, 22 had dementia, 42 lived in another region, 23 were already on treatment for osteoporosis, $134 \mathrm{did}$ not show up on DXA appointment; 89 did not sign an informed consent; 4 had other reasons (non-consenting group).

One year after the index fracture all patients were contacted to assess if patients had experienced a new fracture. 79 patients $(8,7 \%)$ deceased and follow up data were collected from the hospital database system. Four patients in this group had a new fracture before they deceased.

Table I: The composition of the control group and the intervention group

\begin{tabular}{|c|c|c|c|c|}
\hline & \multicolumn{2}{|c|}{ control group } & \multicolumn{2}{|c|}{ intervention group } \\
\hline & $\mathrm{n} \quad \mathrm{r}$ & $\mathrm{n}$ with 2 nd fracture & $\mathrm{n}$ & $\mathrm{n}$ with 2nd fracture \\
\hline total & \multirow{2}{*}{\multicolumn{2}{|c|}{2444}} & \multirow[t]{2}{*}{940} & \\
\hline \multicolumn{2}{|l|}{ excluded } & & & \\
\hline pathologic fractures & $30(1 \%)$ & & $14(2 \%)$ & \\
\hline living abroad & $41(2 \%)$ & & $22(2 \%)$ & \\
\hline patients in follow up & \multicolumn{2}{|l|}{$2373(97 \%)$} & $904(96 \%)$ & \multirow{3}{*}{$4^{b}$} \\
\hline deceased ${ }^{a}$ (number per 100 patient years) & $568(6.4)$ & 42 & $79(5.9)$ & \\
\hline alive receiving questionnaires & \multicolumn{2}{|l|}{1805} & 825 & \\
\hline responders & \multicolumn{2}{|l|}{1262} & \multicolumn{2}{|l|}{796} \\
\hline non responders ${ }^{c}$ & \multicolumn{2}{|l|}{543} & \multicolumn{2}{|l|}{29} \\
\hline patients with second fracture & & 154 & & 33 \\
\hline
\end{tabular}

a follow up period in control group from 1999/2000-2001 till may 2004 / follow up period intervention group from sept 2004 till sept 2006

b 1 consenting group / 3 non-consenting group

c results found in hospital database

d 15 consenting group / 14 non-consenting group 
In total, 796 patients (88.1\%) could be contacted; 548 in the consenting group and 248 in the non-consenting group. Of the contacted patients, 29 reported new fractures of which 26 could be verified in the hospital database. Three patients were treated in an other hospital. In a group of 29 patients who did not respond there were no new fractures found in the hospital database. In summary, 33 of the 904 patients had a new fracture during one year follow up.

The control group counted 2444 patients treated in the years 1999, 2000 and 2001 (Table I) of which 71 patients were excluded (30 pathologic fractures, 41 living abroad). Of the remaining 2373 patients, 2238 patients had one fracture, 116 had two fractures, 18 had 3 fractures and 1 patient had 4 fractures. In the 568 patients that already were deceased at the time of this investigation (April 2004) we found 42 patients with a new fracture in the hospital database. All other patients were sent a questionnaire by mail. The 1262 patients that responded included 76 patients with a new fracture of which 61 could be verified in the hospital database. Fifteen patients were treated at another institution. In the 543 patients that did not respond, 36 patients with a new fracture were found in the hospital database.

Table II: patient group characteristics

\begin{tabular}{llcccc}
\hline & intervention group & $\begin{array}{c}\text { consenting } \\
\text { group }\end{array}$ & $\begin{array}{c}\text { non-consenting } \\
\text { group }\end{array}$ & control group \\
\hline number of patients & 904 & 568 & 336 & 2373 \\
mean age (range) & $70(50-99)$ & $67^{\mathrm{a}}(50-95)$ & $75^{\mathrm{a}}(50-99)$ & $71(50-103)$ \\
sex (\% women) & 72 & 72 & 73 & 73 \\
fracture location (\%) & upper extremity & 48 & 49 & 47 & 46 \\
& lower extremity & 38 & 37 & 39 & 41 \\
& vertebral & $4^{\mathrm{a}}$ & 3 & $4^{\text {a }}$ & 2 \\
& other & $7^{\mathrm{a}}$ & 6 & $8^{\text {a }}$ & 5 \\
& multiple & $4^{\mathrm{a}}$ & 5 & $2^{\text {a }}$ & 6 \\
\hline
\end{tabular}

${ }^{a} p<0,05$ vs

controlgroup

Table III : Cox regression analysis with correction for age, sex and fracture type.

\begin{tabular}{lcccc}
\hline & $\begin{array}{c}\text { intervention } \\
\text { group }\end{array}$ & $\begin{array}{c}\text { consenting } \\
\text { group }\end{array}$ & $\begin{array}{c}\text { non-consenting } \\
\text { group }\end{array}$ & $\begin{array}{c}\text { control } \\
\text { group }\end{array}$ \\
\hline $\begin{array}{l}\text { number of patients } \\
\text { number of patients } \\
\text { with new fractures in 1 year(\%) }\end{array}$ & 904 & 568 & 336 & 2373 \\
hazard ratio vs. control group & 0.57 & $16(2.8)$ & $17(5.1)$ & $154(6.5)$ \\
$\begin{array}{l}\text { 95\% confidence interval } \\
\text { vs. control group }\end{array}$ & $0.39-0.83$ & $0.26-0.72$ & $0.48-1.31$ & \\
p value & 0.003 & 0.001 & 0.37 & \\
\hline
\end{tabular}




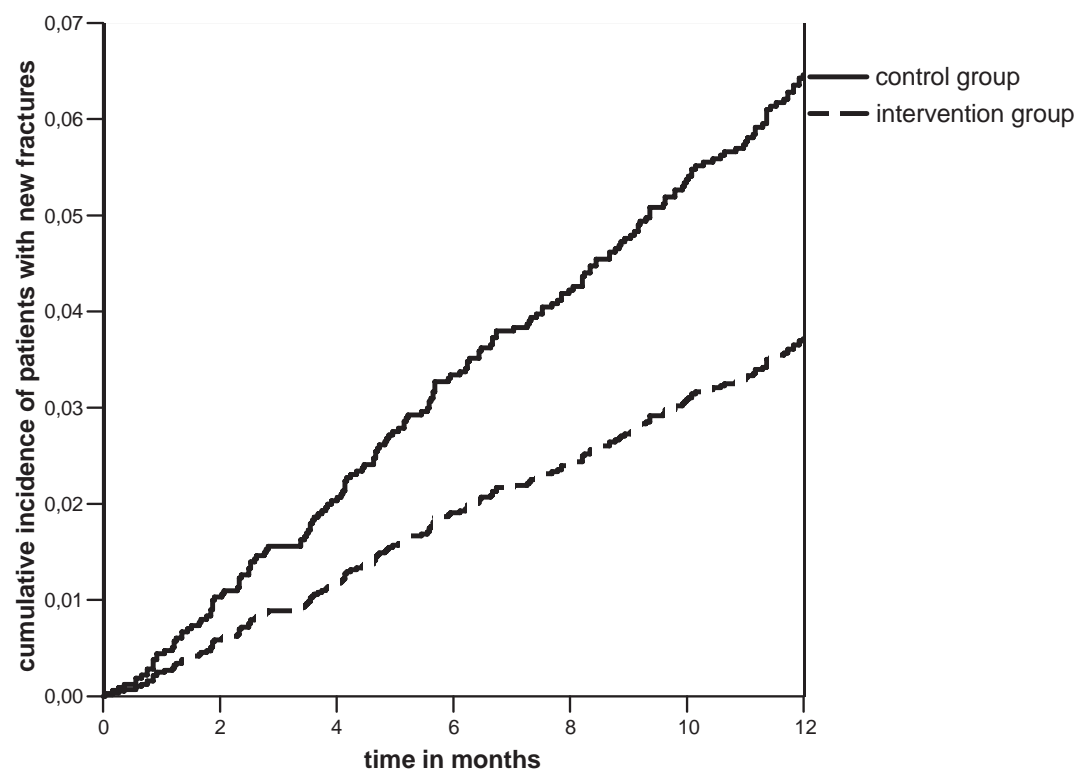

Figure 1: Cumulative incidence of patients with new fractures in 1 year (age, gender and fracture location-adjusted): control group and intervention group. (HR: 0.57, Cl: 0.39 to 0.83)

In summary, at least 154 patients of the 2373 patients had a new fracture during one year follow-up.

Comparison of the different groups was possible for age at the time of the index fracture, sex and type of fracture (Table II). The intervention group differed slightly in fracture distribution compared to the control group. As expected the mean age in the non-consenting group was higher accounting for those individuals not able to participate in the risk assessment.

A $43 \%$ decrease in the one year new fracture incidence was shown with Cox regression analysis comparing the total intervention group with the control group (HR 0.57; 95\% Cl 0.39 to 0.83) (Table III / Figure 1). The decrease was $57 \%$ comparing the consenting group with the control group (HR $0.43 ; 95 \% \mathrm{Cl}$ 0.26 to 0.72 ). The difference between the non-consenting group and the control group was not significant (HR $0.79 ; 95 \% \mathrm{Cl} 0.48$ to 1.31 ).

Fracture reduction was similar in women (HR: $0.58,0.38$ to 0.89 ) and men (HR: $0.52, \mathrm{Cl}: 0.23$ to 1.18 ), in patients younger (HR: $0.58, \mathrm{Cl}: 0.31$ to 1.09 ) and older than 70 years (HR: $0.55, \mathrm{Cl}: 0.35$ to 0.89 ) and after a hip fracture (HR: $0.34, \mathrm{Cl}: 0.12$ to 0.95$)$ compared to other fractures at baseline (HR: $0.62, \mathrm{Cl}$ : 0.41 to 0.94$)$. 
New fracture incidence was $3.5 \%$ in patients with osteoporosis (who all were prescribed calcium, vitamin $\mathrm{D}$ and mostly bisphosphonates), $2.8 \%$ in patients with osteopenia and $1.7 \%$ in patients with normal BMD ( $p=$ NS by chi square). New fracture incidence in patients with or without fall-related risk factors was similar $(2.6 \%$ versus $3.5 \%$; $p=N S$ by chi square).

\section{Discussion}

Recent reports about fracture prevention mainly focus on the implementation of guidelines to perform any kind of assessment to detect osteoporosis and/or fall risk factors ${ }^{40-43}$. To our knowledge this is the first study to describe the effect of these guideline implementations in terms of fracture reduction compared with a well documented control group. The $43 \%$ lower fracture incidence in this cohort is the effect of several probably synergetic contributors.

Firstly the dedicated fracture and osteoporosis nurse offered a great deal of counselling to the fracture patients. As described before, the first consultation is used to explain the risks of new fractures in terms of low BMD and fall risk factors. Because most patients in the non-consenting group also had such a first consultation this could be a reason why the new fracture incidence also was slightly lower than in the control group. During the second consultation, only attended by the consenting group, again there is a more extensive explanation about the results of the DXA and an extended fall risk assessment.

Secondly, all diagnosed fall risk factors were discussed with the patient and reported in a letter to the general practitioner. The patient also was stimulated to analyse with their general practitioner how these fall risk factors could be treated. Thirdly, medication was offered to reduce risk of a new fracture to individuals with T scores $\leq-2.5$ and/or a clinical vertebral fracture, again this was carefully explained to the patient.

As shown in this paper not all patients at risk for a new fracture responded to the offer of a dedicated nurse to help them in reducing the risk of a new fracture. In the total group, $37 \%$ of the patients had several reasons not to be implemented in the prevention program. Several studies showed that inclusion of patients at high risk of an osteoporotic fracture in a prevention program is between $50 \%$ and $85 \%{ }^{41}{ }^{44} 42$. The patients that get anti-resorptive drugs prescribed, often have a suboptimal compliance regarding the intake of these prescribed drugs $\mathrm{s}^{45}$. Implementation of a specialised nurse together with a fracture prevention program has to deal with patients who will not or can not be treated. Despite this fact the overall new fracture reduction in 1 year was $43 \%$. 
This study has several shortcomings. Firstly, as the intervention in this study is a summation of effects of the assessments and the forthcoming individualised advices given by the osteoporosis nurse, it is not possible to know the precise contribution of all these measures in the total group. Thus it is not possible to conclude to what degree certain measures or assessments contributed to fracture reduction.

Secondly, the most powerful proof of intervention effect would have been conducting a randomised controlled trial. However, in the light of the current osteoporosis guideline, it is not possible (especially not in one and the same institution) to asses and diagnose patients with low BMD without starting a treatment. Thus the comparison for intervention effect with a well matched control group treated in the same hospital seems the next best possibility.

Thirdly, it is possible that some people did not correctly answer the questions regarding new fractures done by an interview on the phone or in a letter. However, reported fractures in the questionaires were checked in the hospital database and could be confirmed in $90 \%$ both in the intervention and control group. The other $10 \%$ reported new fractures were treated in other institutions en could therefore not be verified with an X-ray report. Nevertheless, a study performed by Ismail et al assessed the validity of self-reported incident nonspine fractures using a postal questionnaire and concluded that this method is accurate for obtaining information about the occurrence of most fractures ${ }^{46}$. In deceased patients and those not responding, follow up information was collected from the hospital database system in the intervention and control group. It is possible that these individuals did experience a new fracture before their death, but were treated at another institution. However the response rate was rather high in both the intervention group and the control group ( $96 \%$ and $70 \%$ respectively).

We conclude that systematic implementation, by a dedicated fracture nurse, of guidelines for osteoporosis and fall prevention immediately after a recent clinical fracture significantly reduces the risk for new fractures within one year compared to previous incidence when no guidelines were available. We therefore suggest implementation of such guidelines in all services taking care of patients with a recent fracture in order to minimize new fractures in these patients.

\section{REFERENCES}

1. Klotzbuecher CM, Ross PD, Landsman PB, Abbott TA, Berger M. : Patients with prior fractures have an increased risk of future fractures: a summary of the literature and statistical synthesis. : J Bone Miner Res 2000;15(4):721-39. 
2. Kanis JA, Borgstrom F, De Laet $C$, Johansson $H$, Johnell $O$, Jonsson $B$, et al. Assessment of fracture risk. Osteoporos Int 2005;16(6):581-9.

3. van Helden S, Cals J, Kessels F, Brink P, Dinant GJ, Geusens P. Risk of new clinical fractures within 2 years following a fracture. Osteoporos Int 2006;17(3):348-54.

4. Center JR, Bliuc D, Nguyen TV, Eisman JA. Risk of subsequent fracture after low-trauma fracture in men and women. Jama 2007;297(4):387-94.

5. Geusens PP, Lems WF, Verhaar HJ, Leusink G, Goemaere S, Zmierczack H, et al. Review and evaluation of the Dutch guidelines for osteoporosis. J Eval Clin Pract 2006;12(5):539-48.

6. Geusens PP. Review of guidelines for testing and treatment of osteoporosis. Curr Osteoporos Rep 2003;1(2):59-65.

7. Sambrook P, Cooper C. Osteoporosis. Lancet 2006;367(9527):2010-8.

8. Oliver D, Britton M, Seed P, Martin FC, Hopper AH. Development and evaluation of evidence based risk assessment tool (STRATIFY) to predict which elderly inpatients will fall: case-control and cohort studies. Bmj 1997;315(7115):1049-53.

9. Chang JT, Morton SC, Rubenstein LZ, Mojica WA, Maglione M, Suttorp MJ, et al. Interventions for the prevention of falls in older adults: systematic review and metaanalysis of randomised clinical trials. Bmj 2004;328(7441):680.

10. Stenvall M, Olofsson B, Lundstrom M, Englund U, Borssen B, Svensson O, et al. A multidisciplinary, multifactorial intervention program reduces postoperative falls and injuries after femoral neck fracture. Osteoporos Int 2007;18(2):167-75.

11. Bliuc D, Ong CR, Eisman JA, Center JR. Barriers to effective management of osteoporosis in moderate and minimal trauma fractures: a prospective study. Osteoporos Int 2005;16(8):977-82.

12. Solomon DH, Brookhart MA, Gandhi TK, Karson A, Gharib S, Orav EJ, et al. Adherence with osteoporosis practice guidelines: a multilevel analysis of patient, physician, and practice setting characteristics. Am J Med 2004;117(12):919-24.

13. Solomon DH, Connelly MT, Rosen CJ, Dawson-Hughes B, Kiel DP, Greenspan SL, et al. Factors related to the use of bone densitometry: survey responses of 494 primary care physicians in New England. Osteoporos Int 2003;14(2):123-9.

14. Feldstein A, Elmer PJ, Orwoll E, Herson M, Hillier T. Bone mineral density measurement and treatment for osteoporosis in older individuals with fractures: a gap in evidencebased practice guideline implementation. Arch Intern Med 2003;163(18):2165-72.

15. Jaglal SB, Mclsaac WJ, Hawker G, Carroll J, Jaakkimainen L, Cadarette SM, et al. Information needs in the management of osteoporosis in family practice: an illustration of the failure of the current guideline implementation process. Osteoporos Int 2003;14(8):672-6.

16. Siris ES, Bilezikian JP, Rubin MR, Black DM, Bockman RS, Bone HG, et al. Pins and plaster aren't enough: a call for the evaluation and treatment of patients with osteoporotic fractures. J Clin Endocrinol Metab 2003;88(8):3482-6.

17. Taylor JC, Sterkel B, Utley M, Shipley M, Newman S, Horton M, et al. Opinions and experiences in general practice on osteoporosis prevention, diagnosis and management. Osteoporos Int 2001;12(10):844-8. 
18. Mauck KF, Cuddihy MT, Atkinson EJ, Melton LJ, 3rd. Use of clinical prediction rules in detecting osteoporosis in a population-based sample of postmenopausal women. Arch Intern Med 2005;165(5):530-6.

19. Elliott ME, Drinka PJ, Krause P, Binkley NC, Mahoney JE. Osteoporosis assessment strategies for male nursing home residents. Maturitas 2004;48(3):225-33.

20. Streeten EA, Mohamed A, Gandhi A, Orwig D, Sack P, Sterling R, et al. The inpatient consultation approach to osteoporosis treatment in patients with a fracture. Is automatic consultation needed? J Bone Joint Surg Am 2006;88(9):1968-74.

21. Chevalley T, Hoffmeyer P, Bonjour JP, Rizzoli R. An osteoporosis clinical pathway for the medical management of patients with low-trauma fracture. Osteoporos Int 2002;13(6):450-5.

22. Feldstein AC, Nichols GA, Elmer PJ, Smith DH, Aickin M, Herson M. Older women with fractures: patients falling through the cracks of guideline-recommended osteoporosis screening and treatment. J Bone Joint Surg Am 2003;85-A(12):2294-302.

23. Elliott ME, Meek PD, Kanous NL, Schill GR, Weinswig PA, Bohlman JP, et al. Osteoporosis screening by community pharmacists: use of National Osteoporosis Foundation resources. J Am Pharm Assoc (Wash) 2002;42(1):101-10; quiz 110-1.

24. Elliot-Gibson V, Bogoch ER, Jamal SA, Beaton DE. Practice patterns in the diagnosis and treatment of osteoporosis after a fragility fracture: a systematic review. Osteoporos Int 2004;15(10):767-78.

25. Skedros JG, Holyoak JD, Pitts TC. Knowledge and opinions of orthopaedic surgeons concerning medical evaluation and treatment of patients with osteoporotic fracture. $\mathrm{J}$ Bone Joint Surg Am 2006;88(1):18-24.

26. CBO kvdg. tweede herziene richtlijn osteoporose 2002. available at: http://www.cbo.nl/product/richtlijnen/folder20021023121843/osteoporose.pdf/view accessed august 17, 2005.

27. CBO kvdg. Preventie van valincidenten bij ouderen 2004. available at: http://www.cbo.nl/product/richtlijnen/folder20021023121843/val-richtlijn2004.pdf/view accessed june 5, 2006.

28. Tinetti ME, Speechley M, Ginter SF. Risk factors for falls among elderly persons living in the community. N Engl J Med 1988;319(26):1701-7.

29. O'Loughlin JL, Robitaille Y, Boivin JF, Suissa S. Incidence of and risk factors for falls and injurious falls among the community-dwelling elderly. Am J Epidemiol 1993;137(3):342-54.

30. Tromp AM, Pluijm SM, Smit JH, Deeg DJ, Bouter LM, Lips P. Fall-risk screening test: a prospective study on predictors for falls in community-dwelling elderly. J Clin Epidemiol 2001;54(8):837-44.

31. Nevitt MC, Cummings SR, Kidd S, Black D. Risk factors for recurrent nonsyncopal falls. A prospective study. Jama 1989;261(18):2663-8.

32. Northridge ME, Nevitt MC, Kelsey JL. Non-syncopal falls in the elderly in relation to home environments. Osteoporos Int 1996;6(3):249-55.

33. Lord SR, Dayhew J. Visual risk factors for falls in older people. J Am Geriatr Soc 2001;49(5):508-15. 
34. Luukinen H, Koski K, Kivela SL, Laippala P. Social status, life changes, housing conditions, health, functional abilities and life-style as risk factors for recurrent falls among the home-dwelling elderly. Public Health 1996;110(2):115-8.

35. Stalenhoef PA, Diederiks JP, Knottnerus JA, Kester AD, Crebolder HF. A risk model for the prediction of recurrent falls in community-dwelling elderly: a prospective cohort study. J Clin Epidemiol 2002;55(11):1088-94.

36. Luukinen H, Koski K, Laippala P, Kivela SL. Predictors for recurrent falls among the home-dwelling elderly. Scand J Prim Health Care 1995;13(4):294-9.

37. Campbell AJ, Borrie MJ, Spears GF. Risk factors for falls in a community-based prospective study of people 70 years and older. J Gerontol 1989;44(4):M112-7.

38. Schwartz AV, Villa ML, Prill M, Kelsey JA, Galinus JA, Delay RR, et al. Falls in older Mexican-American women. J Am Geriatr Soc 1999;47(11):1371-8.

39. Weiner DK, Hanlon JT, Studenski SA. Effects of central nervous system polypharmacy on falls liability in community-dwelling elderly. Gerontology 1998;44(4):217-21.

40. Bogoch ER, Elliot-Gibson V, Beaton DE, Jamal SA, Josse RG, Murray TM. Effective initiation of osteoporosis diagnosis and treatment for patients with a fragility fracture in an orthopaedic environment. J Bone Joint Surg Am 2006;88(1):25-34.

41. Hegeman JH, Willemsen G, van Nieuwpoort J, Kreeftenberg HG, van der Veer E, Slaets $\mathrm{JP}$, et al. Effective tracing of osteoporosis at a fracture and osteoporosis clinic in Groningen; an analysis of the first 100 patients. Ned Tijdschr Geneeskd 2004;148(44):2180-5.

42. McLellan AR, Gallacher SJ, Fraser M, McQuillian C. The fracture liaison service: success of a program for the evaluation and management of patients with osteoporotic fracture. Osteoporos Int 2003;14(12):1028-34.

43. Scott V, Votova K, Scanlan A, Close J. Multifactorial and functional mobility assessment tools for fall risk among older adults in community, home-support, long-term and acute care settings. Age Ageing 2007;36(2):130-9.

44. Murray AW, McQuillan C, Kennon B, Gallacher SJ. Osteoporosis risk assessment and treatment intervention after hip or shoulder fracture. A comparison of two centres in the United Kingdom. Injury 2005;36(9):1080-4.

45. Cramer JA, Gold DT, Silverman SL, Lewiecki EM. A systematic review of persistence and compliance with bisphosphonates for osteoporosis. Osteoporos Int 2007;18(8):1023-31.

46. Ismail, Neill AAO, Cockerill TW, Finn W, Cannata JD, Hoszowski JB, et al.: Validity of self-report of fractures: results from a prospective study in men and women across Europe. EPOS Study Group. European Prospective Osteoporosis Study Group. : Osteoporos Int 2000;11(3):248-54. 


\section{CHAPTER 9}

\section{Summary and Conclusions}




\section{SUMMARY AND GENERAL CONCLUSION}

In Chapter 1, a concise overview of the factors that contribute to a patient's fracture risk was given. For quite some time, case finding and the diagnosis of osteoporosis was focused mainly on low bone mineral density (BMD). Low BMD was found to be a predictor of future fracture risk, it could be measured in daily practice, and its results were used to determine thresholds for diagnosis and therapy. Since then, prospective population-based studies have shown that many bone-related risks other than low BMD, in addition to fall-related risks, contribute to fracture risk, independent of low BMD. We therefore hypothesised that the systematic implementation of a fracture prevention program that is based on a whole spectrum of risk factors and performed during fracture care could decrease the risk of subsequent fracture.

The highest level of evidence for documenting anti-fracture effects of a prevention program is a randomised controlled study. However, because straightforward guidelines for osteoporosis and its treatment are in place, it is considered unethical to withhold treatment from a control group with diagnosed and welldocumented fracture risks. We therefore applied another study design by looking at groups before and after clinicians began to use the guidelines, and then compared the group in which the guidelines were implemented to a control group in which there has been no intervention (i.e. before guidelines were available). Therefore, in Chapter 2 we reported on the construction of a large historical control group of fracture patients. This group comprised all patients with a recent clinical fracture that were treated at Maastricht University Hospital between 1999 and 2001, before the guidelines were available. In total, 2419 male and female patients aged 50 years and older with a total of 2575 baseline fractures were included. Of this group, 139 had multiple simultaneous fractures. The main outcome measure was the absolute risk for fractures (i.e. the incidence of subsequent fractures) within the two years following a clinical fracture. The mean age was 66 years for men and 72 years for women. Over these two years, the cumulative percentage of patients with new clinical fractures was $10.8 \%$.

Cox regression analyses showed that age, gender, and multiple simultaneous fractures independently contributed to a higher subsequent fracture incidence. New fracture incidence increased with age (HR 1.2 per decade $\{\mathrm{Cl} 1.1-1.3\})$, was higher in women than in men $(12.2 \%$ compared to $7.4 \%$; $\mathrm{HR} 1.5\{\mathrm{Cl} 1.1$ $2.0\})$, and was higher in patients with multiple baseline fractures $(17.3 \% \mathrm{com}$ pared to $10.4 \%$ in patients with one baseline fracture (HR $1.8\{\mathrm{Cl} 1.2-2.7\})$. Of all clinical fractures occurring within two years after a clinical fracture, $60 \%$ occurred during the first year and $40 \%$ occurred during the second year $(p=$ 
0.005). The high incidence of subsequent fractures served as the stimulus for a fracture nurse driven fracture prevention program in our hospital.

The aim of the study in Chapter 3 was to evaluate the impact of a strategy on referral to a DXA measurement by comparing the implementation of the osteoporosis guideline by a fracture nurse to a referral for DXA in hospitals where no fracture nurse is employed. We retrospectively compared Maastricht University Hospital (reference hospital with fracture nurse) to five hospitals in the surrounding area.

During a two-week period, all female patients over 50 years of age who presented with a fracture at the emergency department in the six participating hospitals were included. The follow-up was a minimum of 11 weeks. The primary outcome was the referral for DXA measurement. In total, 135 patients were included. Of these patients, 33 were seen at Maastricht University Hospital and 102 at the other participating hospitals. In both groups, mean age and fracture location were similar. At Maastricht University Hospital, 14 patients qualified for DXA measurement. Ten of these patients actually underwent a DXA scan $(71 \%)$. In the other participating hospitals, 78 patients qualified for a DXA. Of these, only three actually underwent a DXA scan (4\%). Taking into account a refusal percentage for DXA of $33 \%$ as was found in the reference centre (Maastricht University Hospital), 47 patients in the other hospitals should have qualified for DXA measurement. Thus, successful referral at the hospitals other than Maastricht University Hospital was 3 out of $47(6 \%)$ patients. This indicated that referral for DXA was low in hospitals where no fracture nurse is employed. This suggests that the presence of a fracture nurse significantly increases the amount of patients receiving adequate osteoporosis screening with DXA measurement after a recent fracture (RR 11.0 (95\% Cl: 3.6 - 35.1).

In Chapter 4, results of broad spectrum fracture risk evaluation during the first inclusion year of the fracture and osteoporosis outpatient clinic were presented. All men and women older than 50 years of age who had been admitted for a recent fracture during a one-year period were offered an evidence-based (according to the Dutch guidelines) bone and fall-related risk assessment and bone densitometry. Of the 940 consecutive patients, 797 (85\%) were eligible for this study and $568(60 \%)$ agreed to participate. Fall-related risk factors $(75 \%$ [95\%Cl:71\%-78\%]; $n=425)$ and bone-related risk factors (53\% [95\%Cl:49\%$57 \%$ ]; $n=299$ ) were more frequently present at the time of fracture than osteoporosis (DXA T score $\leq-2.5$ in spine and/or hip, 35\% [95\% Cl:31\%-39\%]; $\mathrm{n}=201$ ), and were also present irrespective of the fracture location, the age categories included, and sex. 
Risk factors were overlapping, heterogeneous, and found in multiple combinations. This was the case regardless of age, fracture location, and sex. Using the Dutch guidelines, only a limited number of patients could have been identified to be at risk for fractures before their current fracture. The findings imply that an integrated bone and fall-related risk factor assessment is effective and therefore a more preferable means of identifying subjects at risk for subsequent fracture than identification based on low BMD alone.

In patients with osteoporosis, further evaluation was performed in an effort to explore the presence of contributors to secondary osteoporosis and morphometric vertebral deformities (MVD). This was addressed in Chapter 5. The study reported in this chapter included 100 consecutive men and women over the age of 50 who presented at the hospital with a recent clinical fracture and a T-score $\leq-2.5$. The participants were subjected to clinical and laboratory assessments and a vertebral fracture assessment by densitometry.

Of 73 women and 27 men (mean age: 68 years) included in this study, contributors to secondary osteoporosis were known in 27 patients. Additionally, 50 patients had newly diagnosed contributors (mainly vitamin D deficiency), 14 patients needed further exploration because of laboratory abnormalities, 54 patients had bone-related fracture risks, 79 patients had fall-related fracture risks, and 53 patients had previously undiagnosed MVD. Many of these contributors were correctable (i.e. a disturbed calcium homeostasis and endocrine diseases). These results suggest that patients presenting with a clinical fracture and osteoporosis require an even broader evaluation that includes a search for contributors to osteoporosis and MVD.

Recent data indicate that many patients presenting with a non-vertebral fracture have a vertebral fracture, even in the absence of low BMD. This is important because vertebral fractures contribute to fracture risk and are an indication for treatment at any level of BMD.

Therefore, in Chapter 6, we systematically evaluated the prevalence of morphometric vertebral deformities in patients with a recent non-vertebral fracture using a quantitative vertebral fracture assessment (VFA) that employs lateral DXA and the Genant grading for defining morphometric vertebral deformities (MVDs).

Among the 1302 eligible patients over 50 years of age (range: 50-95 years), $695(53 \%)$ provided consent for the evaluation.

MVDs of $\geq 25 \%$ were found in $27 \%$ of the participating patients Of these MVDs, $55 \%$ were found in patients without osteoporosis. MVDs of $20-24 \%$ were found in $22 \%$ of the participating patients and MVDs of $<20 \%$ were found in $51 \%$ of the participating patients. 
These results indicate that many patients presenting with a non-vertebral fracture had a MVD, also in the absence of osteoporosis and that VFA can be used to determine this. Clearly, VFA can help to select patients in whom an additional X-ray of the spine would allow for the verification of the presence of a radiographic morphometric vertebral fracture. Such a clinical pathway supports treatment decisions that better reflect the patient's subsequent absolute fracture risk and thus can be considered more beneficial than decisions that are based on BMD and clinical risks alone.

In Chapter 7, falls and fall-related risk factors were assessed in 277 consenting women and men aged 50 years and older who presented with a clinical fracture. These participants did not have dementia and were not already receiving treatment for osteoporosis before the fracture occurred. Fall-related risk factors were assessed according to the Dutch fall prevention guidelines. Follow-up information on falls and fractures was collected through a monthly telephone interview during the first three months after the fracture. A new fall incident was reported by 42 patients (15\%), of whom 5 had a new fracture. Of the 42 patients who had a new fall, 32 had one new fall and 10 had two or more.

Multivariate analyses of the total group with sex, age, ADL difficulties, urinary incontinence, and polypharmacy showed that sex and ADL were significant fallrelated risk factors. Women had an OR of $3.02(95 \% \mathrm{Cl} 1.13-8.06)$ and patients with ADL-difficulties had an OR of 2.50 (95\% Cl 1.27-4.93). Multivariate analyses using only female participants, with age, ADL difficulties, polypharmacy, and presence of orthostatic hypotension indicated that polypharmacy was the predominant risk factor (OR 2.51; 95\% Cl: 1.19 - 5.28). The incidence of falls was $35 \%$ in women with low ADL score and polypharmacy compared to $15 \%$ in women without these risk factors (OR 3.56: $\mathrm{Cl} 1.47$ - 8.67).

In Chapter 8, the impact of implementing guidelines using a fracture nurse driven fracture prevention program at Maastricht University Hospital was presented.

Over the period of one year, a dedicated fracture nurse offered a bone-related and fall-related risk factor evaluation and treatment program according to the Dutch guidelines to all patients older than 50 with a recent clinical fracture ( $\mathrm{n}=940,670$ women and 270 men). One-year fracture incidence in this group was compared to the $6.5 \%$ one-year incidence in patients who were treated with a fracture in 1999-2001 in the same hospital before the guidelines were available and no special post-fracture risk assessment was performed. A subsequent fracture within one year occurred in 33 of the 904 patients (3.7\%) in the total study group, indicating a risk reduction of $43 \%$ compared to control group (HR: 0.57, Cl: 0.39-0.83). Fracture reduction was similar in men and women at 
all ages. These data suggest that the systematic implementation of guidelines for osteoporosis and fall prevention immediately applied after a recent clinical fracture by a dedicated fracture nurse significantly reduces the risk for new fractures within one year when compared to the incidence before the guidelines were available. Randomised trials are necessary to analyse the efficiency and cost-effectiveness of this clinical pathway and the components that contribute to its effect.

Chapter 9 summarises the results of the different studies and highlighted the most important conclusions.

\section{GeneRAL CONCLUSIONS}

The implementation of guidelines for osteoporosis and fall prevention, and of validated case finding strategies in daily practice, remains unsatisfactory for primary as well as for secondary prevention ${ }^{1-12}$. The reasons for lack of guideline implementation are poorly defined and dependent on factors related to both doctors and patients ${ }^{2-9,12-14}$.

The position surgeons find themselves in today shows striking resemblance to that of cardiologists some twenty years ago. At that time, treatment focused on the acute treatment of cardiovascular diseases, such as myocardial infarction and stroke. No efforts were made to start secondary preventive measures even though it was known that the risk for subsequent cardiovascular (CV) events was high. It took some time before it became evident that a patient recovering from such an attack and his or her family are in the ideal state of mind to comply with preventive advice and prescribed medication. In 1985, the American Heart Association (AHA) therefore launched a program called "Get with the Guidelines" (GWTG). The implementation of that program following an acute myocardial infarction resulted in an enhanced adherence to secondary prevention guidelines within one year of use ${ }^{15}$. Returning to surgeons and fracture care, the parallel is obvious:

"You have to hit the iron when it's hot"

Trauma and orthopaedic surgeons treating patients with fractures are responsible for not only optimal treatment of the fracture itself but also for the initiation of measures to prevent a new, subsequent fracture. For this, they must look beyond the fracture, as do cardiologists who increasingly look beyond the CV event (e.g. the heart's condition) by using guidelines for secondary prevention and by focusing on other well-documented risk factors for subsequent CV events 
such as sex, weight, blood pressure, lipids, and lifestyle, many of which are correctable. The goal of implementing the GWTG was a $25 \%$ reduction in CV events and risks over 10 years ${ }^{16}$.

A presumably effective program to reach such a goal in fracture patients has been presented in this dissertation. The "fracture and osteoporosis outpatient clinic" program was designed to study the impact of implementing osteoporosis and fall-prevention guidelines on treatment initiation, lifestyle changes, and ultimately, on the incidence of subsequent fractures.

All participating patients were advised about bone-related lifestyle measures, including adequate calcium and vitamin $D$ intake, quitting smoking, and ensuring that alcohol intake is moderate. Patients with BMD-osteoporosis were examined for the presence of secondary osteoporosis and correctable contributors to secondary osteoporosis were treated. In patients with osteoporosis, bone-directed drug treatment was initiated, which has resulted in a decreased risk for subsequent fractures. Fall-related risks were evaluated and, in the presence of such risk, general and/or targeted advice was provided by the fracture nurse.

We demonstrated a $43 \%$ decrease in subsequent fractures within one year of follow up when compared to historical control subjects.

Concerning this fracture and osteoporosis clinic, several aspects have to be discussed: First, ideally, an impact study would randomise patients to two conditions, namely the application or non-application of guidelines. It would then follow up on the patients for relevant outcomes including quality of life, morbidity, and resource utilisation. Randomisation of individual patients is unlikely to be appropriate because one would expect the participating clinicians to incorporate the guidelines into the care of all their patients. A suitable alternative is to randomise institutions or practice settings and then conduct analyses appropriate to these larger units of randomisation. Another potential design is to look at a group before and after clinicians began to use the guidelines ${ }^{17}$. We applied the latter approach and thus compared the effect of a systematic implementation of the guidelines in patients prospectively followed after a fracture with historical control subjects that were treated before the guidelines were available and before post-fracture initiatives for fracture prevention were taken. However, our results are of a lower level of evidence than a randomised study.

Second, for the optimal implementation of guidelines, it is presumably necessary to use the services of a dedicated fracture nurse as we have shown in Chapter 3. This is not always feasible especially given the current financial structure in Dutch health care that does not reimburse extra care for subsequent fracture prevention in fracture patients. 
Third, fall-related risk assessment in our program was rather laborious. We chose to asses a whole battery of fall-related risk factors including tests for gait evaluation and muscle strength. Future investigation should try to distinguish the most important fall-related risk factors in fracture patients and, in doing so, focus on those in clinical practice. This could reduce the time needed to evaluate these patients. This is particularly relevant given the growing population of older people. Patients diagnosed with a certain number of fall-related risk factors could be referred to a more extensive fall risk assessment. This, in turn, could be followed by an intervention program constructed especially for the fall risks diagnosed in each particular patient. The outcome of such a program should primarily be aimed at a reduction of falls. Fall prevention early after a clinical fracture may result in fracture prevention but this has to be confirmed in future studies.

Fourth, the results suggest that the program was effective for secondary fracture prevention. Surprisingly, by looking beyond the fracture, we found that only a limited number of fracture patients could be identified before the current fracture using the Dutch osteoporosis guidelines. Thirty percent had a previous fall in the year prior, which according to the Dutch fall prevention guidelines, justifies a fall and fracture risk evaluation.

This emphasises the need for an even broader spectrum of approaches in primary prevention to identify patients at risk for clinical, and mostly non-vertebral, fractures. Such an initiative is in fact underway. The World Health Organisation (WHO) initiative to calculate the absolute fracture risk based on a BMD and a larger group of clinical bone-related risk factors than those reported in the Dutch guidelines (poly-pharmacy, cigarette smoking, excessive alcohol intake, rheumatoid arthritis, and self-rated poor health status $)^{18}$. The WHO initiative acknowledges that it has limited itself to only bone-related risks. While it did stress the importance of fall-related risks, these were excluded. In light of our results, the proposed algorithms put forth by the WHO may underestimate actual fracture risk in patients with a higher risk of falls. The extent to which such algorithms overestimate the risk in those who have not had a fall is also unclear and therefore requires further large scale prospective population studies that integrate bone-related and fall-related risks. A recent review of osteoporosis by Sambrook and Cooper supported the view that case finding and therapeutic strategies will shift from an approach primarily based on DXA results to an approach in which both bone and fall-related fracture risks are used to predict absolute fracture risk ${ }^{19}$.

Finally, fracture and fall prevention intervention programs need to be analysed for their cost-effectiveness. Health care insurers, together with physicians, have to define treatment thresholds for various interventions. These thresholds will 
vary between countries depending on the incidence of fractures and the health care resources.

In conclusion, in order to initiate the prevention of new fractures on time, patients 50 years of age and older presenting with a clinical fracture should be subjected to an immediate broad-spectrum evaluation to assess their risk for subsequent fractures. The results of this dissertation indeed suggest that the systematic implementation of validated bone-related and fall-related risk guidelines by a fracture nurse decreases subsequent fracture risk in daily practice, even in the short term.

\section{REFERENCES}

1. Geusens PP, Lems WF, Verhaar HJ, Leusink G, Goemaere S, Zmierczack H, et al. Review and evaluation of the Dutch guidelines for osteoporosis. J Eval Clin Pract. 2006 Oct;12(5):539-48.

2. Bliuc D, Ong CR, Eisman JA, Center JR. Barriers to effective management of osteoporosis in moderate and minimal trauma fractures: a prospective study. Osteoporos Int. 2005 Aug;16(8):977-82.

3. Solomon DH, Brookhart MA, Gandhi TK, Karson A, Gharib S, Orav EJ, et al. Adherence with osteoporosis practice guidelines: a multilevel analysis of patient, physician, and practice setting characteristics. Am J Med. 2004 Dec 15;117(12):919-24.

4. Solomon DH, Connelly MT, Rosen CJ, Dawson-Hughes B, Kiel DP, Greenspan SL, et al. Factors related to the use of bone densitometry: survey responses of 494 primary care physicians in New England. Osteoporos Int. 2003 Apr;14(2):123-9.

5. Feldstein A, Elmer PJ, Orwoll E, Herson M, Hillier T. Bone mineral density measurement and treatment for osteoporosis in older individuals with fractures: a gap in evidence-based practice guideline implementation. Arch Intern Med. 2003 Oct 13;163(18):2165-72.

6. Jaglal SB, Mclsaac WJ, Hawker G, Carroll J, Jaakkimainen L, Cadarette SM, et al. Information needs in the management of osteoporosis in family practice: an illustration of the failure of the current guideline implementation process. Osteoporos Int. 2003 Aug;14(8):672-6.

7. Siris ES, Bilezikian JP, Rubin MR, Black DM, Bockman RS, Bone HG, et al. Pins and plaster aren't enough: a call for the evaluation and treatment of patients with osteoporotic fractures. J Clin Endocrinol Metab. 2003 Aug;88(8):3482-6.

8. Taylor JC, Sterkel B, Utley M, Shipley M, Newman S, Horton M, et al. Opinions and experiences in general practice on osteoporosis prevention, diagnosis and management. Osteoporos Int. 2001;12(10):844-8.

9. Mauck KF, Cuddihy MT, Atkinson EJ, Melton LJ, 3rd. Use of clinical prediction rules in detecting osteoporosis in a population-based sample of postmenopausal women. Arch Intern Med. 2005 Mar 14;165(5):530-6. 
10. Elliott ME, Drinka PJ, Krause P, Binkley NC, Mahoney JE. Osteoporosis assessment strategies for male nursing home residents. Maturitas. 2004 Jul 15;48(3):225-33.

11. Streeten EA, Mohamed A, Gandhi A, Orwig D, Sack P, Sterling R, et al. The inpatient consultation approach to osteoporosis treatment in patients with a fracture. Is automatic consultation needed? J Bone Joint Surg Am. 2006 Sep;88(9):1968-74.

12. Chevalley T, Hoffmeyer P, Bonjour JP, Rizzoli R. An osteoporosis clinical pathway for the medical management of patients with low-trauma fracture. Osteoporos Int. 2002;13(6):450-5.

13. Feldstein AC, Nichols GA, Elmer PJ, Smith DH, Aickin M, Herson M. Older women with fractures: patients falling through the cracks of guideline-recommended osteoporosis screening and treatment. J Bone Joint Surg Am. 2003 Dec;85-A(12):2294-302.

14. Elliott ME, Meek PD, Kanous NL, Schill GR, Weinswig PA, Bohlman JP, et al. Osteoporosis screening by community pharmacists: use of National Osteoporosis Foundation resources. J Am Pharm Assoc (Wash) 2002 Jan-Feb;42(1):101-10; quiz 10-1.

15. Boden SD, Einhorn TA, Morgan TS, Tosi LL, Weinstein JN. An AOA critical issue. The future of the orthopaedic surgeon-proceduralist or keeper of the musculoskeletal system? J Bone Joint Surg Am. 2005 Dec;87(12):2812-21.

16. Smaha LA. The American Heart Association Get With The Guidelines program. Am Heart J. 2004 Nov;148(5 Suppl):S46-8.

17. McGinn TG, Guyatt GH, Wyer PC, Naylor CD, Stiell IG, Richardson WS. Users' guides to the medical literature: XXII: how to use articles about clinical decision rules. Evidence-Based Medicine Working Group. Jama. 2000 Jul 5;284(1):79-84.

18. Kanis JA, Borgstrom $F$, De Laet $C$, Johansson $H$, Johnell $O$, Jonsson $B$, et al. Assessment of fracture risk. Osteoporos Int. 2005 Jun;16(6):581-9.

19. Sambrook P, Cooper C. Osteoporosis. Lancet. 2006 Jun 17;367(9527):2010-8. 
ChAPTER 10

\section{Samenvatting en Conclusies}




\section{SAMENVATTING EN CONCLUSIES}

In hoofdstuk 1 wordt een beknopt overzicht gegeven van de factoren die bijdragen aan het risico van een patiënt op een botbreuk (fractuur). Sinds langere tijd was case-finding en de diagnose van osteoporose voornamelijk gericht op de vaststelling van een lage bot dichtheid (BMD). Lage BMD werd gezien als een voorspeller van het toekomstige risico op fracturen, het kan worden gemeten in de dagelijkse praktijk, en de resultaten ervan werden gebruikt voor de vaststelling van drempelwaarden voor diagnose en therapie. Sindsdien is op basis van prospectieve populatie studies aangetoond dat veel botgerelateerde risico factoren, andere dan een lage BMD, in aanvulling op valgerelateerde risico's, bijdragen tot het risico op fracturen, onafhankelijk van een lage BMD. Onze hypothese is dan ook dat de systematische implementatie van een fractuur preventie programma dat is gebaseerd op een heel spectrum van risicofactoren en uitgevoerd gedurende de fractuur zorg, het risico van een volgende fractuur kan verminderen.

Het hoogste niveau van bewijs voor het documenteren van de effecten van een preventieprogramma is een gerandomiseerde gecontroleerde studie. Omdat er echter duidelijke richtlijnen voor osteoporose en de behandeling ervan zijn, is het onethisch om de behandeling te onthouden aan een controlegroep met gediagnosticeerde en goed gedocumenteerde fractuur risico's. Daarom hebben we een ander studie design toegepast door te kijken naar groepen voor en nadat dokters gebruik begonnen te maken van deze richtlijnen.

Daarom wordt in hoofdstuk 2 beschreven hoe er een grote historische controlegroep van fractuurpatiënten werd gevormd. Deze groep bestond uit alle patiënten met een recente klinische fractuur die werden behandeld in het Maastricht University Medical Center (MUMC+${ }^{+}$) tussen 1999 en 2001, voordat de richtlijnen beschikbaar waren. In totaal werden 2419 mannelijke en vrouwelijke patiënten in de leeftijd van 50 jaar en ouder met een totaal van 2575 baseline fracturen gevolgd. De belangrijkste uitkomstmaat was het absolute risico op een fractuur binnen twee jaar na een klinische fractuur. De gemiddelde leeftijd was 66 jaar voor mannen en 72 jaar voor vrouwen. Gedurende deze twee jaar was het cumulatieve percentage patiënten met nieuwe klinische fracturen $10,8 \%$.

De cox regressie analyse toonde dat leeftijd, geslacht en het gelijktijdig hebben van meerdere fracturen onafhankelijk bijdroegen aan een hogere kans op een nieuwe fractuur. De incidentie van nieuwe fracturen nam toe met de leeftijd (HR 1,2 per decennium; Cl 1.1-1.3), was hoger bij vrouwen dan bij mannen (12,2\% vergeleken met 7,4\%; HR 1,5; Cl 1.1-2.0), en was hoger bij patiënten met meerdere baseline fracturen $(17,3 \%$ vergeleken met $10,4 \%$ bij patiën- 
ten met één fractuur (HR 1,8; $\mathrm{Cl} 1.2-2.7)$. Van alle nieuwe fracturen in die twee jaar gebeurde $60 \%$ tijdens het eerste jaar en $40 \%$ tijdens het tweede jaar ( $p=$ $0,005)$. Deze hoge incidentie van nieuwe fracturen diende als stimulans voor de start van de fractuur en osteoporose polikliniek in ons ziekenhuis uitgevoerd met de inzet van een verpleegkundige.

Het doel van de studie in hoofdstuk 3 was om te onderzoeken wat het effect is van de inzet van een osteoporose verpleegkundige op het aantal verwijzingen naar een DXA scan in vergelijking met ziekenhuizen waar geen osteoporose verpleegkundige werkzaam is. We vergeleken het $\mathrm{MUMC}^{+}$(referentie ziekenhuis met een fractuur verpleegkundige) met 5 ziekenhuizen in de omgeving. Gedurende een periode van twee weken, werden alle vrouwelijke patiënten ouder dan 50 jaar die zich met een fractuur presenteerden, geïncludeerd. De follow-up was minimaal 11 weken. De primaire uitkomst was de verwijzing voor een DXA scan . In totaal werden 135 patiënten opgenomen. Van deze patiënten, waren er 33 gezien in het $\mathrm{MUMC}^{+}$en 102 in de andere deelnemende ziekenhuizen. In beide groepen, was de gemiddelde leeftijd en het locatie van de fracturen vergelijkbaar. In het $\mathrm{MUMC}^{+}$kwamen 14 patiënten in aanmerking voor een DXA meting. Tien van deze patiënten ondergingen daadwerkelijk een DXA scan (71\%). In de andere deelnemende ziekenhuizen, kwamen 78 patiënten in aanmerking voor een DXA scan. Hiervan ondergingen slechts drie patiënten werkelijk een DXA scan (4\%). Rekening houdend met een weigeringspercentage van $33 \%$ zoals gevonden in het referentie centrum, zouden 47 patiënten in de andere ziekenhuizen in aanmerking zijn gekomen voor een DXA meting. Het verwijzingspercentage in de omliggende ziekenhuizen komt daarmee op 3 op 47 patiënten (6\%). Dit geeft aan dat de verwijzing voor een DXA scan laag was in ziekenhuizen waar geen osteoporose verpleegkundige werkzaam is. Dit suggereert dat de aanwezigheid van een osteoporose verpleegkundige het aantal patiënten die een DXA meting krijgen na een recente fractuur aanzienlijk verhoogt (RR 11,0 (95\% Cl: 3,6 tot 35,1).

In hoofdstuk 4 worden de resultaten gepresenteerd van de risico-evaluatie uit het eerste jaar van de fractuur en osteoporose polikliniek. Alle mannen en vrouwen ouder dan 50 jaar die zijn behandeld voor een fractuur tijdens deze periode werden een evidence-based (volgens de Nederlandse richtlijnen) boten valgerelateerde risicobeoordeling en botdichtheidsmeting aangeboden. Van de 940 opeenvolgende patiënten, waren er 797 (85\%) die in aanmerking kwamen voor deze studie en $568(60 \%)$ stemden ermee in om deel te nemen. Valgerelateerde risicofactoren (75\% [95\% Cl: 71\% -78\%]; $n=425)$ en botgerelateerde risicofactoren ( $53 \%$ [95\% Cl: $49 \%-57 \%]$; $n=299)$ waren vaker aan- 
wezig op het moment van de fractuur dan osteoporose (DXA T-score $\leq-2,5$ in de wervelkolom en / of heup, 35\% [95\% Cl: $31 \%-39 \%] ; n=201$ ), en waren ook aanwezig, onafhankelijk van de fractuur locatie, de leeftijd categorieën en het geslacht.

Risicofactoren waren overlappend, heterogeen en werden in verschillende combinaties gevonden. Dit was eveneens het geval, ongeacht leeftijd, fractuur locatie en het geslacht. Met behulp van de Nederlandse richtlijnen had slechts een beperkt aantal van de patiënten geïdentificeerd kunnen worden als risicopatiënt voordat ze de huidige fractuur opliepen. De bevindingen houden in dat een geïntegreerde bot- en valgerelateerde risico-evaluatie effectief is en dus een beter middel voor het identificeren van patiënten die risico lopen op een latere fractuur dan een identificatie alleen gebaseerd op een lage botdichtheid.

Bij patiënten met osteoporose werd een verdere evaluatie uitgevoerd om de aanwezigheid van oorzaken van secundaire osteoporose en werveldeformiteiten aan te tonen. Dit werd beschreven in hoofdstuk 5. In deze studie werden 100 opeenvolgende mannen en vrouwen boven de leeftijd van 50 jaar geïncludeerd die behandeld werden met een recente klinische fractuur en een T-score $\leq-2,5$. De deelnemers kregen een klinische evaluatie en een laboratorium onderzoek en er werd gezocht naar werveldeformiteiten met een zijwaartse opname van de wervelzuil op de DXA scan (morfometrie).

Van de 73 vrouwen en 27 mannen (gemiddelde leeftijd: 68 jaar) die in deze studie meededen, waren bij 27 patiënten oorzaken van secundaire osteoporose bekend. Daarnaast werden bij 50 patiënten nieuwe oorzaken gevonden (vooral vitamine D-deficiëntie), 14 patiënten hadden verder onderzoek nodig in verband met laboratoriumafwijkingen. Vierenvijftig patiënten hadden botgerelateerde risicofactoren, 79 patiënten hadden valgerelateerde risicofactoren en bij 53 patiënten werden eerder onbekende wervelafwijkingen gevonden. Veel van deze oorzaken waren te behandelen (dwz een verstoorde calcium homeostase en endocriene ziekten). Deze resultaten suggereren dat patiënten met een klinische fractuur en osteoporose een nog bredere evaluatie vereisen namelijk een zoektocht naar mogelijke onderliggende oorzaken van osteoporose en werveldeformiteiten.

Uit recente gegevens blijkt dat veel patiënten die met een niet-wervelfractuur behandeld worden toch ook een wervelfractuur blijken te hebben, zelfs als ze geen lage botdichtheid hebben. Dit is belangrijk omdat wervelfracturen bijdragen aan het risico op fracturen en een indicatie zijn voor de behandeling ongeacht de resultaten van de botdichtheidsmeting. 
Daarom wordt in hoofdstuk 6 systematisch onderzocht wat de prevalentie is van morfometrische wervellichaam deformiteiten bij patiënten met een recente nietwervelfractuur. Hiervoor werd gebruik gemaakt van een kwantitatieve wervelfractuur beoordeling (VFA) met behulp van de zijwaartse DXA scan en de Genant indeling voor het definiëren van morfometrische vertebrale misvormingen (MVDs).

Van de 1302 patiënten die in aanmerking kwamen waren er 695 (53\%) die toestemming gaven voor de evaluatie.

Wervelinzakkingen van $\geq 25 \%$ werden aangetroffen in $27 \%$ van de deelnemende patiënten Van deze wervelinzakkingen werd $55 \%$ vastgesteld bij patiënten met osteoporose. Inzakkingen van $20-24 \%$ werd gevonden in $22 \%$ van de deelnemende patiënten en inzakkingen van $<20 \%$ werden aangetroffen in $51 \%$ van de deelnemende patiënten.

Deze resultaten geven aan dat veel patiënten met een niet-wervel fractuur een wervelinzakking hadden, ook bij het ontbreken van osteoporose en dat VFA kan worden gebruikt om dat vast te stellen. Het spreekt vanzelf dat een VFA zou kunnen helpen bij het selecteren van patiënten bij wie een extra röntgen foto van de wervelkolom nuttig kan zijn om de aanwezigheid van een wervelfractuur te bevestigen. Een dergelijk klinisch pad ondersteunt behandelkeuzes die beter rekening houden met het absolute risico op toekomstige fracturen van de patiënt.

In hoofdstuk 7 werden vallen en valgerelateerde risicofactoren beoordeeld in 277 vrouwen en mannen in de leeftijdsgroep van 50 jaar en ouder die zich presenteerden met een klinische fractuur. Valgerelateerde risicofactoren werden beoordeeld op basis van de Nederlandse valpreventie richtlijn. Follow-up informatie over vallen en fracturen is verzameld door middel van een maandelijks telefonisch interview in de eerste drie maanden na de fractuur. Een nieuw val incident werd gemeld door 42 patiënten (15\%), van wie er 5 een nieuwe fractuur opliepen. Van de 42 patiënten die een nieuwe val doormaakten waren er 32 met één nieuwe val en 10 hadden twee of meer valincidenten.

Multivariate analyses van de totale groep met geslacht, leeftijd, ADL moeilijkheden, urine-incontinentie, en polyfarmacie toonden dat vrouwelijk geslacht en ADL problemen significante valgerelateerde risicofactoren waren. Vrouwen hadden een OR van 3,02 (95\% Cl 1,13-8,06) en patiënten met ADL problemen had een OR van 2,50 (95\% Cl 1,27-4,93). Multivariate analyse met alleen de vrouwelijke deelnemers, met de leeftijd, ADL moeilijkheden, polyfarmacie, en de aanwezigheid van orthostatische hypotensie, toonden polyfarmacie als de voornaamste risicofactor (OR 2,51; 95\% Cl: 1,19-5,28). De incidentie van vallen was $35 \%$ bij vrouwen met ADL problemen en polyfarmacie in vergelijking met $15 \%$ bij vrouwen zonder deze risicofactoren (OR 3,56: $\mathrm{Cl} 1,47$ tot 8,67). 
In hoofdstuk 8 werd de impact beschreven van de toepassing van osteoporose en valpreventierichtlijnen met de inzet van een fractuur verpleegkundige op de fractuur en osteoporose polikliniek van het $\mathrm{MUMC}^{+}$.

Gedurende de periode van één jaar bood een speciale fractuur verpleegkundige een bot- en valgerelateerde risicofactor evaluatie en behandel programma aan volgens de Nederlandse richtlijnen voor alle patiënten ouder dan 50 met een recente klinische fractuur $(n=940,670$ vrouwen en 270 mannen). De 1-jaars nieuwe fractuur incidentie in deze groep werd vergeleken met de 6,5\% 1-jaars incidentie bij patiënten die werden behandeld met een fractuur in de periode 1999-2001 in hetzelfde ziekenhuis voordat de richtlijnen beschikbaar waren en er geen speciale risico-evaluatie werd uitgevoerd. Een volgende fractuur binnen een jaar deed zich voor in 33 van de 904 patiënten (3,7\%) in de totale studie-groep. Dat betekent een risicoreductie van $43 \%$ ten opzichte van de controlegroep (HR: 0,57, Cl: 0.39-0.83). Fractuur reductie was vergelijkbaar bij mannen en vrouwen in alle leeftijden. Deze gegevens duiden erop dat de systematische implementatie van richtlijnen voor osteoporose en valpreventie onmiddellijk toegepast na een recente klinische fractuur door een gespecialiseerde fractuur verpleegkundige het risico op een nieuwe fractuur binnen een jaar aanzienlijk vermindert in vergelijking met de incidentie voordat de richtlijnen beschikbaar waren. Gerandomiseerde studies zijn nodig om de kosteneffectiviteit van dit klinisch pad en de specifieke onderdelen die bijdragen tot het effect ervan te analyseren.

Hoofdstuk 9 geeft een samenvatting van de resultaten van de verschillende studies en beschrijft de belangrijkste conclusies.

\section{Algemene CONCLUSies}

De implementatie van richtlijnen voor osteoporose en valpreventie, en van gevalideerde case-finding strategieën in de dagelijkse praktijk blijft nog steeds onvoldoende zowel voor primaire preventie als voor secundaire preventie $e^{1-12}$. De redenen voor het gebrek aan richtlijn implementatie zijn niet erg duidelijk, en afhankelijk van factoren gerelateerd aan zowel artsen als patiënten ${ }^{2-9,}{ }^{12-14}$.

De positie waarin chirurgen zich bevinden op dit moment toont opvallende gelijkenis met die van cardiologen ongeveer twintig jaar geleden. Op dat moment waren zij gericht op de acute behandeling van hart en vaatziekten, zoals een hartinfarct. Er werd geen moeite gedaan om te beginnen met secundaire preventieve maatregelen, hoewel het bekend was dat het risico voor latere cardiovasculaire (CV) aandoeningen hoog was. Het duurde enige 
tijd voordat duidelijk werd dat een patiënt die herstellende is van bijvoorbeeld een hartinfarct en zijn of haar familie in de ideale "state of mind" zijn om advies te krijgen over mogelijke preventie. In 1985 is de American Heart Association (AHA) daarom gestart met een programma genaamd "Get with the guidelines" (GWTG). De uitvoering van dat programma na een acuut myocardinfarct heeft geleid tot een verbeterde naleving van secundaire preventie richtlijnen binnen één jaar ${ }^{15}$.

Terugkomend op chirurgen en fractuurzorg ligt de parallel voor de hand:

"Je moet het ijzer smeden als het heet is"

Trauma chirurgen en orthopedisch chirurgen die patiënten met fracturen behandelen zijn niet alleen verantwoordelijk voor een optimale behandeling van de fractuur zelf, maar ook voor de initiatie van maatregelen ter voorkoming van een nieuwe, latere fractuur. Om dat te doen moeten ze verder kijken dan de fractuur, net als cardiologen die steeds verder kijken dan het cardiovasculaire event (bijvoorbeeld de staat van het hart) door gebruik te maken van de richtlijnen voor secundaire preventie en door zich te richten op andere goed gedocumenteerde risicofactoren voor latere cardiovasculaire events zoals geslacht, gewicht, bloeddruk, lipiden, en levensstijl, waarvan er vele te corrigeren zijn. Het doel van de uitvoering van de GWTG was een vermindering van CV events met $25 \%$ gedurende 10 jaar $^{16}$.

Een vermoedelijk effectieve programma met een dergelijke doelstelling bij fractuur patiënten wordt gepresenteerd in dit proefschrift. De "fractuur en osteoporose polikliniek" is ontworpen om de impact te bestuderen van de implementatie van osteoporose en valpreventie richtlijnen op de initiatie van behandeling, lifestyle veranderingen, en uiteindelijk, op de incidentie van nieuwe fracturen. Alle deelnemende patiënten werden geadviseerd over botgerelateerde levensstijl maatregelen, met inbegrip van voldoende calcium en vitamine $D$ inname, stoppen met roken en matiging van alcohol inname. Patiënten met osteoporose werden onderzocht op de aanwezigheid van secundaire osteoporose en eventuele oorzaken die bijdroegen aan secundaire osteoporose werden behandeld. Bij patiënten met osteoporose werd tevens een behandeling met geneesmiddelen gestart. Valgerelateerde risico's werden geëvalueerd en bij de aanwezigheid van dergelijke risico's werden algemene en/of gerichtte adviezen verstrekt door de fractuurverpleegkundige.

We toonden een daling van $43 \%$ in de daaropvolgende fracturen binnen één jaar van follow-up in vergelijking met historische controle patiënten. 
Ten aanzien van deze fractuur en osteoporose kliniek dienen diverse aspecten besproken te worden:

Ten eerste, ideaal gesproken zou een impactstudie de patiënten randomiseren in 2 groepen, namelijk het wel of niet toepassen van de richtlijnen. De follow-up van de patiënten zou moeten plaatsvinden met relevante eindpunten met inbegrip van de kwaliteit van leven, de morbiditeit en kosten effectiviteit. Randomisatie van de individuele patiënt is echter onwaarschijnlijk omdat men verwacht dat de deelnemende artsen de richtlijnen gebruiken voor de verzorging van al hun patiënten. Een geschikt alternatief is de randomisatie van verschillende instellingen. Een andere mogelijk ontwerp is te kijken naar een groep voordat en nadat dokters gebruik begonnen te maken van de richtlijnen ${ }^{17}$. We pasten laatstgenoemde benadering toe en vergeleken het effect van een systematische implementatie van de richtlijnen bij patiënten prospectief gevolgd na een fractuur met een historische controle groep die werden behandeld vóórdat de richtlijnen beschikbaar waren en voordat fractuur preventie-initiatieven werden genomen. Maar onze resultaten zijn van een lager niveau van bewijs dan een gerandomiseerde studie.

Ten tweede, voor de optimale implementatie van richtlijnen is het waarschijnlijk nodig om gebruik te maken van de diensten van een gespecialiseerde fractuur verpleegkundige zoals we hebben aangetoond in hoofdstuk 3 . Dit is niet altijd haalbaar is, vooral gezien de huidige financiële structuur in de Nederlandse gezondheidszorg die extra aandacht voor preventie van de daaropvolgende fractuur niet vergoed.

Ten derde, de valgerelateerde risico-evaluatie in ons programma was nogal uitgebreid. We kozen een flink aantal valgerelateerde risicofactoren inclusief enkele testen. Toekomstig onderzoek moeten proberen een onderscheid te maken tussen de belangrijkste valgerelateerde risicofactoren bij fractuurpatiënten. Dit zou de tijd kunnen verminderen die nodig is voor de evaluatie van deze patiënten. Dit is met name van belang gezien het groeiende aantal ouderen. Patiënten met een bepaald aantal valgerelateerde risicofactoren kunnen dan worden verwezen voor een meer uitgebreide risico-evaluatie. Dit kan op zijn beurt worden gevolgd door een interventie programma aangepast aan de gediagnosticeerde valrisicofactoren bij elke patiënt. De uitkomst van een dergelijk programma moeten in de eerste plaats zijn gericht op een vermindering van vallen. Valpreventie vroegtijdig na een klinische fractuur zou kunnen leiden tot de preventie van fracturen, maar dat moet nog bevestigd worden in toekomstig onderzoek.

Ten vierde, de resultaten wijzen erop dat de fractuur en osteoporosepolikliniek werkzaam was voor secundaire preventie van fracturen. Tot onze verrassing hebben we vastgesteld dat slechts een beperkt aantal fractuurpatiënten 
konden worden geïdentificeerd met behulp van de Nederlandse osteoporose richtlijnen als zijnde " at risk" voordat ze de huidige fractuur opliepen. Dertig procent had een eerdere val in het voorafgaande jaar, zodat ze volgens de Nederlandse valpreventie richtlijnen, in aanmerking komen voor een val en fractuur risico-evaluatie. Dit onderstreept de noodzaak voor een nog breder spectrum van benaderingen in de primaire preventie om patiënten te identificeren met een risico voor klinische, en meestal niet-wervel, fracturen. Een dergelijk initiatief is in feite reeds in gang gezet. De Wereldgezondheidsorganisatie (WHO) ontwikkelde een instrument voor de berekening van het absolute risico op fracturen, gebaseerd op de botdichtheid en een grotere groep van klinische botgerelateerde risicofactoren dan die in de Nederlandse richtlijnen (polyfarmacie, roken, overmatig alcoholgebruik, reumatoïde artritis en zelf ingeschatte slechte gezondheidstoestand $)^{18}$. De WHO erkent dat dit initiatief zich beperkt tot botgerelateerde risico's. Weliswaar benadrukken ze het belang van valgerelateerde risico's, maar deze werden toch uitgesloten. In het licht van onze resultaten kunnen de voorgestelde algoritmes van de WHO leiden tot onderschatting van het werkelijke risico op fracturen bij patiënten met een hoog valrisico. De mate waarin dergelijke algoritmen een overschatting maken van het risico in diegenen die geen valrisicofactoren hebben is ook onduidelijk en vereist dan ook een verdere grootschalige prospectieve bevolkingsstudie die bot- en valgerelateerde risico's integreert. Een recente review over osteoporose door Sambrook en Cooper ondersteunt het standpunt dat de therapeutische strategieën zullen verschuiven van een aanpak die vooral gebaseerd is op botdichtheidsmetingen naar een aanpak waarin zowel bot- alsmede valgerelateerde risico's worden gebruikt voor het voorspellen van het absolute risico op fracturen ${ }^{19}$.

Tot slot, fractuur en valpreventie interventieprogramma's moeten worden geanalyseerd op hun kosteneffectiviteit. Verzekeraars in de gezondheidszorg zullen samen met artsen behandeling drempels moeten definiëren voor verschillende interventies. Deze drempels zullen verschillen tussen de diverse landen, afhankelijk van de incidentie van fracturen en de beschikbare middelen voor de gezondheidszorg.

Samenvattend: ter preventie van nieuwe fracturen dienen patiënten van 50 jaar en ouder die zich presenteren met een klinische fractuur deel te nemen aan een onmiddellijke breed-spectrum beoordeling van hun risico voor latere fracturen. De resultaten van dit proefschrift suggereren inderdaad dat de systematische toepassing van gevalideerde osteoporose en valpreventie richtlijnen door een fractuurverpleegkundige het risico op nieuwe fracturen doet afnemen in de dagelijkse praktijk, zelfs al op de korte termijn. 


\section{Referenties}

1. Geusens PP, Lems WF, Verhaar HJ, Leusink G, Goemaere S, Zmierczack H, et al. Review and evaluation of the Dutch guidelines for osteoporosis. J Eval Clin Pract. 2006 Oct;12(5):539-48.

2. Bliuc D, Ong CR, Eisman JA, Center JR. Barriers to effective management of osteoporosis in moderate and minimal trauma fractures: a prospective study. Osteoporos Int. 2005 Aug;16(8):977-82.

3. Solomon DH, Brookhart MA, Gandhi TK, Karson A, Gharib S, Orav EJ, et al. Adherence with osteoporosis practice guidelines: a multilevel analysis of patient, physician, and practice setting characteristics. Am J Med. 2004 Dec 15;117(12):919-24.

4. Solomon DH, Connelly MT, Rosen CJ, Dawson-Hughes B, Kiel DP, Greenspan SL, et al. Factors related to the use of bone densitometry: survey responses of 494 primary care physicians in New England. Osteoporos Int. 2003 Apr;14(2):123-9.

5. Feldstein A, Elmer PJ, Orwoll E, Herson M, Hillier T. Bone mineral density measurement and treatment for osteoporosis in older individuals with fractures: a gap in evidence-based practice guideline implementation. Arch Intern Med. 2003 Oct 13;163(18):2165-72.

6. Jaglal SB, Mclsaac WJ, Hawker G, Carroll J, Jaakkimainen L, Cadarette SM, et al. Information needs in the management of osteoporosis in family practice: an illustration of the failure of the current guideline implementation process. Osteoporos Int. 2003 Aug;14(8):672-6.

7. Siris ES, Bilezikian JP, Rubin MR, Black DM, Bockman RS, Bone HG, et al. Pins and plaster aren't enough: a call for the evaluation and treatment of patients with osteoporotic fractures. J Clin Endocrinol Metab. 2003 Aug;88(8):3482-6.

8. Taylor JC, Sterkel B, Utley M, Shipley M, Newman S, Horton M, et al. Opinions and experiences in general practice on osteoporosis prevention, diagnosis and management. Osteoporos Int. 2001;12(10):844-8.

9. Mauck KF, Cuddihy MT, Atkinson EJ, Melton LJ, 3rd. Use of clinical prediction rules in detecting osteoporosis in a population-based sample of postmenopausal women. Arch Intern Med. 2005 Mar 14;165(5):530-6.

10. Elliott ME, Drinka PJ, Krause P, Binkley NC, Mahoney JE. Osteoporosis assessment strategies for male nursing home residents. Maturitas. 2004 Jul 15;48(3):225-33.

11. Streeten EA, Mohamed A, Gandhi A, Orwig D, Sack P, Sterling R, et al. The inpatient consultation approach to osteoporosis treatment in patients with a fracture. Is automatic consultation needed? J Bone Joint Surg Am. 2006 Sep;88(9):1968-74.

12. Chevalley T, Hoffmeyer P, Bonjour JP, Rizzoli R. An osteoporosis clinical pathway for the medical management of patients with low-trauma fracture. Osteoporos Int. 2002;13(6):450-5.

13. Feldstein AC, Nichols GA, Elmer PJ, Smith DH, Aickin M, Herson M. Older women with fractures: patients falling through the cracks of guideline-recommended osteoporosis screening and treatment. J Bone Joint Surg Am. 2003 Dec;85-A(12):2294-302.

14. Elliott ME, Meek PD, Kanous NL, Schill GR, Weinswig PA, Bohlman JP, et al. Osteoporosis screening by community pharmacists: use of National Osteoporosis Foundation resources. J Am Pharm Assoc (Wash). 2002 Jan-Feb;42(1):101-10; quiz 10-1. 
15. Boden SD, Einhorn TA, Morgan TS, Tosi LL, Weinstein JN. An AOA critical issue. The future of the orthopaedic surgeon-proceduralist or keeper of the musculoskeletal system? J Bone Joint Surg Am. 2005 Dec;87(12):2812-21.

16. Smaha LA. The American Heart Association Get With The Guidelines program. Am Heart J. 2004 Nov;148(5 Suppl):S46-8.

17. McGinn TG, Guyatt GH, Wyer PC, Naylor CD, Stiell IG, Richardson WS. Users' guides to the medical literature: XXII: how to use articles about clinical decision rules. Evidence-Based Medicine Working Group. Jama. 2000 Jul 5;284(1):79-84.

18. Kanis JA, Borgstrom F, De Laet C, Johansson $H$, Johnell $O$, Jonsson B, et al. Assessment of fracture risk. Osteoporos Int. 2005 Jun;16(6):581-9.

19. Sambrook P, Cooper C. Osteoporosis. Lancet. 2006 Jun 17;367(9527):2010-8. 
Dankwoord 
Toen ik in December 2002 gebeld werd door Peter Brink met de vraag of ik in Maastricht wilde komen werken hoefde ik daar niet lang over na te denken. Ik was opgeleid tot traumatoloog in het Academisch Ziekenhuis te Groningen en had daar ruim twee jaar tijd naar volle tevredenheid gewerkt. Het zuiden lonkte echter en zo kwam het dat ik in Maart 2003 startte in wat toen nog heette het Academisch Ziekenhuis Maastricht.

Werken in de academie betekent naast patiëntencontact ook onderzoek doen en onderzoek doen betekende in mijn geval promoveren. In de CHIVO tijd en ook mijn assistenten tijd had ik mij voornamelijk toegelegd op het klinisch werk en was er eigenlijk weinig aandacht voor onderzoek. De eerste paar maanden dat ik in Maastricht werkte woonde mijn gezin nog in Groningen terwijl ikzelf een appartement in Maastricht betrokken had. Deze situatie is niet bevorderlijk voor het gezinsleven, maar wel voor het opzetten van onderzoek. In de eerste maanden heb ik me naast het klinische werk dan ook toegelegd op het ontwerpen en beschrijven van een fractuur en osteoporose polikliniek.

In Juni 2003 ben ik samen met Han Hegeman uit Groningen gaan kijken in Glasgow, daar hadden de internisten Dr. A.R. McLellan en Dr. S.J. Gallacher een fractuur- en osteoporose polikliniek gestart en om dit uit te dragen organiseerden zij cursussen hoe een en ander precies in zijn werk ging. Han heeft bij terugkomst de zaak in Nederland voortvarend opgepakt en startte in Groningen eind 2003 al met de eerste fractuur- en osteoporose poli. Ik ben in Maastricht snel op zoek gegaan naar partners met eenzelfde interesse en hoefde daarvoor niet lang rond te kijken. Het bleek dat op de afdeling reumatologie in Maastricht een internist werkte, die reeds lange tijd osteoporose onderzoek deed en naast nationale ook internationale naam had gemaakt op dit gebied.

Geachte Prof. dr. P. Geusens, beste Piet, we troffen elkaar voor de eerste keer in Amsterdam op een symposium over hoe kan het ook anders osteoporose en ik stelde me voor als ongevalchirurg uit Maastricht, geïnteresseerd in het opzetten van een osteoporose polikliniek. Je interesse was snel gewekt en terwijl je een sigaar wegrookte deed ik mijn plannen uit de doeken. Dat eerste contact is nu uitgemond in de voltooiing van een proefschrift. Ik denk met veel plezier terug aan de vele uren die wij samen besteed hebben aan de berg gegevens die gegenereerd werd door de fractuur- en osteoporose poli. Die data werden allemaal door ons verwerkt in abstracts waarbij jij diverse internistische congressen bezocht en ik met dezelfde abstracts chirurgie congressen kon bezoeken. Later maakten wij hier dan artikelen van die nu terug te vinden zijn in dit document. Soms had ik wel wat moeite als het artikel volledig klaar was en naar mijn zin weg zou kunnen, dat je voorstelde het weer compleet om te gooien nadat je ergens anders gehoord of gelezen had dat het ook op een 
andere manier geanalyseerd kon worden. Jij van jouw kant moest waarschijnlijk wennen aan een chirurg als promovendus die de wetenschappelijke boodschap vaak wat korter verwoordt dan de gemiddelde internist. Uiteindelijk hebben we een heel goed compromis kunnen vinden. Natuurlijk had ik nog veel meer collega's nodig om de fractuurpoli te kunnen starten en een van de eerste die ik ook benaderde was Prof. dr. Geesink van de afdeling Orthopedie. In een kort gesprek bleek dat ik bij de opzet van een osteoporose polikliniek volledige medewerking zou krijgen van de afdeling Orthopedie en dat was ook heel belangrijk, omdat op die manier iedere patiënt die zich bij het azM zou melden met een fractuur dezelfde aandacht zou krijgen als het ging om preventieve maatregelen voor de toekomst. Ik waardeer het ook dat je voorzitter wilde zijn van de beoordelingscommissie. Snel volgden meerdere contacten in dit ziekenhuis en met het gevaar enkele namen te vergeten, noem ik ze op. Geert Jan Dinant, Arie Kruseman, Eveline Pijpers, Marinus van Kroonenburgh, Alfons Kessels, Trudy van der Weijden, Antonia van Geel, Rene ten Broeke. Allemaal collega's die hun schouders zetten onder de start en continuering van de fractuur- en osteoporose polikliniek.

Nadat we voldoende fondsen hadden geworven konden we een fulltime osteoporose verpleegkundige aanstellen. Beste Gittie; je sollicitatiebrief was de slechtste die ertussen zat, maar je was echter de beste kandidaat die ik me kon wensen. Je hebt keihard gewerkt de afgelopen jaren om de doelen te halen die we ons stelden, mede dankzij jou is deze promotie nu afgerond. Ik had er eigenlijk op gerekend dat jij eerst een afstudeerfeestje zou houden, maar daar moeten we nog even op wachten. We rekenen er in ieder geval wel op en ik weet dat je het kunt.

Naast de collega's in het ziekenhuis zijn er ook veel studenten en assistenten geweest die mee hebben geholpen met al het osteoporose- en valonderzoek dat we verricht hebben. Met name de volgende mensen wil ik hier vermelden. Wendy Koeyers, Jochen Cals, Björn Telgenkamp, Tim Boymans, Caroline Wyers, Eveline Cauberg, Bianca Dumitrescu, Sevginur Kosar en Demien Broekhuis.

Naast de voorzitter van de beoordelingscommissie wil ik ook de andere commissieleden bedanken: allereerst Prof. dr. P.L.O. Broos. Jaren geleden startte ik de geneeskunde studie in Leuven en uiteindelijk koos ik ook voor de chirurgische opleiding aldaar. Ik stel het erg op prijs dat $u$ als een van mijn oud-opleiders erbij kan zijn deze dag.

Prof. dr. H.J. Ten Duis, beste Henk Jan. Ik herinner me nog goed een van de eerste gesprekken die we hadden op jouw kamer in Groningen, vlak nadat ik 
begonnen was. Je wilde ook wel eens weten of ik geïnteresseerd was in onderzoek en je vroeg toen aan me of ik een dokter was die vooral met zijn handen werkte of misschien een dokter die vooral met zijn hoofd werkte. Ik moet toegeven dat ik mijn CHIVO tijd vooral gebruikt heb om bekend te raken met de praktische zaken van het vak en wetenschap secundair was. Het doet me deugd dat je het leuk vindt om naar Maastricht af te zakken vanuit het Groningse en deze gelegenheid bij te wonen. Ik hoop dat het proefschrift voldoende bewijs is dat deze dokter ook met zijn hoofd kan werken.

Dr. P. Stalenhoef, beste Paul. Ik waardeer het dat je zitting wilde nemen in de beoordelingscommissie en ook aanwezig zal zijn bij de promotie. Slechts helemaal in de beginfase van de osteoporose polikliniek hebben we elkaar eens ontmoet op een vergadering van de interval onderzoeksgroep. Jouw kennis van vallen bij ouderen is heel groot en ik hoop dat we in de toekomst wellicht vaker van gedachten kunnen wisselen over vallen bij ouderen.

Prof. dr. W. Buurman, beste Wim. Onderzoek doen en jouw naam zijn bijna synoniem en toen ik naar Maastricht ging zei Henk Jan ten Duis al tegen mij, je moet eens met Wim Buurman praten. Nou dat is zeker gelukt en ik stel het erg op prijs dat je zitting hebt willen nemen in de beoordelingscommissie.

Dr. A. McLellan, dear Alistair. I would like to thank you for reviewing my PhD Thesis, but even more for your inspiring lectures in Glasgow in 2003. Those lectures made me realize that things had to be organized in a different way for the benefit of fracture patients.

Zo'n fractuur- en osteoporose polikliniek is geheel afhankelijk van de welwillendheid van anderen die ook in contact komen met fractuur patiënten en zonder specifieke namen te noemen wil ik mijn dank uiten naar de Spoedeisende Hulp, waarvandaan fractuur patiënten altijd netjes een weg vinden naar het osteoporose spreekuur. Verder de verpleegafdelingen waar fractuur patiënten opgenomen worden, met name A4 re en C4 en niet te vergeten natuurlijk de poliklinieken van de Chirurgie en van de Orthopedie, waar Gittie al snel een vaste plaats heeft verworven en helemaal geïntegreerd werd in polibezoeken van de fractuur-patiënten. 's Ochtends bij de Traumatologie en dinsdagmiddag en donderdagmiddag bij de Orthopedie. De gipsmeesters verdienen ook een woord van dank omdat zij altijd alert zijn geweest en ons attendeerden op het feit dat sommige patiënten niet bij Gittie waren geweest en dan alsnog een afspraak regelden. Ook heel belangrijk was de inzet van Lia, Florence en Martine op de nucleaire geneeskunde; het aantal DXA scans is met de start van onze poli verveelvoudigd en dat werd allemaal perfect geregeld door hen. 
Beste Stephane, het is alweer een tijdje geleden dat we elkaar voor het eerst ontmoetten, namelijk toen jij naar Leuven kwam na 3 jaar geneeskunde studeren in Namen. Sinds die tijd hebben wij altijd contact onderhouden en nu ik weer in Maastricht woon en jij in Brussel, is het ook wat makkelijker om elkaar weer eens te zien. Fijn dat je erbij bent als paranimf en we gaan er een mooie dag van maken.

Beste Rombout, we ontmoetten elkaar voor het eerst in Groningen. Ik was CHIVO traumatologie en jij assistent, ook wel geïnteresseerd in traumatologie en samen belandden we ook op de traumahelikopter. We hebben heel wat trainingen samen gehad en ook na jouw vertrek uit Groningen hebben we contact gehouden. Jij bent nu in Den Bosch beland en ik in Maastricht, maar we zien elkaar nog regelmatig als we met vrouw en kinderen weer iets ondernemen. Fijn dat je me vandaag bijstaat als paranimf.

Ook een woord van dank voor mijn secretaresse Yvonne Daemen die mij altijd goed helpt met de hele papierwinkel die samengaat rondom zo'n promotie. Ook Johanna Boesten verdient een pluim voor al werk dat ze verrichtte als er weer enquete formulieren verstuurd moesten worden.

Liefste Liesbeth, jaren geleden ontmoette ik je op een feest in Leuven. Sindsdien zijn wij een hecht team en dat kan ook niet anders, want voor mij verliet je je net aangeschafte appartement in Geldrop en verhuisde naar Turnhout. Van Turnhout gingen we naar Heerlen, van Heerlen naar Leuven, van Leuven naar Groningen en van Groningen naar Maastricht. Dat is nog maar een deel van het verhaal want in die tijd kregen we ook nog eens vier mooie kinderen. In elk ziekenhuis waar ik werkte vanaf de Heerlense tijd werd er eentje geboren. Jij hebt het grootste deel van de zorg voor ze op je genomen. Dat bewonder en waardeer ik enorm. Bovendien besloot ik ook nog eens om een proefschrift te maken en ook daar heb je het nodige van meegekregen. Het boekje is nu af. Dat is mooi voor mij, maar vooral voor het hele gezin. Het is dus tijd voor een feest. 
Curriculum Vitae 
Svenhjalmar van Helden was born in Eindhoven on December 5th 1968 and moved with his parents to Eersel. There he attended the Katholieke Basisschool St. Willibrordus followed by the Rythoviuscollege. In 1987 he graduated from high school and started medical school at the Catholic University of Leuven. During his student years he was a member of Hollandia Lovanienses and served as the president of this club in the academic year 1989-90.

He graduated from medical school in 1994 and started his training in general surgery that same year at the department of Prof. dr. P. Broos (academic hospital Leuven). The second and third year of his residency he spent in the department of Dr. P. Quisthoudt (KLINA- Brasschaat). The fourth year of his surgical training he went to Heerlen in the department of Dr. P. Brink (Atrium Medisch Centrum / formerly De Wever ziekenhuis). His last two years of training were completed in Leuven including 6 months at the service of Dr. G. Vangertruyden and Dr. P. Hourlay at Hasselt (Salvator ziekenhuis). In 1998 he married with Elisabeth van der Meer and at present they have four children: Laura-Marie, Caspar-Johannes, Carlijn-Sophie and Olaf-Sven. After his residency he started his training in trauma surgery in 2000 at the university hospital Groningen in the department of Prof. dr. HJ ten Duis. During this period he also was a member of the helicopter mobile medical team. Since march 2003 he is employed as a surgeon at the Maastricht University Medical Centre (MUMC+); specialized in trauma surgery and laparoscopic surgery. In this hospital he founded in September 2004 the fracture and osteoporosis outpatient clinic, the basis for his thesis. 